San Jose State University

SJSU ScholarWorks

Master's Theses

Master's Theses and Graduate Research

1998

\title{
The effects of a Cr1-xRux underlayer on the magnetic properties of Co64Cr22Pt14 thin films
}

Mingyuan Liu

San Jose State University

Follow this and additional works at: https://scholarworks.sjsu.edu/etd_theses

\section{Recommended Citation}

Liu, Mingyuan, "The effects of a Cr1-xRux underlayer on the magnetic properties of Co64Cr22Pt14 thin films" (1998). Master's Theses. 1649.

DOI: https://doi.org/10.31979/etd.c84f-s7vk

https://scholarworks.sjsu.edu/etd_theses/1649

This Thesis is brought to you for free and open access by the Master's Theses and Graduate Research at SJSU ScholarWorks. It has been accepted for inclusion in Master's Theses by an authorized administrator of SJSU ScholarWorks. For more information, please contact scholarworks@sjsu.edu. 


\section{INFORMATION TO USERS}

This manuscript has been reproduced from the microfilm master. UMI films the text directly from the original or copy submitted. Thus, some thesis and dissertation copies are in typewriter face, while others may be from any type of computer printer.

The quality of this reproduction is dependent upon the quality of the copy submitted. Broken or indistinct print, colored or poor quality illustrations and photographs, print bleedthrough, substandard margins, and improper alignment can adversely affect reproduction.

In the unlikely event that the author did not send UMI a complete manuscript and there are missing pages, these will be noted. Also, if unauthorized copyright material had to be removed, a note will indicate the deletion.

Oversize materials (e.g., maps, drawings, charts) are reproduced by sectioning the original, beginning at the upper left-hand corner and continuing from left to right in equal sections with small overlaps. Each original is also photographed in one exposure and is included in reduced form at the back of the book.

Photographs included in the original manuscript have been reproduced xerographically in this copy. Higher quality 6" $\times 9$ " black and white photographic prints are available for any photographs or illustrations appearing in this copy for an additional charge. Contact UMI directly to order.

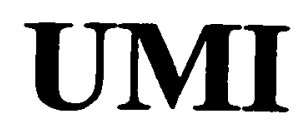

A Bell \& Howell Information Company 

•

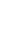
.

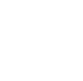




\title{
THE EFFECTS OF A Cr $r_{1-x} \mathrm{Ru}_{\alpha}$ UNDERLAYER ON THE MAGNETIC PROPERTIES OF $\mathrm{Co}_{64} \mathrm{Cr}_{22} \mathrm{Pt}_{14}$ THIN FULMS
}

\author{
A Thesis \\ Presented to \\ The Faculty of the Department of Chemical and Materials Engineering \\ San Jose State University
}

\author{
In Partial Fulfillment \\ of the Requirements for the Degree \\ Master of Science
}

By

Ming-Yuan Liu

May 1998 
UMI Number: 1389660

\section{Copyright 1998 by \\ Liu, Ming-Yuan}

All rights reserved.

UMI Microform 1389660

Copyright 1998, by UMI Company. All rights reserved.

This microform edition is protected against unauthorized copying under Title 17, United States Code.

\section{UMI}

300 North Zeeb Road

Ann Arbor, MI 48103 
(C) 1998

Ming-Yuan Liu

ALL RIGHTS RESERVED 


\section{APPROVED FOR THE DEPARTMENT OF}

\section{CHEMICAL AND MATERIALS ENGDNEERNG}

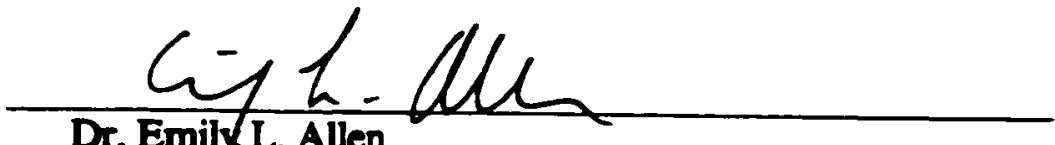

Dr. Emily L. Allen
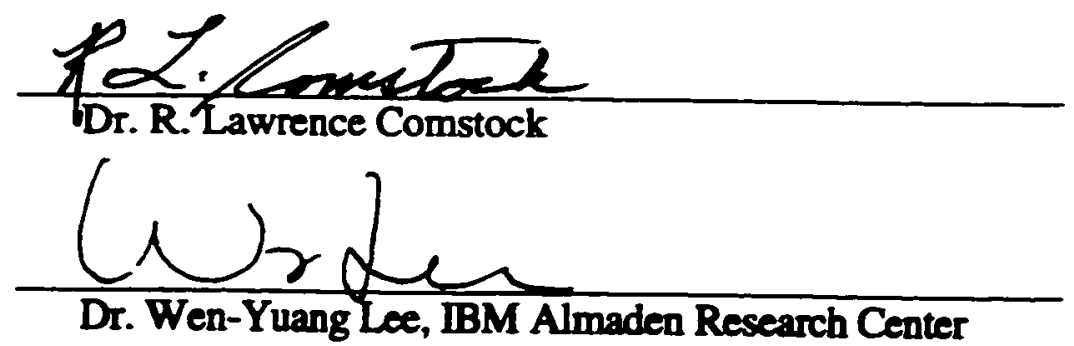

APPROVED FOR THE UNIVERSITY

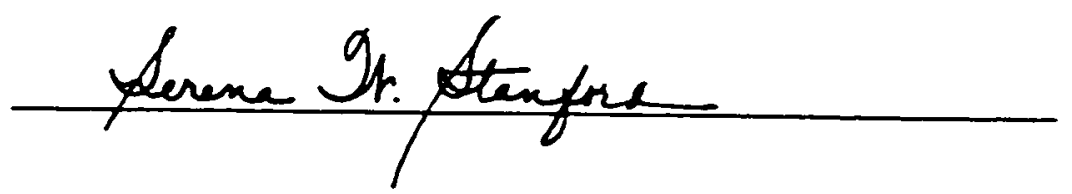




\begin{abstract}
THE EFFECTS OF A $\mathrm{Cr}_{1-x} \mathrm{Ru}_{x}$ UNDERLAYER ON THE MAGNETIC PROPERTIES OF $\mathrm{Co}_{64} \mathrm{Cr}_{22} \mathrm{Pt}_{14}$ THIN FILMS

by Ming-Yuan Liu

The magnetic properties of $\mathrm{Co}_{64} \mathrm{Cr}_{22} \mathrm{Pt}_{14} / \mathrm{Cr}_{1-\mathrm{x}} \mathrm{Ru}_{\mathrm{x}}$ thin films sputter deposited on glass substrates used in longitudinal recording were investigated. In-plane coercivity as a function of $\mathrm{Ru}$ concentration, $\mathrm{Cr}_{1-\mathrm{x}} \mathrm{Ru}_{\mathrm{x}}$ layer thickness, and deposition temperature were studied. The in-plane coercivity increased to 4,100 Oe when a CoCrPt layer was deposited on a $500 \AA \mathrm{Cr}_{43} \mathrm{Ru}_{57}$ underlayer at $250^{\circ} \mathrm{C}$. X-ray diffraction showed that the cause of the coercivity increase was the increase of $\operatorname{Co}(10 \overline{10})$ and $\operatorname{Co}(10 \overline{1} 1)$ textures and the decrease of $\mathrm{Co}(0002)$ texture. Good lattice matching caused $\mathrm{Co}_{64} \mathrm{Cr}_{22} \mathrm{Pt}_{14}$ film to grow epitaxially on top of the $\mathrm{Cr}_{1-x} \mathrm{Ru}_{\mathrm{x}}$ film. The preferred c-axis in-plane orientation of $\mathrm{Cr}_{1-x} R u_{x}$ layer controlled the texture of $\mathrm{Co}_{64} \mathrm{Cr}_{22} \mathrm{Pt}_{14}$ layer. The coercivity peak at 57 at.\% $\mathrm{Ru}$ was very narrow, resulting in a reproducibility problem, which might limit the commercial application of the $\mathrm{Cr}_{1-x} \mathrm{Ru}_{\mathrm{x}}$ underlayer.
\end{abstract}




\section{Acknowledgments}

I would like to thank my thesis advisor Emily L. Allen for many helpful discussions and advisement; Wen-Yuang Lee of IBM for the engagement throughout the thesis, especially the help of the experiment; $R$. Lawrence Comstock for being my thesis committee member and his great course of magnetic materials in SJSU; Dolores Miller for the help of x-ray diffraction; A. Kellock for the help of the RBS; and many other people who helped me for the thesis. I would also like to thank the organizations who sponsored for the thesis.

This thesis has been funded by a National Science Foundation Grant [\#CHE9625628], and has been sponsored by IBM Almaden Research Center. 


\section{Table of Contents}

\section{Chapter}

\section{Page}

\section{Introduction}

1.1 Background

1.2 Disk Structure and Manufacture 1

1.3 Fundamental Magnetic Media Measurements 3

1.4 Magnetic Anisotropy 5

1.5 High Areal Density Media Requirements 6

$\begin{array}{ll}\text { 1.6 Thesis Objective } & 7\end{array}$

2. Literature Review $\quad 8$

2.1 Crystallographic Texture $\quad 9$

2.2 Grain Size 9

$\begin{array}{ll}2.3 \text { Magnetic Isolation } & 10\end{array}$

2.4 Stacking Faults 11

2.5 Characteristics of Specific Underlayer Materials $\quad 12$

$\begin{array}{ll}2.5 .1 \mathrm{Cr} \text { Underlayer } & 12\end{array}$

$\begin{array}{ll}2.5 .2 \mathrm{CrV} \text { Underlayer } & 14\end{array}$

$\begin{array}{ll}2.5 .3 \mathrm{NiAl} \text { Underlayer } & 16\end{array}$

$\begin{array}{ll}2.5 .4 \mathrm{Cr} / \mathrm{Al} \text { Underlayer } & 18\end{array}$

2.5.5 CrTi Underlayer 19

$\begin{array}{ll}2.5 .6 \mathrm{Ru} \text { Underlayer } & 21\end{array}$

2.6 Summary of Literature Review $\quad 22$

3. Experimental Procedures 23

$\begin{array}{ll}3.1 \text { Experiment Outline } & 23\end{array}$ 
3.2.1 Phase I - The Effect of the Ru Concentration on the $\mathrm{Co}_{64} \mathrm{Cr}_{22} \mathrm{Pt}_{14} / \mathrm{Cr}_{1-x} \mathrm{Ru}_{\mathrm{x}}$ Magnetic Properties

3.2.2 Phase II - The Effects of the CrRu Thickness and the Deposition

Temperature on $\mathrm{Co}_{64} \mathrm{Cr}_{22} \mathrm{Pt}_{14} / \mathrm{Cr}_{1-x} \mathrm{Ru}_{x}$ Magnetic Properties

3.3 Magnetic Properties Measurement

3.4 X-ray Diffraction Measurement

3.4.1 Crystal Structure and Lattice Parameter Determination

3.4.2 Lattice Misfit Determination

3.4.3 Crystallographic Texture determination

3.5 Film Thickness, Composition and Resistivity Measurement

4. Results

4.I X-ray Diffraction Spectra

4.2 Dependence of $\mathrm{Cr}_{1-x} \mathrm{Ru}_{\mathrm{x}}$ Resistivity on the Ru Concentration

4.3 Textures of $\mathrm{Cr}_{1-x} \mathrm{Ru}_{x}$ and $\mathrm{Co}_{64} \mathrm{Cr}_{22} \mathrm{Pt}_{14}$ thin films

4.4 Dependence of $\mathrm{H}_{\mathrm{C}}$ and $\mathrm{S}^{*}$ on $\mathrm{Cr}_{1 \cdot x} \mathrm{Ru}_{\mathrm{x}}$ Composition

4.5 Dependence of $\mathrm{H}_{\mathrm{C}}$ and $\mathrm{S}^{*}$ on $\mathrm{Cr}_{1-\mathrm{x}} \mathrm{Ru}_{\mathrm{x}}$ Thickness and Substrate Temperature

\section{Discussion}

5.1 The Structure of $\mathrm{Co}_{64} \mathrm{Cr}_{22} \mathrm{Pt}_{14}$ and $\mathrm{Cr}_{1-x} \mathrm{Ru}_{\mathrm{x}}$ Thin Films

5.2 The Magnetic Anisotropy of CoCrPt Thin Film

5.3 The Epitaxy of $\mathrm{Co}_{64} \mathrm{Cr}_{22} \mathrm{Pt}_{14}$ Thin Film on $\mathrm{Cr}_{1-\mathrm{x}} \mathrm{Ru}_{\mathrm{x}}$ Underlayer

5.4 The Effects of the $\mathrm{Co}_{64} \mathrm{Cr}_{22} \mathrm{Pt}_{14} / \mathrm{Cr}_{1-\mathrm{x}} \mathrm{Ru}_{\mathrm{x}}$ Crystallographic Texture on the In-plane Coercivity 
6. Conclusions

6.1 Summary and Conclusions

6.2 Suggestions for Future Study

References 


\section{List of Tables}

Table

I. Parameters of the recording media.

Page

II. Crystallographic Relations of $\mathrm{Co}$ grain with their $\mathrm{Cr}$ underlayer.

III. Magnetic properties of $\mathrm{Al}$ underlayer and $\mathrm{Al}$ overlayer thin films.

IV. Summary of different underlayer materials.

V. Experiment samples of Phase I.

VI. Experiment samples of Phase II.

VII. Resistivity of $\mathrm{Cr}_{1-x} \mathrm{Ru}_{\mathrm{x}}$ at different $\mathrm{Ru}$ concentration.

VIII. The experiment data from Phase I.

IX. The experiment data from Phase II.

$\mathrm{X}$. Structure, metallic radius, and lattice parameter of $\mathrm{Co}, \mathrm{Cr}, \mathrm{Pt}$. $\mathrm{Ru}$, and their alloys. 


\section{List of Figures}

Figure

Page

1. Typical disk structure and manufacture.

2. Diagram of vibrating sample magnetometer.

3. VSM output -- hysteresis loop.

4. Hysteresis loops along magnetic easy axis and hard axis. 6

5. Two variants of a $\mathrm{Co}$ alloy form on a single $\mathrm{Cr}$ grain. 13

6. $\mathrm{H}_{\mathrm{c}}$ and misfit as a function of $\mathrm{Cr}-\mathrm{V}$ composition. 14

7. X-ray diffraction analysis of $\mathrm{CoCrPt/Cr}-\mathrm{V}$. 15

8. Crystal structures of the $\mathrm{Cr}(\mathrm{BCC})$ and $\mathrm{NiAl}$ (B2). 16

9. Coercivity vs. underlayer thickness without substrate bias. 17

10. Coercivity vs. underlayer thickness with a $-200 \mathrm{~V}$ substrate bias during $\quad 17$ Co alloy deposition.

11. Coercivity vs. substrate bias during the NiAl's deposition. 18

12. $H_{c}$ and $S^{*}$ as a function of Ti content. 20

13. Grain size of $\mathrm{Cr}-\mathrm{Ti}$ as a function of Ti content. 20

14. Profile of the samples for Phase I. 25

15. Profile of the samples for Phase II. 27

16. VSM output. 29

17. X-ray diffraction output. 31

18. X-ray diffraction spectra of $\mathrm{Cr}_{1-\mathrm{x}} \mathrm{Ru}_{\mathrm{x}}$ film with different $\mathrm{Ru}$ concentration. $\quad 35$

19. X-ray diffraction spectra of $\mathrm{Co}_{64} \mathrm{Cr}_{22} \mathrm{Pt}_{14} / \mathrm{Cr}_{1 \cdot x} \mathrm{Ru}_{x}$ with different $\mathrm{Ru} \quad 36$ concentration.

20. The resistivity of $\mathrm{Cr}_{1-x} \mathrm{Ru}_{\mathrm{x}}$ vs. $\mathrm{Ru}$ concentration. 
21. Sketch of $\mathrm{Cr}-\mathrm{Ru}$ texture as a function of $\mathrm{Ru}$ concentration

22. X-ray diffraction intensity ratio of $\mathrm{Co}(10 \overline{10})$ and $\mathrm{Co}(0002)$ vs. $\mathrm{X}$-ray intensity ratio of $\mathrm{Ru}(10 \overline{10})$ and $\mathrm{Ru}(0002)$.

23. The in-plane coercivity of $\mathrm{Co}_{64} \mathrm{Cr}_{22} \mathrm{Pt}_{14} / \mathrm{Cr}_{1-x} \mathrm{Ru}_{\mathrm{x}}$ vs. $\mathrm{Ru}$ concentration.

24. The coercivity squareness of $\mathrm{Co}_{64} \mathrm{Cr}_{22} \mathrm{Pt}_{14} / \mathrm{Cr}_{1-x} \mathrm{Ru}_{\mathrm{x}}$ vs. $\mathrm{Ru}$ concentration. 43

25. $\mathrm{H}_{\mathrm{C}}$ as a function of the $\mathrm{Cr}_{1-\mathrm{x}} \mathrm{Ru}_{\mathrm{x}}$ layer thickness and substrate temperature. $\quad 45$

26. The $X$-ray diffraction ratio of $\operatorname{Co}(10 \overline{10})$ and $C o(0002)$ vs. substrate temperature.

27. The structures and lattice parameters of $\mathrm{Co}_{64} \mathrm{Cr}_{22} \mathrm{Pt}_{14}, \mathrm{Ru}$ and $\mathrm{Cr}$.

28. $\mathrm{Cr}-\mathrm{Ru}$ phase diagram.

29. $\mathrm{M}$-H loop comparison of $\mathrm{Co}_{64} \mathrm{Cr}_{22} \mathrm{Pt}_{14}$ with out-of-plane texture and $\mathrm{Co}_{64} \mathrm{Cr}_{22} \mathrm{Pt}_{14}$ with in-plane texture.

30. Four common crystallographic planes of HCP structure.

31. Plane view of (0002) and (10̄0) of Co and Ru lattices.

32. The lattice mismatch of $\mathrm{Co}[0002]$ and $\mathrm{Ru}[0002]$ vs. Ru concentration.

33. In-plane coercivity vs. $\mathrm{x}$-ray intensity ratio $\mathrm{Co}(10 \overline{10}) / \mathrm{Co}(0002)$. 


\section{Chapter 1}

\section{Introduction}

\subsection{Background}

The recording medium for a disk drive is a film of magnetically hard material on a circular substrate. In the past ten years, the fundamental technology of recording has evolved from particulate to thin film. The introduction of magnetoresistive (MR) heads in 1991 has had further impact on the design of thin film media. This has caused the areal density to increase rapidly. $10 \mathrm{~Gb} / \mathrm{in}^{2}$ areal density is expected to be achieved by 2010 [13]. In order to reach the high areal density, certain magnetic properties are desired [4]. Because the magnetic properties of a recording media can be controlled by the underlayer of a disk, exploring a new material for underlayer is one way to reach the high density recording requirements.

\subsection{Disk Structure and Manufacture}

The function of a disk is to store data by a magnetic field produced from a recording head, which flies only a few tens of nanometers ( $\mathrm{nm}$ ) above the disk surface. The data is recorded as a series of magnetic transitions which are replicated onto the disk from the signal input into the head. The data is then read back by measuring the magnetic field change by a reading head. The recording media discussed in this thesis is longitudinal recording media, which means the magnetization direction of the media lies in the film plane. The cross section of a general longitudinal disk is shown in Figure 1 [4]. The disk structure consists of a substrate, a sublayer, an underlayer, a magnetic layer, a protective layer, and a lubricant layer. 


\begin{tabular}{|c|c|c|c|}
\hline Purpose & Disk cross section & Thickness & Process \\
\hline Lubrication & Lubricant & $10 \AA$ & Dipping \\
\hline Protection & Protective layer (C) & $150 \AA$ & Sputtering \\
\hline Recording & Magnetic layer (Co-alloy) & $300 \AA$ & Sputtering \\
\hline Orientation control & Underlayer $(\mathrm{Cr})$ & $500 \AA$ & Sputtering \\
\hline \multirow[t]{2}{*}{ Hardness } & Sublayer (Ni-P) & $10 \mu \mathrm{m}$ & $\begin{array}{l}\text { Electroless } \\
\text { plating }\end{array}$ \\
\hline & Substrate (Al-Mg or glass) & $0.635 \mathrm{~mm}$ & \\
\hline
\end{tabular}

Figure 1. Typical disk structure and manufacture.

The base structure of the substrate is $\mathrm{Al}-\mathrm{Mg}$ alloy that is fabricated to different dimensions depending on the drive size. Nowadays, 3.5-inch diameter and 2.5-inch diameter are the most common size. Glass has also been used as a disk substrate material because of its stiffness and hardness.

The second layer of $\mathrm{Ni}-\mathrm{P}$, with a thickness of $10 \mu \mathrm{m}$, is electroless plated onto the aluminum substrate surface [5]. The purpose of the Ni-P layer is to cover up the defects of the aluminum substrate, and to pïvide a hard layer which can be polished to a mirror-like surface. The polished surface is then textured to add roughness [6,7]. The texture has three purposes: (1) to reduce the stiction force, (2) to stabilize the head when it is flying over the disk and, (3) to provide an orientation direction for sputtered films in order to introduce magnetic anisotropy on the disk and to make uniform magnetic read-back signals. 
An underlayer of $\mathrm{Cr}$ of thickness $200-1,000 \AA$ is then sputtered onto the textured disk. The purpose of the $\mathrm{Cr}$ layer is to ensure the nucleation of the magnetic film with the easy axis of magnetization in-plane [8]. The $\mathrm{Cr}$ underlayer also controls the grain structure of the magnetic layer, which is critical in determining the media noise.

A magnetic layer, with about $300 \AA$ thickness, is then sputtered onto the $\mathrm{Cr}$ layer. Ferromagnetic materials are needed for the magnetic layer. Co-based alloys are suitable for this layer because of their large magnetic anisotropy and high coercivity $[1,4]$.

Amorphous carbon is then sputtered for protection. This protective layer is typically $100-150 \AA$. Finally, a lubricant of thickness $10-30 \AA$ is applied onto the surface of the disk by dipping and draining. The lubricant reduces the friction and wear between the disk and the head.

\subsection{Fundamental Magnetic Media Measurements}

The vibrating sample magnetometer (VSM) is the most often used instrument for measuring the magnetic properties of recording media. Figure 2 shows a diagram of a typical VSM. The time rate of change of magnetic flux in the pick-up coils is produced by vibrating the magnetized sample. The magnetizing field in a VSM is provided by an electromagnet; typical maximum field is over 10,000 Oe. The sample is attached on a nonmagnetic rod, which vibrates vertically with an amplitude of about $1 / 16$ inch and a frequency of about $60 \mathrm{~Hz}$. When the sample vibrates, the pick-up coils will produce an electrical polarity. The ac voltage is proportional to the sample's magnetic moment. Then this signal along with the applied field signal are connected to an $x-y$ plotter to generate a hysteresis loop. 


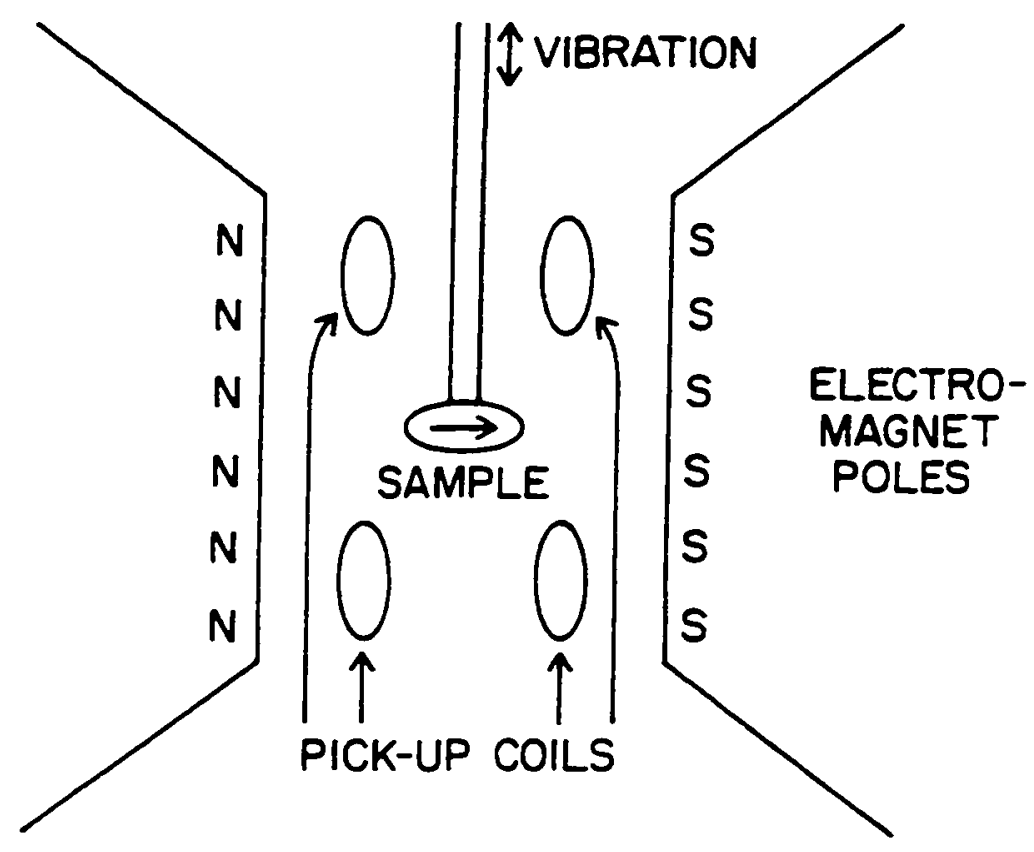

Figure 2. Diagram of vibrating sample magnetometer [4].

Figure 3 is a hysteresis loop of a thin film disk taken with a VSM. The horizontal axis is the magnetic field $(H)$; the vertical axis is the magnetization (M). Several characteristics can be determined from the hysteresis loop. The maximum magnetization is called the saturation magnetization $\mathbf{M}_{s}$. The magnetization remaining when the field $\mathrm{H}$ is reduced to zero is called the remanent magnetization $\mathbf{M}_{\mathbf{r}}$. The field required to reduce the magnetization to zero is called the coercive force or coercivity $H_{c}$. The squareness $S$ and coercivity squareness $S^{*}$ are determined geometrically by the hysteresis curve. $S$ equals $M / M_{s}$ and $S^{*}$ equals b/a, see Figure 3 for the definitions of a and b. Both $S$ and $S^{*}$ vary from 0 to 1 . $S=0$ indicates $M_{r}=0 ; S=1$ indicates $M_{r}=M_{s}$. $S^{*}=0$ indicates the hysteresis curve would be a straight line from $\mathrm{H}=-\mathrm{H}_{\mathrm{C}}$ to $\mathrm{M}=\mathrm{M}_{\mathrm{r}} ; \mathrm{S}^{*}=1$ indicates the slope of the hysteresis curve at $\mathrm{H}=-\mathrm{H}_{\mathrm{C}}$ is infinity. 


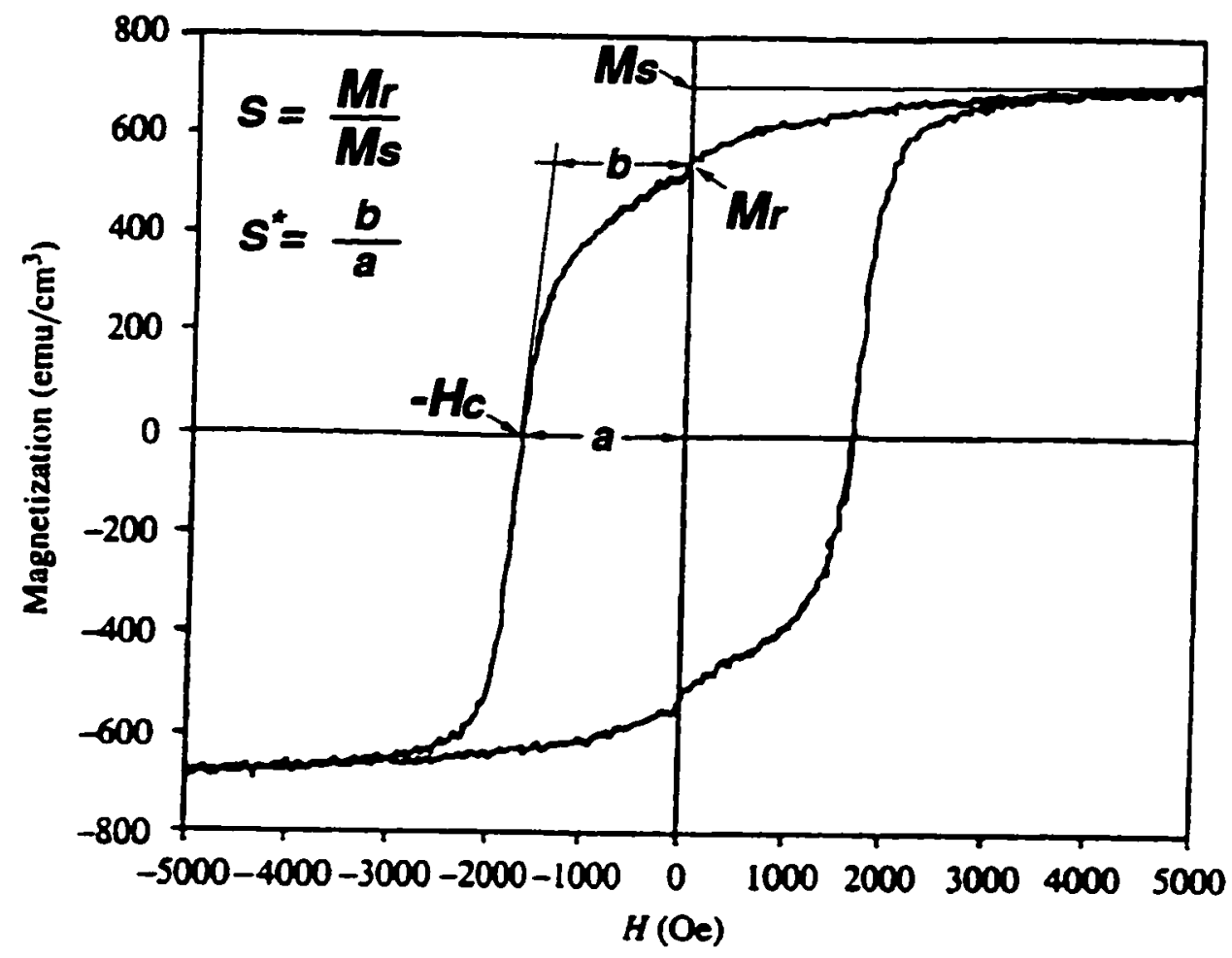

Figure 3. VSM output - hysteresis loop.

\subsection{Magnetic Anisotropy}

Ferromagnetic materials exhibit magnetic anisotropy, which means that the magnetic properties are different along different crystal directions. The direction which needs the least magnetic field to saturate the crystal is called the easy axis. The direction which needs the greatest magnetic field to saturate the crystal is called the hard axis. The magnetization along the easy axis needs the least energy, whereas the magnetization along the hard axis consumes the greatest amount of energy.

Figure 4 shows two hysteresis loops. One loop is along the easy axis, and the other is along the hard axis. The hysteresis loop along easy axis looks more square and has greater $\mathrm{H}_{c}$ than the hysteresis loop along hard axis. The magnetic anisotropy is an important property to produce a high $\mathrm{H}_{\mathrm{C}}$ recording media. 

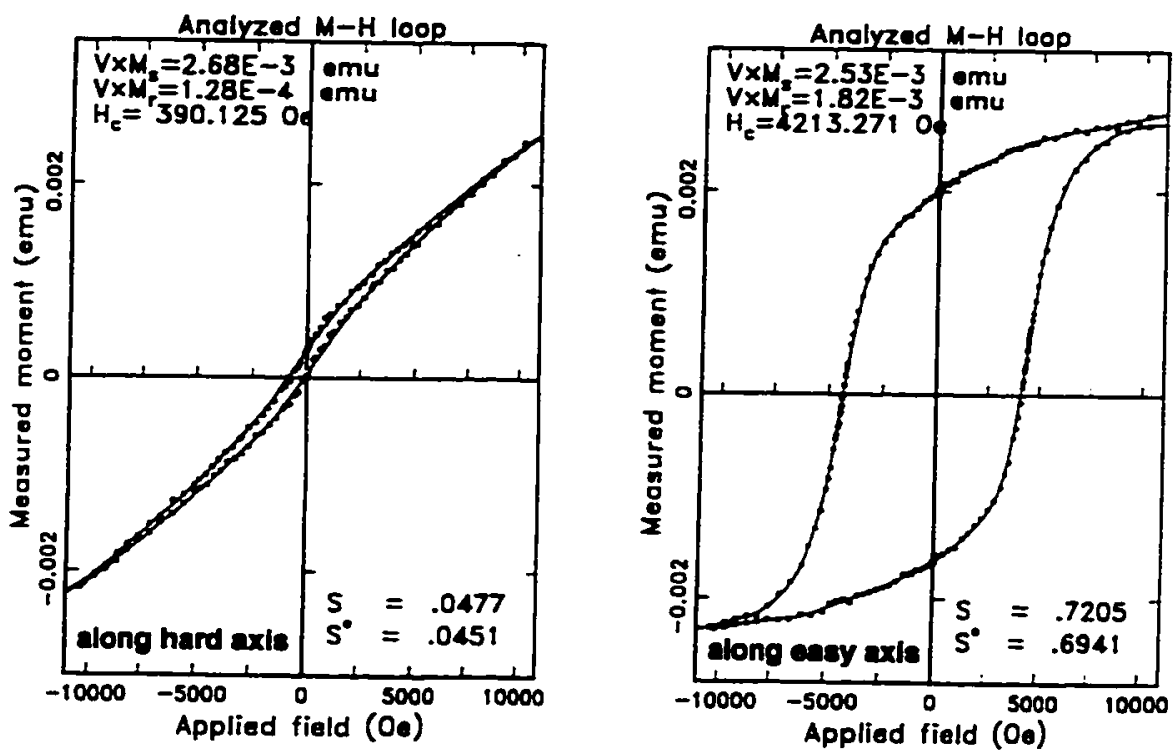

Figure 4. Hysteresis loops along magnetic easy axis and hard axis.

\subsection{High Areal Density Media Requirements}

The general design criterion for high density media is to increase the coercivity $\mathrm{H}_{c}$ as much as possible without exceeding the writability of the head, keep coercivity squareness $S^{*}$ high for sharp transition, and keep magnetic film thickness $\delta$ low for highfrequency output and to preclude magnetoresistive (MR) head saturation. Remanence $M_{\text {r }}$ must be adjusted to give adequate signal output without sacrificing resolution.

The values of $\mathrm{H}_{\mathrm{C}}$ in use today are around $2,800 \mathrm{Oe}$. $\mathrm{S} *$ values are typically larger than 0.8 , but $S^{*}$ values above 0.9 may not be desirable since they often indicate high media noise.

The signal-to-noise ratio is another parameter determining the performance of a disk drive. With the use of MR head, media noise become the major noise contributor in the disk drive. The origin of noise in a disk is the nonuniformity in the magnetic domain boundary [9]. There are three major approaches to reduce media noise: physical grain separation $[10,11]$, compositional segregation [12,13], and multilayers [14]. 
The magnetic properties of a disk are determined by the film microstructure of both magnetic layer and underlayer. The magnetic properties can be improved by using new materials or new processes in the both layers.

\subsection{Thesis Objective}

This thesis investigated $\mathrm{Cr}_{1-\mathrm{x}} \mathrm{Ru}_{\mathrm{x}}$ as an underlayer material for longitudinal recording media. There were two objectives of this project. The first objective was to analyze the magnetic properties of $\mathrm{Co}_{64} \mathrm{Cr}_{22} \mathrm{Pt}_{14} / \mathrm{Cr}_{1-\mathrm{x}} \mathrm{Ru}_{\mathrm{x}}$ and determine whether $\mathrm{Cr}_{1-\mathrm{x}} \mathrm{Ru}$ is a suitable material for underlayer. The second objective was to understand the relationship between sputtering parameters and magnetic properties for the $\mathrm{Co}_{64} \mathrm{Cr}_{22} \mathrm{Pt}_{14} / \mathrm{Cr}_{1-\mathrm{x}} \mathrm{Ru}_{\mathrm{x}}$ thin film system.

Chapter 2 of this thesis describes the previous published work relevant to this project. Chapter 3 describes the experimental procedures. Chapter 4 shows the results of the experiment. Chapter 5 discusses the structure and magnetic properties of $\mathrm{Co}_{64} \mathrm{Cr}_{22} \mathrm{Pt}_{14} / \mathrm{Cr}_{1-x} \mathrm{Ru}_{x}$ thin films. Chapter 6 gives a conclusion of this thesis and some suggestions for future study. 


\section{Chapter 2}

\section{Literature Review}

The literature review focused on two areas. The first area was articles evaluating new underlayer material for longitudinal recording. All of the closely related articles in this area were published after 1990. The second area of interest was the articles describing the relationship between microstructure and magnetic properties of recording thin films. The articles in this area offer a more basic understanding of thin films.

Many different underlayer materials for longitudinal media have been studied, such as $\mathrm{Cr}$ [15,16], Mo [15], W [15,17], Ti [18], NiP [16], NiAl [19-21], MgO [22], and Cr-X binary alloys $(X=V, T i, M o . .$.$) [23-26]. Only a few of them, however, actually perform$

well. Among them, $\mathrm{Cr}, \mathrm{Cr}-\mathrm{V}, \mathrm{Cr}-\mathrm{Ti}, \mathrm{NiAl}$ and $\mathrm{Cr}$-Mo have received the most intensive investigation.

The performance of a recording media is determined by both the magnetic layer and the underlayer. The magnetic properties of a disk are correlated to the film microstructure and the sputtering processes. Table I summarizes the possible parameters. The process parameters can change the film microstructure, and hence change the magnetic properties. The film microstructure is a way to understand the relationship between the process parameters and film properties.

A general discussion of microstructure effects on the magnetic property of a disk will be made, in Sections 2.1 to 2.4. Section 2.5 reviews the six most important underlayer materials that have been studied. They are $\mathrm{Cr}, \mathrm{Cr}-\mathrm{V}, \mathrm{NiAl}, \mathrm{Cr} / \mathrm{Al}, \mathrm{Cr}-\mathrm{Ti}$, and Ru. Section 2.6 gives a summary of the literature review. 


\begin{tabular}{|l|l|l|}
\hline $\begin{array}{l}\text { Processes (of underlayer } \\
\text { and magnetic layer) }\end{array}$ & $\begin{array}{l}\text { Microstructure (of underlayer } \\
\text { and magnetic layer) }\end{array}$ & Properties (of media) \\
\hline composition & crystallographic texture & coercivity $\mathrm{H}_{\mathrm{c}}$ \\
thickness & grain size & squareness S \\
substrate temperature & magnetic isolation & coercivity squareness $\mathrm{S}^{*}$ \\
bias & stacking faults & media noise \\
sputtering power (rate) & & \\
argon pressure & & \\
\hline
\end{tabular}

Table I. Parameters of a recording media.

\subsection{Crystallographic Texture}

By controlling the crystallographic texture of the underlayer, the texture of the magnetic film can be changed which in turn changes the magnetic properties of the $\mathrm{CO}$ based film $[27,40]$. For longitudinal recording it is necessary to have most of the magnetic grains with their easy axes of magnetization in or near the plane of the film. Co-based alloys, which are hexagonal close-packed, have their $c$-axis as the easy axis. For Co-based films with their $(1 \overline{010})$ or $(1 \overline{12} 0)$ planes parallel to the plane of the film, the $c$-axes will be in the film plane. If the $(10 \overline{1} 1)$ planes are in the film plane, the $c$-axis will be about $28^{\circ}$ out of the film plane. Using $\mathrm{Cr}(\mathrm{BCC})$ underlayer is a way to produce such $\mathrm{HCP}$ films.

\subsection{Grain Size}

It has been found that as the thickness of the $\mathrm{Cr}$ films increases, the grain size also increases [28]. If the $\mathrm{Cr}$ underlayer thickness is varied at $260^{\circ} \mathrm{C}$ while keeping the $\mathrm{CoCr} \mathrm{Ta}$ thickness constant, it was found that the increase in $\mathrm{H}_{\mathrm{c}}$ at $260^{\circ} \mathrm{C}$ was less than $10 \%$ when 
Cr thickness was increased from 150 to $3000 \AA$ [29]. This indicates that $\mathrm{H}_{C}$ of the CoCrTa films is not strongly influenced by the $\mathrm{Cr}_{\mathrm{r}}$ underlayer grain size.

It is worth pointing out that the grain size of the Co film is often not well defined because the grains have low angle grain boundaries and form clusters with closely related crystallographic orientation. The size of these clusters plays an important role in determining the magnetic properties of the films because magnetic coupling among the grains in the cluster should be strong. It is believed that the cluster size plays a more important role than does the grain size in determining the magnetic properties of $\mathrm{CoCr} T a / C r$ media [30].

\subsection{Magnetic Isolation}

It has been generally accepted that reduction in the intergranular exchange coupling is critical to obtain low noise magnetic thin film recording media [31,32]. Yogi et al. [28] used high sputtering Ar pressures to generate physical separation of grains which apparently leads to the reduced intergranular interaction. Isolation of magnetic grains has also been reported by Yamashita and Chen [33] by controlling the nucleation and growth of the underlayer NiP film in the CoNiPt/NiP system. In sputtered $\mathrm{CoCrTa} / \mathrm{Cr}$ recording media the low noise and high coercivity have been attributed to the segregation of the nonmagnetic constituents to the grain boundaries [34].

Using nuclear magnetic resonance (NMR) spectroscopy to investigate the local composition around the Co nuclei in the $\mathrm{CoCrTa} / \mathrm{Cr}$ films, Maeda et al. [35] found that the NMR spectra varied systematically with the substrate temperature. In the CoCrTa system, Cheong et al. [36] have observed $\mathrm{Ta}$ rich precipitates $\left(\mathrm{Co}_{3} \mathrm{Ta}, \mathrm{Ll}_{2}\right)$ in the HCP CoCrTa matrix, after heat-treatment at $500^{\circ} \mathrm{C}$. 


\subsection{Stacking Faults}

The stacking fault density and the degree of crystalline perfection between the faults is most important in increasing the coercivity and improving signal-noise properties. High substrate temperatures and high $\mathrm{Cr}$ and $\mathrm{Ta}$ concentrations promote the occurrence of the stacking faults in the films [30]. These faults provide possible sites for elemental segregation which is partially responsible for reducing the magnetic coupling among the unfaulted HCP regions in the CoCrTa films.

Fringe contrast within the grains has often been observed in Co based longitudinal recording media. Hono et al. [37] demonstrated that the fringe contrast is due to (0002) stacking faults, which appear to be the dominant structural defects in Co-based alloy film. In the $\mathrm{CoCr}$ system, $\mathrm{Cr}$ additions were found to increase the fault density [38]. The faults and grain boundaries in $\mathrm{CoCr}$ bulk alloys have been reported to act as pinning sites which impede domain wall motion [38].

The impact of a high density of stacking faults can be considered in two ways. First, these faults could provide sites for solute segregation which could reduce exchange coupling between the HCP regions separated by the stacking faults. Elemental segregation at stacking faults has been commonly known as the Suzuki effect [39]. Second, the elastic strain in the films would be minimized due to the formation of the high density of stacking faults. If the strain had built up, the magnetocrystalline anisotropy may have decreased thereby lowering the $\mathrm{H}_{\mathrm{C}}$ and noise properties of the films.

The lower Co concentration films $\left(\mathrm{Co}_{82.8} \mathrm{Cr}_{14.6} \mathrm{Ta}_{2.6} / \mathrm{Cr}\right)$ had much higher $\mathrm{H}_{\mathrm{C}}$ than the Co richer films for a given substrate temperature, even though they had a lower $\mathbf{M}_{\mathbf{s}}$. Fewer stacking faults were observed in the Co rich films $\left(\mathrm{Co}_{86} \mathrm{Cr}_{12} \mathrm{Ta}_{2} / \mathrm{Cr}\right)$ [30]. This also suggests that the higher $\mathrm{H}_{\mathrm{C}}$ of the film with less $\mathrm{Co}$ is probably due to a higher density of the faults and therefore possibly more segregation for a given substrate temperature. 


\subsection{Characteristics of Specific Underlayer Materials}

\subsubsection{Cr Underlayer}

Laughlin et al. [40] discussed various ways that the crystallographic texture of a thin film can be controlled. The control of other microstructural aspects such as grain size and crystalline perfection by means of underlayers was also included.

In order to produce a thin film of a Co based alloy (HCP) with its c-axis in or near the plane of the film, an underlayer must be used. This is because all crystalline materials have preferred growth directions when produced as thin films. The planes parallel to the film usually will be the closest packed ones. Therefore, an HCP phase will usually grow with its c-axis perpendicular to the film plane, unless it is forced to do otherwise during the initiation of its formation on the substrate.

$\mathrm{Cr}$ thin films (BCC) deposited at room temperature tend to develop the $\{110\}$ inplane crystallographic texture. $\mathrm{Cr}$ underlayers with this crystallographic texture will produce Co-alloy thin films with their c-axis out-of-plane. However, by controlling the processing variables, $\mathrm{Cr}$ films with a $\{200\}$ in plane crystallographic texture can be produced. This texture will produce Co-alloy thin films with their $\{1 \overline{12} 0\}$ parallel to the film plane, i.e., c-axis in-plane. This change in crystallographic texture has been explained in terms of a model which emphasizes the role of surface energies during the nucleation stage of the $\mathrm{Cr}$ thin films [41]. This model assumes that the closest packed $\{110\}$ planes of $\mathrm{C}_{r}$ have lower surface energies than the $\{200\}$ planes. Thus, when the nuclei of $\mathrm{Cr}$ first form, they will tend to maximize the amount of $\{110\}$ surface area.

For epitaxy to arise between a magnetic film and its underlayer, one or two directions in the magnetic film must have good atomic matching with directions of the underlayer. When this occurs, specific planes of atoms in the film orient themselves with respect to specific underlayer planes. Thus, if the underlayer has a crystallographic texture, the magnetic film will start off with a crystallographic texture that is controlled by the 
$(10 \overline{1} 1) \mathrm{Co} \|(110) \mathrm{Cr}$

(1120) Co \| (002) Cr

(1010) Co $\|(112) \mathrm{Cr}$

(1010) Co $\|(113) \mathrm{Cr}$

(1121) Co $\|(111) \mathrm{Cr}$

Table II. Crystallographic Relations of Co grain with their Cr underlayer [40].

crystallographic texture of the underlayer. Table II summarizes some of the observed crystallographic relationships between $\mathrm{Co}$-alloy films and their $\mathrm{Cr}$ underlayers. Each of these crystallographic relationships can be understood in terms of epitaxy.

Figure 5 is a schematic of a single grain of $\mathrm{Cr}$ with its (002) plane parallel to the film. It is possible for the $\mathrm{Co}$ alloy that is deposited on top of $\mathrm{Cr}$ to form two distinct orientations of grains. Since the (002) plane of $\mathrm{Cr}$ has four-fold symmetry, the (0002) planes of the Co alloy may form parallel to either of the mutually perpendicular (110) and (110) $\mathrm{Cr}$ planes. This degeneracy will occur if the rate of formation of the Co nuclei is fast enough to form several nuclei before the lateral growth covers the $\mathrm{Cr}$ grain. Faster sputtering rates favor this situation. Thus for every grain of $\mathrm{C} r$, there may be several grains of the Co film .

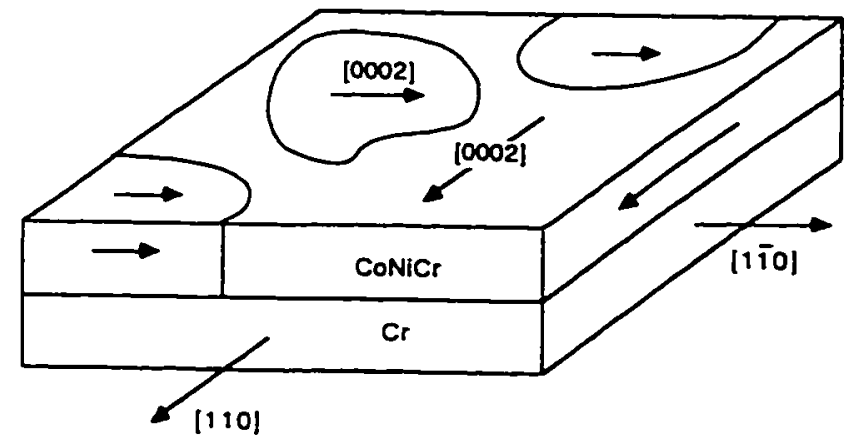

Figure 5. Two variants of a Co alloy form on a single $\mathrm{Cr}$ grain [40]. 
Another microstructural feature that can be controlled is the perfection of the grain. A film formed with an applied bias shows a higher degree of crystal perfection than without bias. Finally, the use of underlayers affect the properties of the Co alloy films by means of inter-diffusion. The $\mathrm{Cr}$ atoms diffuse into the magnetic Co films along the grain boundaries. This not only changes the composition of the magnetic films, but also increases the magnetic grain isolation, causing changes in coercivity and coercivity squareness.

\subsubsection{Cr-V Underlayer}

Parker et al. [23] investigated the influence of a $\mathrm{CrV}$ underlayer on the microstructure, crystallography, and epitaxy of $\mathrm{CoCrPt}$, and the effects on the coercivity. The samples consisted of $350 \AA \mathrm{Co}_{75} \mathrm{Cr}_{13} \mathrm{Pt}_{12}$ magnetic layer deposited on $500 \AA$ underlayers of $\mathrm{Cr}-\mathrm{V}$ with the following compositions in at.\% $\mathrm{V}$ : pure $\mathrm{Cr}, 10 \%, 20 \% .50 \%$. $80 \%$, and pure $\mathrm{V}$.

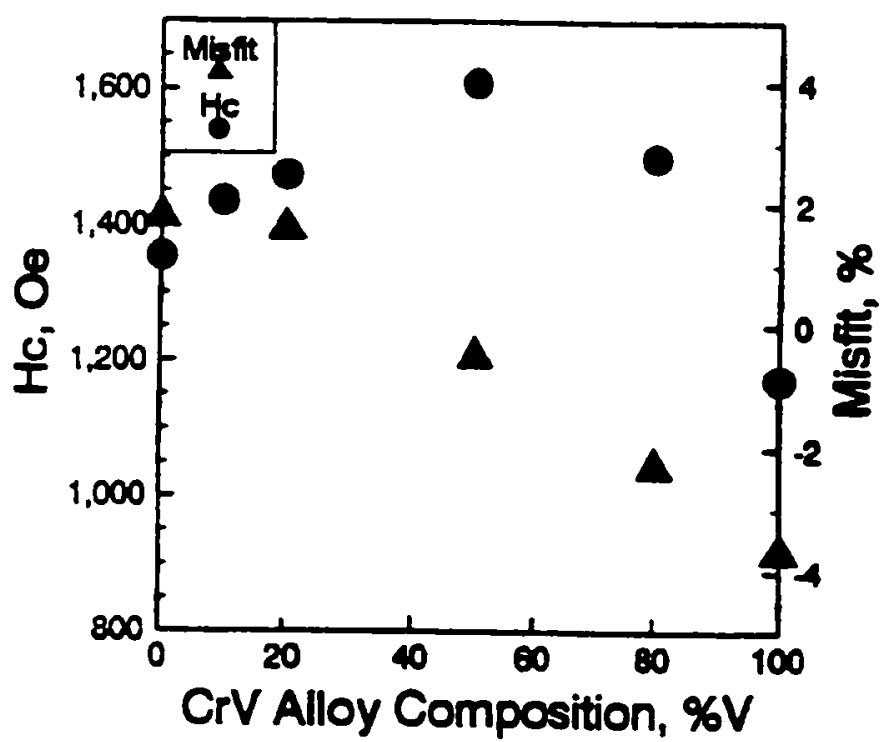

Figure 6. $\mathrm{H}_{\mathrm{C}}$ and misfit as a function of $\mathrm{Cr}-\mathrm{V}$ composition [23]. 
Figure 6 shows the variation of coercivity $\mathrm{H}_{c}$ in the $\mathrm{CoCrPt}$ films as a function of the composition of the $\mathrm{Cr}-\mathrm{V}$ underlayer. The calculated misfits between the (0001) $\mathrm{Co}$ and (110) $\mathrm{Cr}$ interplanar spacing are given on the right axis of the plot; minimal misfit occurs at approximately $50 \% \mathrm{~V}$. This is also the composition with the highest coercivity. The plot suggests that improving the lattice match between the underlayer and the magnetic layer improves $\mathrm{H}_{C}$. The lattice parameters of $\mathrm{CoCrPt}$ and $\mathrm{Cr}-\mathrm{V}$ were determined by $\mathrm{X}$-ray diffraction analysis. By analyzing the intensity of the peaks, the texture of the films can also be determined, as shown in Figure 7.

The coercivity increased between 20 and $50 \% \mathrm{~V}$ content because of the increasing fraction of $(11 \overline{2} 0)$ Co grains with c-axis in plane; $c$-axis of Co alloy is the magnetic easy axis. The increasing $\mathrm{c}$-axis in-plane is because of the improving degree of epitaxy between the $\mathrm{CoCrPt}$ and the $\mathrm{Cr}-\mathrm{V}$ underlayer.

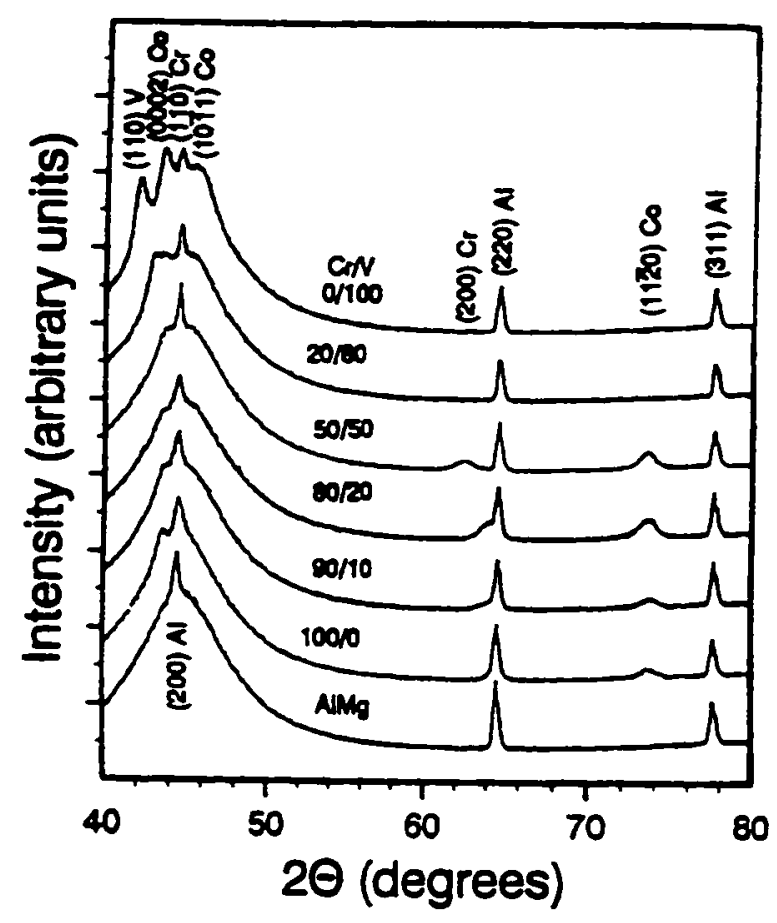

Figure 7. X-ray diffraction analysis of $\mathrm{CoCrP} / \mathrm{Cr}-\mathrm{V}$ [23]. 
The authors report significant effort in transmission electron microscopy (TEM) and $\mathrm{X}$-ray analysis. They also showed that the $\mathrm{S}^{*}$ was increased by using a $\mathrm{Cr}-\mathrm{V}$ underlayer. But the authors did not provide other magnetic properties, such as $S$ and media noise, in order to evaluate whether $\mathrm{Cr}-\mathrm{V}$ is a suitable material for the underlayer.

\subsubsection{NiAl Underlayer}

Lee et al. [19] investigated $\mathrm{Co}_{86} \mathrm{Cr}_{12} \mathrm{Ta}_{2}$ magnetic films which were sputterdeposited on NiAl underlayers on glass substrates. The magnetic layer, CoCrTa, was maintained at a constant thickness of $40 \mathrm{~nm}$ for all samples. The relationship between inplane coercivity and underlayer thickness was investigated. Substrate bias during deposition of NiAl underlayer was also studied.

The NiAl film was found to have the B2 structure with a lattice parameter of 0.2884 $\mathrm{nm}$. NiAl has an almost identical lattice parameter as $\mathrm{Cr}, 0.2887 \mathrm{~nm}$. Schematics of the crystal structures of NiAl and $\mathrm{Cr}$ are shown in Figure 8. The grain size of a $100 \mathrm{~nm}$ NiAl film is about $15 \mathrm{~nm}$, which is about $50 \%$ smaller than the grain size of a $\mathrm{Cr}$ film. A uniform, fine grain underlayer is beneficial because it will give rise to a Co magnetic layer with smaller grain size. which would yield better signal-to-noise ratios in their recording performance.

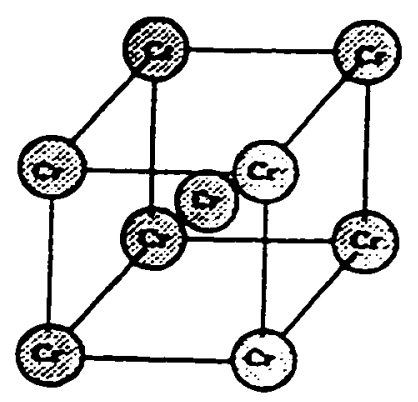

$$
\text { Cr, scc }
$$
$0.288 \mathrm{~nm}$

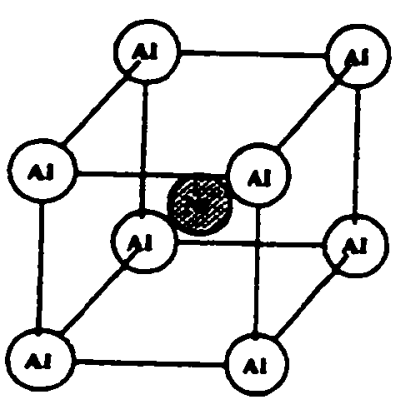

Ma4, 82 $0=0.2887 \mathrm{~mm}$

Figure 8. Crystal structures of the $\mathrm{Cr}(\mathrm{BCC})$ and $\mathrm{NiAl}$ (B2) [19]. 


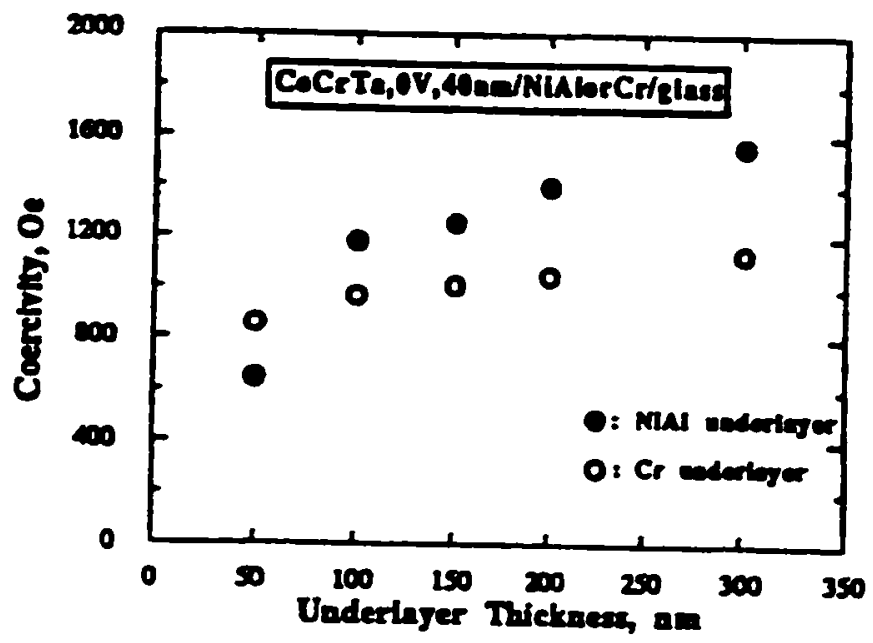

Figure 9. Coercivity vs. underlayer thickness without substrate bias [19].

Figure 9 shows the coercivity value of magnetic layers on various thickness of NiAl or $\mathrm{Cr}$ underlayers without substrate bias or heating. In both cases, the coercivity increased as the underlayer thickness increased. Figure 10 is similar to Figure 9 except the CoCrTa layer was deposited at a $-200 \mathrm{~V}$ substrate bias. The substrate bias increases coercivity in both $\mathrm{CoCrTa} / \mathrm{Cr}$ and $\mathrm{CoCrTa} / \mathrm{NiAl}$ films. But the coercivity increase in CoCrTa/NiAl films is higher.

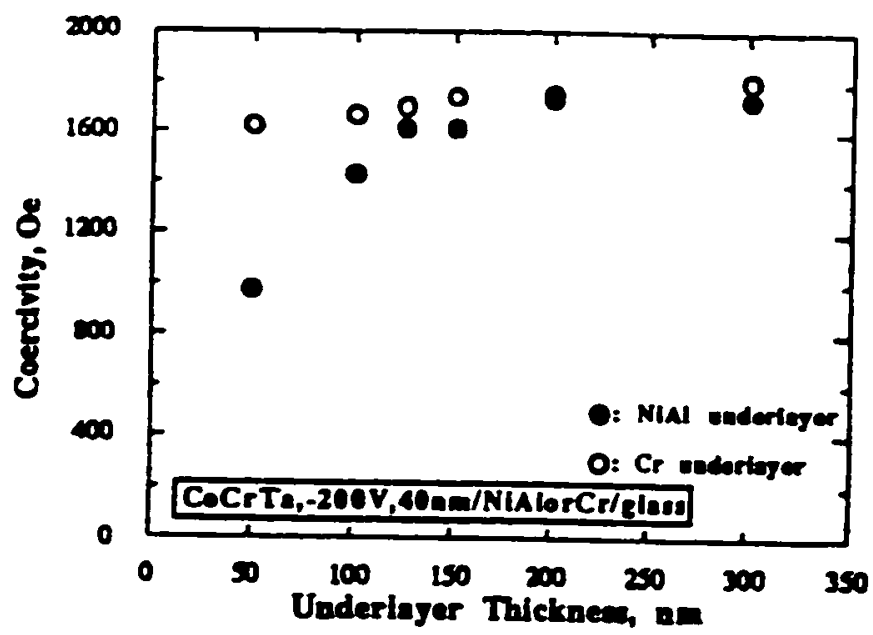

Figure 10. Coercivity vs. underlayer thickness with a $-200 \mathrm{~V}$ substrate bias during Co alloy deposition [19]. 
The substrate bias during the $\mathrm{Cr}$ sputtering process alone can increase the coercivity of the $\mathrm{CoCrTa} / \mathrm{Cr}$ film by about $60 \%$. However, the substrate bias during NiAl sputtering decreased the coercivity of the CoCrTa/NiAl film, Figure 11 . The energy dispersive X-ray spectroscopy analysis showed that the bias sputtering changed the composition of the NiAI film. An increase of substrate bias voltage from 0 to $-200 \mathrm{~V}$ can change the $\mathrm{Al}$ content from 52.3 at.\% to 42 at.\%. This is due to the preferential resputtering of the $\mathrm{Al}$ during the deposition. With the $-200 \mathrm{~V}$ substrate bias, the NiAl underlayer showed a mixture of $\mathrm{B} 2$ $\mathrm{NiAl}$ and the orthorhombic $\mathrm{Ni}_{5} \mathrm{Al}_{3}$ phases. Therefore, As the bias voltage increased, the CoCrTa film gradually lost its epitaxially growth of c-axis in-plane texture, and as a result its coercivity decreased.

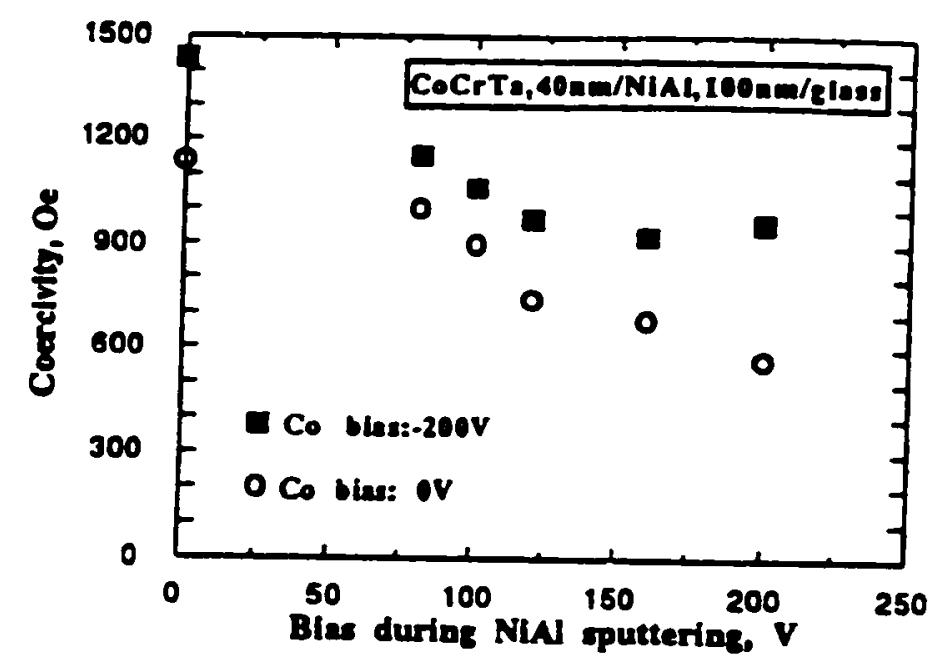

Figure 11. Coercivity vs. substrate bias during the NiAl's deposition [19].

\subsection{4 $\mathrm{Cr} / \mathrm{Al}$ Underlayer}

The effect of $\mathrm{Cr} / \mathrm{Al}$ underlayers on the magnetic properties of $\mathrm{Co}_{77} \mathrm{Cr}_{11} \mathrm{Pt}_{10} \mathrm{Ta}_{2}$ films deposited on glass substrates were investigated by Chang et al. [43]. The effects of an $\mathrm{Al}$ overlayer on the magnetic properties of $\mathrm{CoCrPtTa} / \mathrm{Cr}$ films were also studied. 
The magnetic properties of the thin films are shown in Table III. The coercivity increased and the coercivity squareness decreased by using $\mathrm{Al}$ over-coated and $\mathrm{Al}$ undercoated films, compared to Cr only.

The coercivity increase is attributed to the increase of c-axis in-plane texture, the increase of magnetic isolation of $\mathrm{CoCrPtTa}$ grains, and the refinement of $\mathrm{CoCrPtTa}$ grains deposited on $\mathrm{Cr} / \mathrm{Al}$ underlayers. The decrease of coercivity squareness is attributed to the magnetic isolation of CoCrPtTa grains. The increase of $c$-axis in-plane texture is due to the lattice expansion of a $\mathrm{Cr}$ layer deposited on an $\mathrm{Al}$ layer. The increase of magnetic isolation is due to $\mathrm{Al}$ atoms diffused into the grain boundaries of CoCrPtTa rather than inside CoCrPtTa grains.

\begin{tabular}{|c|c|c|}
\hline Thin films & $\mathrm{H}_{\mathrm{c}}(\mathrm{Oe})$ & $\mathrm{S}^{*}$ \\
\hline $\mathrm{CoCrPtTa} / \mathrm{Cr}$ & 1350 & 0.89 \\
$\mathrm{CoCrPtTa} / \mathrm{Cr} / \mathrm{Al}$ & 1740 & 0.87 \\
$\mathrm{Al} / \mathrm{CoCrPtTa} / \mathrm{Cr}$ & 1475 & 0.84 \\
\hline
\end{tabular}

Table III. Magnetic properties of Al underlayer and Al overlayer thin films [43].

\subsubsection{Cr-Ti Underlayer}

The effects of $\mathrm{Ti}$ addition to a $\mathrm{Cr}$ underlayer on the magnetic and crystallographic properties of $\mathrm{CoCr}_{20} \mathrm{Pt}$ (Pt: 8 and 12 at. \%) media were investigated by Matsuda et al. [24].

In-plane coercivity and coercivity squareness increased as Ti was added up to $25 \%$ to the $\mathrm{Cr}$ underlayer, as shown in Figure 12. The media noise decreased with an increase of the Ti content from 0 to 20 at. \%. Transmission electron microscopy studies showed that the average grain size of $\mathrm{Cr}$-Ti films decreased from 30 to $20 \mathrm{~nm}$ with the Ti content increasing from 0 to 20 at. \%, as shown in Figure 13. 


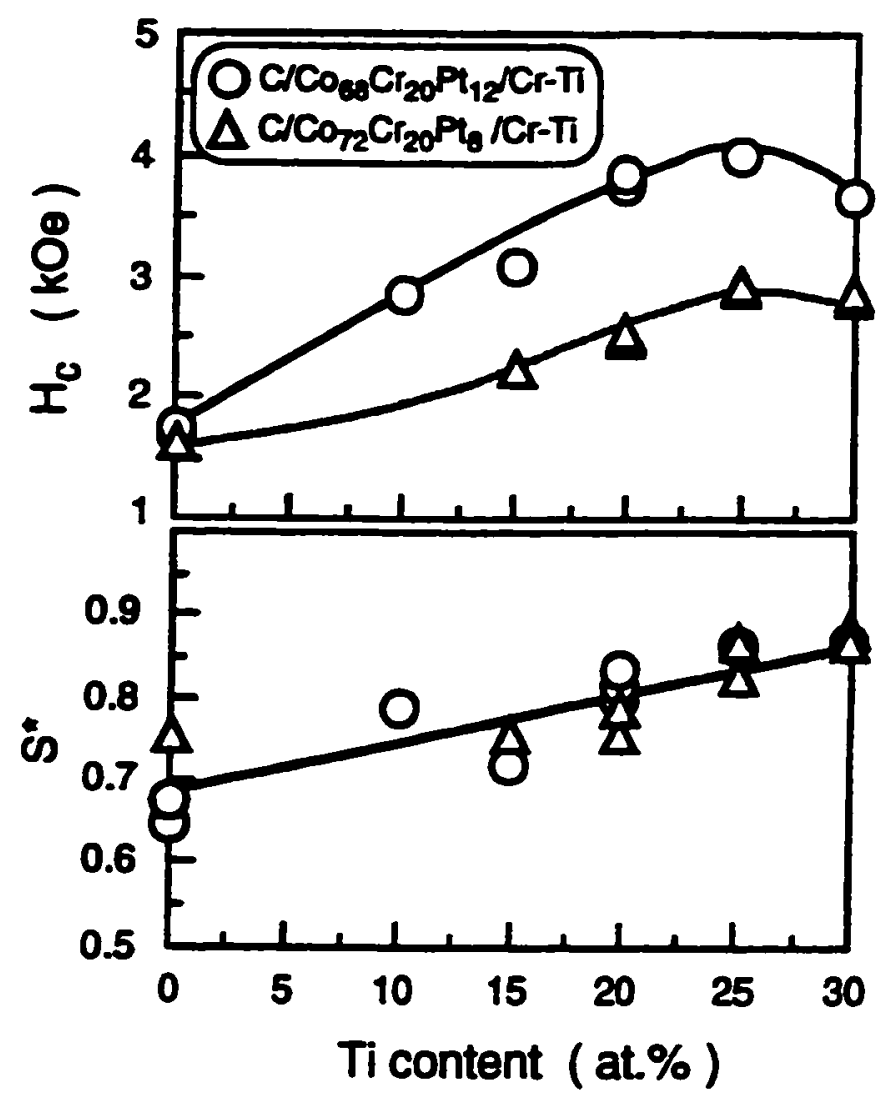

Figure 12. $\mathrm{H}_{\mathrm{C}}$ and $\mathrm{S}^{*}$ as a function of Ti content [24].

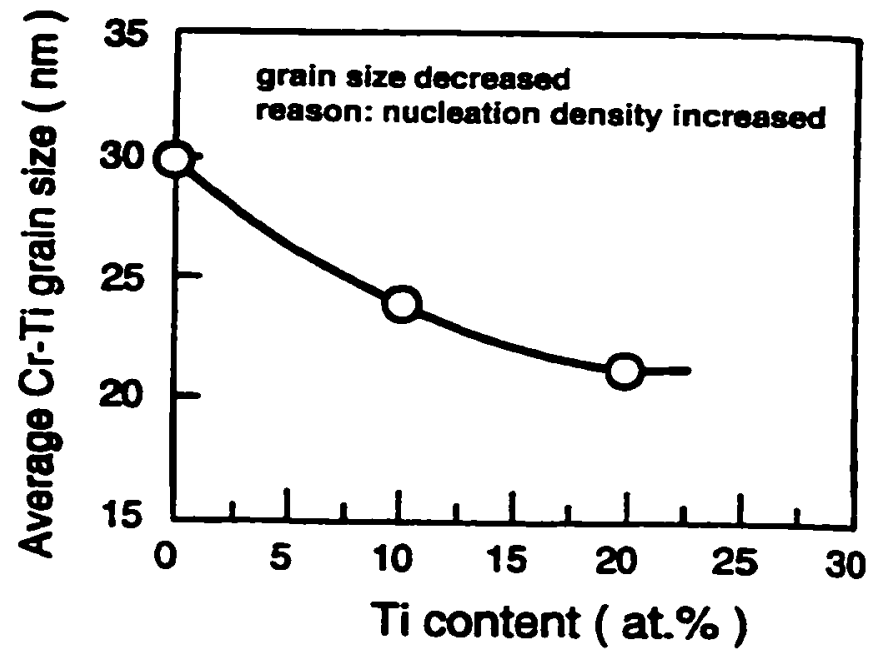

Figure 13. Grain size of $\mathrm{Cr}$-Ti as a function of $\mathrm{Ti}$ content [24]. 
The increase of $\mathrm{H}_{\mathrm{c}}$ and $\mathrm{S}^{*}$ is due to the lattice matching between $\mathrm{CoCr}_{\mathrm{Pt}}$ and $\mathrm{Cr}-\mathrm{Ti}$ films by expanding the $\mathrm{Cr}$ lattice with the addition of $\mathrm{Ti}$. The reduction of media noise is due to the decrease of magnetic grain size which is caused by the decrease of $\mathrm{Cr}-\mathrm{Ti}$ underlayer grain size. The decrease of magnetic grain size seems to be correlated with the nucleation density of the $\mathrm{Cr}$-Ti film. From the structure analyses, it seemed that the increase of noise at the high $\mathrm{Ti}$ content was caused by the increase and a wider distribution of $\mathrm{Cr}$-Ti grain size.

This paper provided $\mathrm{Cr}-\mathrm{Ti}$ as a good candidate for the underlayer. Ti addition to $\mathrm{Cr}$ underlayers is advantageous to improve the recording properties since the media noise is remarkably reduced without a decrease of $\mathrm{H}_{\mathrm{C}}$ and $\mathrm{S}^{*}$. Although this paper showed successful results, it did not explain clearly how the lattice matching related to the increase of $\mathrm{H}_{\mathrm{C}}$ and $\mathrm{S}^{*}$, and how the grain size related to the media noise. Further studies from other papers are necessary to understand these effects.

\subsubsection{Ru Underlayer}

Ru underlayer has been studied by Lee [44]. Ru underlayer can induce high $\mathrm{H}_{C}$. In some cases, the $\mathrm{H}_{\mathrm{c}}$ can reach more than 5,000 Oe. X-ray diffraction showed that the samples with high $\mathrm{H}_{\mathrm{C}}$ have strong $\mathrm{Co} c$-axis in-plane texture. Both $\mathrm{Ru}$ and $\mathrm{Co}$ alloy have the same crystal structure (HCP), and they have similar lattice parameters.

$\mathrm{Ru}$ and most Ru compounds are toxic [45]. Ru is retained in the bones for a long time. When heated to decomposition it emits very toxic fumes of $\mathrm{RuO}_{\mathrm{x}}$ and $\mathrm{Ru}$ which are highly injurious to the eyes and lung and can produce nasal ulcerations. The environmental problem may prevent Ru from being used in some applications. 


\subsection{Summary of Literature Review}

Table IV summarizes different underlayer materials that have been studied. The crystal structures and the maximum $\mathrm{H}_{c}$ are included. The underlayer materials in the literature review are all cubic structures except $R u$, which is HCP. The magnitude of $H_{C}$ is strongly dependent on the deposition parameters and the type of the magnetic films. The $\mathrm{H}_{C}$ in Table IV are the largest possible values found in the literature review.

From the literature review, it is believed that the $\mathrm{Cr}$ binary alloys are strong underlayer candidates for high density longitudinal recording. The $\mathrm{Cr}$ lattice matches with Co alloys in certain planes and certain directions. This lattice matching can induce Co caxis in-plane texture that is desired for high density recording. The lattice matching can be further fine tuned by alloying $\mathrm{Cr}$ with other elements.

$\mathrm{Ru}$ is also a strong candidate material for underlayer. It is possible that if $\mathrm{Cr}$ is alloyed with $\mathrm{Ru}, \mathrm{Cr}_{1-x} \mathrm{Ru}_{\mathrm{x}}$ thin film will induce the required microstructure of Co layer and get the required magnetic property. For this reason, $\mathrm{Cr}_{1-\mathrm{x}} \mathrm{Ru}_{\mathrm{x}}$ underlayer is chosen for this thesis. One drawback to use $\mathrm{Ru}$ is that Ru is toxic. Nevertheless it is still worthy to study the microstructure-properties relationship from the $\mathrm{Co}_{64} \mathrm{Cr}_{22} \mathrm{Pt}_{14} / \mathrm{Cr}_{1-x} \mathrm{Ru}_{\mathrm{x}}$ thin films.

\begin{tabular}{|c|c|c|}
\hline Underlayer Material & Structures & Coercivity $\left(\mathrm{H}_{\mathrm{C}}\right)$ \\
\hline No underlayer & $-\cdots$ & -500 \\
\hline $\mathrm{Cr}$ & $\overline{B C C}$ & $\sim 1,500$ \\
\hline $\mathrm{NiAl}$ & B2 & $-1,700$ \\
\hline $\mathrm{Cr}-\mathrm{V}$ & $\overline{B C C}$ & $-1,700$ \\
\hline$\overline{C r-M o}$ & $\overline{\mathrm{BCC}}$ & $-2,500$ \\
\hline$\overline{C r}-\mathrm{Ti}_{\mathrm{i}}$ & $\overline{B C C}$ & $-3,800$ \\
\hline $\mathrm{Cr} / \mathrm{Al}$ & BCC/FCC & $\sim 1,740$ \\
\hline $\mathrm{Cr} / \mathrm{NiAl}$ & $\mathrm{BCC} / \mathrm{B} 2$ & $-3,000$ \\
\hline NiAl/MgO & $\mathrm{B} 2 / \mathrm{B} 1$ & $-3,400$ \\
\hline $\mathrm{Ru}$ & $\mathrm{HCP}$ & $-5,000$ \\
\hline
\end{tabular}

Table IV. Summary of different underlayer materials 


\section{Chapter 3}

\section{Experimental Procedures}

\subsection{Experiment Outline}

This experiment used $\mathrm{Co}_{64} \mathrm{Cr}_{22} \mathrm{Pt}_{14}$ magnetic layer deposited on top of $\mathrm{Cr}_{1-\mathrm{x}} \mathrm{Ru}_{\mathrm{x}}$ underlayer by sputtering. The experiment investigated the effects of $\mathrm{Cr}_{\mathrm{l}-\mathrm{x}} \mathrm{Ru}_{\mathrm{x}}$ underlayer on the magnetic properties of the $\mathrm{Co}_{64} \mathrm{Cr}_{{ }_{22}} \mathrm{Pt}_{14} / \mathrm{Cr}_{1-x} \mathrm{Ru}_{\mathrm{x}}$ thin films at different $\mathrm{Ru}$ concentration, $\mathrm{Cr}_{\mathrm{I}-\mathrm{x}} \mathrm{Ru}_{\mathrm{x}}$ layer thickness, and substrate temperatures. The process parameters of the $\mathrm{Co}_{64} \mathrm{Cr}_{22} \mathrm{Pt}_{14}$ layer, such as composition, thickness, and deposition rate, were fixed throughout the experiment.

The experiment was comprised of two phases. Phase $I$ was $C r_{1-x} R u_{x}$ composition dependence study. Phase II was $\mathrm{Cr}_{1-\mathrm{x}} \mathrm{Ru}_{\mathrm{x}}$ thickness and substrate temperature dependence study. In Phase I, the composition of $\mathrm{Cr}_{\mathrm{I}-\mathrm{x}} \mathrm{Ru}_{\mathrm{x}}$ was changed from $0 \% \mathrm{Ru}$ to $100 \% \mathrm{Ru}$. The thickness of $\mathrm{Cr}_{1-x} \mathrm{Ru}_{\mathrm{x}}$ layer was fixed at $500 \AA$, and the substrate temperature was fixed at $250^{\circ} \mathrm{C}$. At 57 at.\% Ru, the in-plane $\mathrm{H}_{\mathrm{C}}$ was highest, about 4,100 Oe. $\mathrm{The} \mathrm{Cr}_{\mathrm{l}-\mathrm{x}} \mathrm{Ru}_{\mathrm{x}}$ film of $57 \%$ Ru was used as a fixed composition in Phase II because the samples at this composition have highest $\mathrm{H}_{\mathrm{C}}$. The effects of underlayer thickness and deposition temperature on the magnetic properties were studied in Phase II.

In order to analyze the magnetic properties of the samples, coercivity $\mathrm{H}_{\mathrm{c}}$, coercivity squareness $S^{*}$, and squareness $S$ were measured by VSM. The crystallographic texture was determined by $\mathrm{X}$-ray diffraction. Film thickness, composition, and resistivity were also measured in the experiment.

The following sections explain the details of the experiment procedures. Section 3.2 shows the procedures by which the samples were made. Section 3.3 through Section 3.5 explain the procedures of measuring the properties of the samples. 


\subsection{Sample Preparation}

This experiment used 1-inch-diameter glass substrates on which the films were deposited. The substrates was cleaned by acid etch before depositing films. A DC magnetron sputtering system was used to make the films. The sputtering system used in this experiment was made by Sputter Thin Film Inc. Substrate bias was not able to be controlled in this system. All other sputter parameters such as sputtering power, argon pressure, and substrate temperature were controlled and monitored directly by this system. Six samples were made per pumpdown. These six samples might have different thickness and different composition by controlling the sputtering rate and time, but different substrate temperature in one pumpdown was not practically possible because it took a long time for temperature to be in equilibrium. Six samples of the same substrate temperature were made for each pumpdown in this system. Each pumpdown took overnight to reach high vacuum, about $10^{-7}$ torr. Before the films were made, the tooling factor had been calibrated in order to read the right thickness directly from the display. The procedures of calibrating the tooling factor are illustrated in Section 3.5.

\subsubsection{Phase I -- The Effects of the Ru Concentration on the $\mathrm{Co}_{64} \mathrm{Cr}_{22} \mathrm{Pt}_{14} / \mathrm{Cr}_{1-x} \mathrm{Ru}_{x}$ Magnetic Properties}

The first parameter this experiment investigated was the underlayer composition. $\mathrm{Cr}_{1-x} \mathrm{Ru}_{\mathrm{x}}$ thin films were made by co-sputtering from the targets of pure $\mathrm{Cr}$ and pure $\mathrm{Ru}$. The composition of $\mathrm{Cr}$ and $\mathrm{Ru}$ was controlled by the relative deposition rate of $\mathrm{Cr}$ and $\mathrm{Ru}$; the Ru concentration was varied from $0 \%$ to $100 \%$ with a step of about $5 \%$ (sample \# 1-14 and \# 30-42). For this phase, the underlayer thickness was kept at $500 \AA$, substrate temperature at $250^{\circ} \mathrm{C}$, and argon pressure at $6 \mathrm{mTorr}$. After depositing the underlayer, a magnetic film was sputtered subsequently. As mentioned in Section 3.1, magnetic film deposition parameters were fixed throughout the experiment. The magnetic layer 


\begin{tabular}{|c|l}
\hline $\mathrm{Co}_{64} \mathrm{Cr}_{22} \mathrm{Pt}_{14}$ & $\begin{array}{l}\text { Thickness: } 250 \AA \\
\text { Thickness: } 500 \AA\end{array}$ \\
\hline $\mathrm{Cr}_{1-\mathrm{x}} \mathrm{Ru}_{\mathrm{x}}$ & Substrate temperature: $250^{\circ} \mathrm{C}$ \\
\hline Glass substrate &
\end{tabular}

Figure 14. Profile of the sample for Phase I.

composition was $\mathrm{Co}_{64} \mathrm{Cr}_{22} \mathrm{Pt}_{14}$, and the thickness was kept at $250 \AA$. The magnetic layer was deposited by sputtering the right composition target. The profile of the sample is shown in Figure 14. After the films were made, the magnetic properties of the $\mathrm{Co}_{64} \mathrm{Cr}_{22} \mathrm{Pt}_{14} / \mathrm{Cr}_{1-x} \mathrm{Ru}_{x}$ thin films were measured by VSM. The details about VSM are described in the next section.

When the VSM measurement was finished, the Ru concentration was narrowed down to $L$ at.\% step around the specific composition of interest (sample \# 15-19 and \# 2629). The composition with maximum $\mathrm{H}_{C}$ was determined by the previous step. The composition of 57 at.\% Ru had maximum $\mathrm{H}_{\mathrm{C}}$ and was most interesting. Another six 57\% Ru samples were made during different pumpdowns to investigate uniformity (sample \# 20-25). All the parameters and procedures were the same as in the previous deposition. The relationship between the $\mathrm{H}_{c}$ and the Ru composition was then determined. The samples made in Phase I are summarized in Table V.

The composition of $\mathrm{Cr}_{1-x} \mathrm{Ru}_{\mathrm{x}}$ film was controlled roughly by calculating the relative deposition rate of $\mathrm{Cr}$ and $\mathrm{Ru}$. More accurate composition was determined by Rutherford Backscattering Spectrometry (RBS). In addition to the samples with both $\mathrm{Co}_{64} \mathrm{Cr}_{22} \mathrm{Pt}_{14}$ layer and $\mathrm{Cr}_{1-\mathrm{x}} \mathrm{Ru}$ layer, the samples with $\mathrm{Cr}_{1-\mathrm{x}} \mathrm{Ru}$ layer only were also made. $\mathrm{RBS}, \mathrm{X}$ ray diffraction, and resistivity measurements of $\mathrm{Cr}_{1 \cdot x} \mathrm{Ru}_{\mathrm{x}}$ layer were made without the interference of $\mathrm{Co}_{64} \mathrm{Cr}_{22} \mathrm{Pt}_{14}$ layer. The samples with $\mathrm{Cr}_{1-x} \mathrm{Ru}_{x}$ layer only are also shown in Table V. 


\begin{tabular}{|c|c|c|c|}
\hline \multirow{2}{*}{\multicolumn{2}{|c|}{ 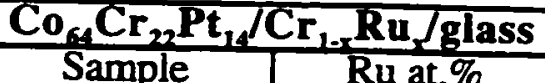 }} & \multicolumn{2}{|c|}{$\mathrm{Cr}_{1,}$ Ru/glass } \\
\hline & & Sample \# & Ru at.\% \\
\hline 1 & 0.3 & 43 & 0.3 \\
\hline 2 & 6.2 & & \\
\hline 3 & 12.5 & 44 & 12.5 \\
\hline 4 & 18.7 & & \\
\hline 5 & 21.2 & & \\
\hline 6 & 24.0 & 45 & 24.0 \\
\hline 7 & 25.1 & & \\
\hline 8 & 27.3 & & \\
\hline 9 & 29.5 & & \\
\hline 10 & 30.6 & & \\
\hline 11 & 37.3 & 46 & 37.3 \\
\hline 12 & 43.4 & & \\
\hline$\overline{13}$ & 47.5 & 47 & 47.5 \\
\hline 14 & 53.3 & 48 & 53.3 \\
\hline 15 & 54.2 & & \\
\hline 16 & 55.1 & 49 & 55.1 \\
\hline 17 & $\overline{56.1}$ & & \\
\hline 18 & 56.1 & & \\
\hline 19 & 57.0 & 50 & 57.0 \\
\hline$\frac{20}{21}$ & 57.0 & 51 & 57.0 \\
\hline 21 & 57.0 & & \\
\hline 22 & 57.0 & & \\
\hline 23 & 57.0 & & \\
\hline 24 & 57.0 & & \\
\hline 25 & 57.0 & & \\
\hline 26 & 58.2 & & \\
\hline 27 & $\overline{58.2}$ & & \\
\hline 28 & 59.4 & 52 & 59.4 \\
\hline 29 & 61.2 & & \\
\hline$\overline{30}$ & 63.9 & & \\
\hline 31 & 68.4 & & \\
\hline 32 & 72.9 & $\overline{53}$ & 72.9 \\
\hline 33 & 77.4 & & \\
\hline 34 & $\overline{79.2}$ & & \\
\hline 35 & 81.0 & $\overline{54}$ & 81.0 \\
\hline 36 & 84.1 & & \\
\hline 37 & 85.6 & & \\
\hline 38 & $\overline{86.4}$ & & \\
\hline 39 & 88.7 & & \\
\hline 40 & 91.7 & & \\
\hline 41 & 95.6 & & \\
\hline 42 & 99.7 & 55 & 99.7 \\
\hline
\end{tabular}

Table V. Experiment samples of Phase I. 


\subsubsection{Phase II -- The Effects of the $C r_{1-x} R u_{x}$ Thickness and the Substrate Temperature on the $\mathrm{Co}_{G 4} \mathrm{Cr}_{22} \mathbf{P t}_{14} / \mathrm{Cr}_{1-x} \mathbf{R u}_{\mathrm{x}}$ Magnetic Properties}

The samples with 57 at.\% Ru had highest $\mathrm{H}_{c}$ by the results of Phase I. In Phase II, the $\mathrm{Cr}_{1-\mathrm{x}} \mathrm{Ru}_{\mathrm{x}}$ composition was fixed at 57 at.\% $\mathrm{Ru}$, and changed six different underlayer thickness and four different substrate temperatures during underlayer deposition to see the magnetic property response. All the other parameters were fixed. The samples were made with underlayer thickness at 50,100,250,500,1000, and $2000 \AA$, and substrate temperatures at $25^{\circ} \mathrm{C}, 100^{\circ} \mathrm{C}, 250^{\circ} \mathrm{C}$ and $350^{\circ} \mathrm{C}$. The magnetic layer composition was $\mathrm{Co}_{64} \mathrm{Cr}_{22} \mathrm{Pt}_{14}$, and the thickness was kept at $250 \AA$. The profile of the sample is shown in Figure 16. After the magnetic properties were measured by VSM, the effects of the $\mathrm{Cr}_{1-x} \mathrm{Ru}_{x}$ thickness and the substrate temperature on the $\mathrm{Co}_{64} \mathrm{Cr}_{22} \mathrm{Pt}_{14} / \mathrm{Cr}_{1-x} \mathrm{Ru}_{\mathrm{x}}$ magnetic properties was determined.

In order to determine the crystallographic texture, $\mathrm{X}$-ray diffraction was used for this experiment. From the $X$-ray diffraction data, the relationship between $\mathrm{H}_{\mathrm{C}}$ and crystallographic texture was determined. For the same reason in Phase I, the samples with $\mathrm{Cr}_{1-\mathrm{x}} \mathrm{Ru}_{\mathrm{x}}$ layer only were made in order to get the measurements feasible and accurate for RBS, X-ray diffraction, and resistivity. The samples of Phase $\Pi$ are summarized in Table VI.

\begin{tabular}{|c|}
\hline $\mathrm{Co}_{64} \mathrm{Cr}_{22} \mathrm{Pt}_{14}$ \\
\hline $\mathrm{Cr}_{43} \mathrm{Ru}_{57}$ \\
\hline Glass substrate \\
\hline
\end{tabular}

Thickness: $250 \AA$

Thickness: 50, 100, 250, 500, 1000, $2000 \AA$

Substrate temperature: $25,100,250,350^{\circ} \mathrm{C}$

Figure 15. Profile of the sample for Phase II. 


\begin{tabular}{|c|c|c|c|c|c|}
\hline \multicolumn{3}{|c|}{$\mathrm{Co}_{64} \mathrm{Cr}_{22} \mathrm{Pt}_{1} / \mathrm{Cr}_{1,0} \mathrm{Ru} /$ glass } & \multicolumn{3}{|c|}{ Cr. Ru/glass } \\
\hline Sample & $\begin{array}{l}\text { Deposition } \\
\text { Temperaure }\end{array}$ & $\begin{array}{l}\mathrm{Cr}_{\mathrm{I}_{1-x} \mathrm{Ru}_{\mathrm{x}}} \\
\text { Thickness }\end{array}$ & Sample \# & $\begin{array}{l}\text { Deposition } \\
\text { Temperature }\end{array}$ & $\begin{array}{c}\mathrm{Cr}_{1-x} \mathrm{Ru}_{\mathrm{x}} \\
\text { Thickness }\end{array}$ \\
\hline 56 & $25^{\circ} \mathrm{C}$ & $50 \mathrm{~A}$ & 77 & $25^{\circ} \mathrm{C}$ & $50 \mathrm{~A}$ \\
\hline 57 & $25^{\circ} \mathrm{C}$ & $100 \mathrm{~A}$ & 78 & $25^{\circ} \mathrm{C}$ & $100 \mathrm{~A}$ \\
\hline 58 & $25^{\circ} \mathrm{C}$ & $250 A$ & 79 & $25^{\circ} \mathrm{C}$ & $250 \mathrm{~A}$ \\
\hline 59 & $25^{\circ} \mathrm{C}$ & $500 \AA$ & 80 & $25^{\circ} \mathrm{C}$ & $500 A$ \\
\hline 60 & $25^{\circ} \mathrm{C}$ & $1000 \AA$ & 81 & $25^{\circ} \mathrm{C}$ & $1000 \mathrm{~A}$ \\
\hline 61 & $25^{\circ} \mathrm{C}$ & $2000 \mathrm{~A}$ & 82 & $25^{\circ} \mathrm{C}$ & $2000 \mathrm{~A}$ \\
\hline 62 & $100^{\circ} \mathrm{C}$ & $50 \AA$ & 83 & $100^{\circ} \mathrm{C}$ & $50 \AA$ \\
\hline 63 & $100^{\circ} \mathrm{C}$ & $100 \mathrm{~A}$ & 84 & $100^{\circ} \mathrm{C}$ & $100 \AA$ \\
\hline 64 & $100^{\circ} \mathrm{C}$ & $250 \AA$ & 85 & $100^{\circ} \mathrm{C}$ & $250 \mathrm{~A}$ \\
\hline 65 & $100^{\circ} \mathrm{C}$ & $500 \AA$ & 86 & $100^{\circ} \mathrm{C}$ & $500 \mathrm{~A}$ \\
\hline 66 & $100^{\circ} \mathrm{C}$ & $1000 \AA$ & 87 & $100^{\circ} \mathrm{C}$ & $1000 \mathrm{~A}$ \\
\hline 67 & $100^{\circ} \mathrm{C}$ & $2000 \AA$ & 88 & $100^{\circ} \mathrm{C}$ & $2000 \mathrm{~A}$ \\
\hline 68 & $250^{\circ} \mathrm{C}$ & $50 \mathrm{~A}$ & 89 & $250^{\circ} \mathrm{C}$ & $50 \mathrm{~A}$ \\
\hline 69 & $250^{\circ} \mathrm{C}$ & $100 \AA$ & 90 & $250^{\circ} \mathrm{C}$ & $100 \AA$ \\
\hline 70 & $250^{\circ} \mathrm{C}$ & $250 A$ & $\overline{91}$ & $250^{\circ} \mathrm{C}$ & $250 A$ \\
\hline 71 & $250^{\circ} \mathrm{C}$ & $500 \AA$ & 92 & $250^{\circ} \mathrm{C}$ & $500 \AA$ \\
\hline 72 & $250^{\circ} \mathrm{C}$ & $1000 \AA$ & 93 & $250^{\circ} \mathrm{C}$ & $1000 \mathrm{~A}$ \\
\hline$\overline{73}$ & $250^{\circ} \mathrm{C}$ & $2000 \mathrm{~A}$ & 94 & $250^{\circ} \mathrm{C}$ & $2000 A$ \\
\hline 74 & $350^{\circ} \mathrm{C}$ & $250 \AA$ & 95 & $350^{\circ} \mathrm{C}$ & $250 \mathrm{~A}$ \\
\hline 75 & $350^{\circ} \mathrm{C}$ & $500 \AA$ & 96 & $350^{\circ} \mathrm{C}$ & $500 \AA$ \\
\hline 76 & $350^{\circ} \mathrm{C}$ & $1000 \AA$ & 97 & $350^{\circ} \mathrm{C}$ & $1000 \mathrm{~A}$ \\
\hline
\end{tabular}

Table VI. Experiment samples of Phase II.

\subsection{Magnetic Properties Measurement}

The magnetic properties of the samples were determined by a VSM. The samples were loaded into the VSM such that the film plane was parallel to the external magnetic field. The magnetic properties were measured parallel to the film plane. The in-plane $\mathrm{H}_{c}$, in-plane $S^{*}$, and other in-plane magnetic properties were used throughout this experiment. The terms without specifying "in-plane" are used in the rest of the thesis.

The VSM was controlled by a computer. For $\mathrm{Co}_{64} \mathrm{Cr}_{r_{2}} \mathrm{Pt}_{14} / \mathrm{Cr}_{1-\mathrm{x}} \mathrm{Ru}_{\mathrm{x}}$ thin films, a maximum magnetic field of 17,000 Oe was used to saturate the samples. The magnetic field was decreased gradually and reached $-17,000 \mathrm{Oe}$. Then it was increased to $17,000 \mathrm{Oe}$ again. During the cycle, the magnetic moment was measured by a "pick-up" coil and 
recorded by the computer. The recorded data were processed to eliminate the interference of the glass substrate. After the data were processed by the computer, a hysteresis loop was plotted and the $\mathrm{H}_{\mathrm{C}}, \mathrm{S}^{*}$, and other magnetic data were determined. A sample VSM output is shown in Figure 16.

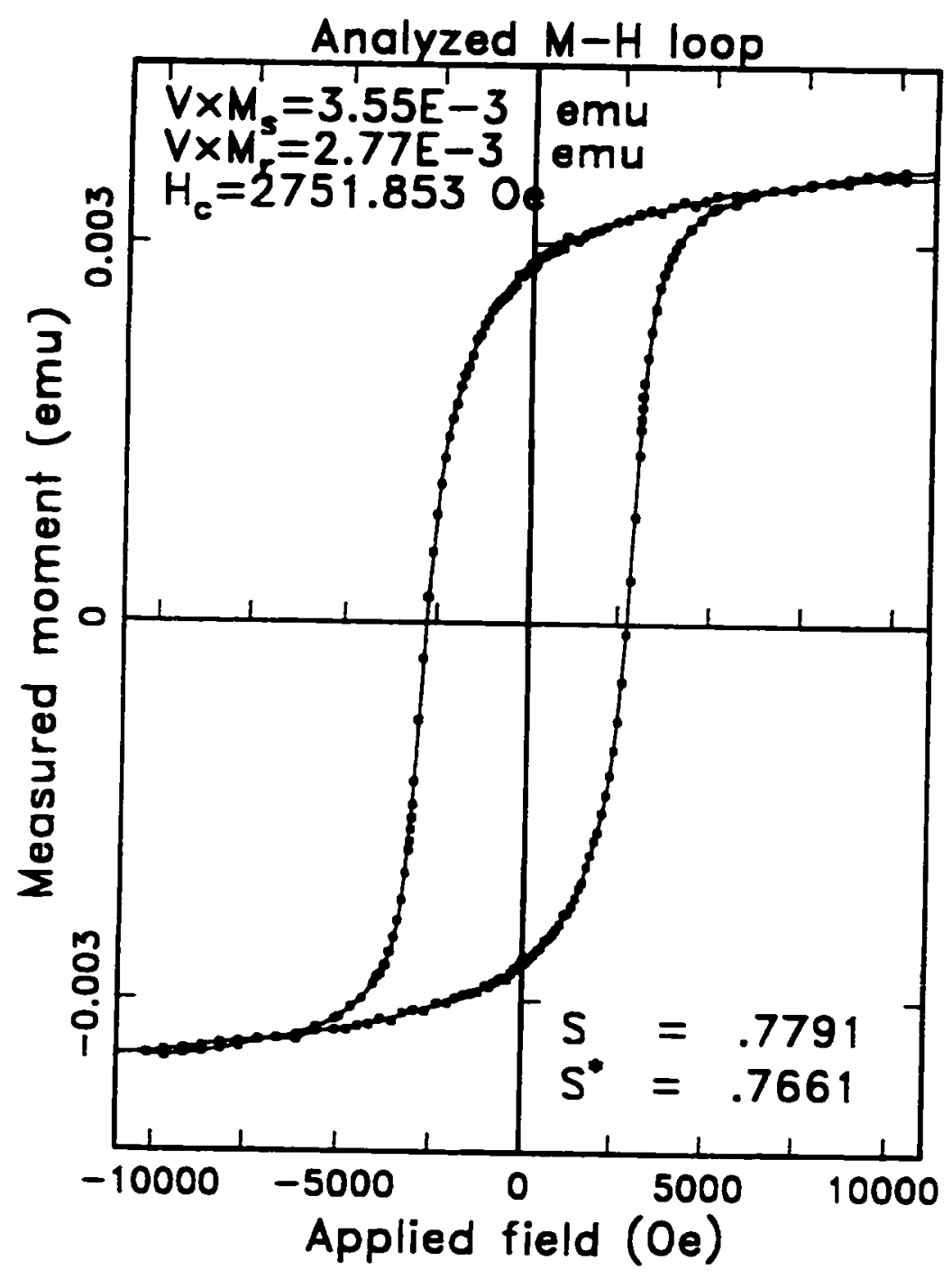

Figure 16. VSM output (sample \#4). 


\subsection{X-ray Diffraction Measurement}

The crystal structure, lattice parameter, and texture of a sample were determined by $\mathrm{X}$-ray diffraction. The $\mathrm{X}$-ray diffractometer used for this experiment was made by Siemens, Model D-5000 which was fully computerized. The X-ray diffraction parameters were controlled by a computer. The data analysis such as the interplanar spacing (d) were also calculated by the computer. The diffractometer used $\mathrm{Cu} \mathrm{K} \alpha_{1}$ radiation with a wavelength of $1.5409 \AA$. The Cu-target $\mathrm{X}$-ray tube operated at $50 \mathrm{kV}$ and $300 \mathrm{~mA}$. The samples were scanned from $2 \theta=35^{\circ}$ to $85^{\circ}$ with a step of $0.05^{\circ}$. The samples were exposed to the $\mathrm{X}$-radiation four seconds per step. It took about one hour for each sample to be scanned. The samples of both Phase I and Phase II were measured with the X-ray diffraction after the VSM measurement.

\subsubsection{Crystal Structure and Lattice Parameter Determination}

Figure 17 shows a $\mathrm{X}$-ray diffraction plot. The $\mathrm{d}$ values of the reflection planes, in $\AA$, are shown on top of each indexed peak. The $d$ value of a characteristic peak was compared with Joint Committee on Powder Diffraction Standards (JCPDS) diffraction data cards of $\mathrm{Co}, \mathrm{Cr}, \mathrm{Ru}$, and $\mathrm{Cr}_{2} \mathrm{Ru}$. The corresponding structure and reflection plane of an individual peak was identified by matching the $d$ value with JCPDS data. The structures and reflection planes are also shown in Figure 17. This plot shows that the $\mathrm{Cr}_{43} \mathrm{Ru}_{57}$ layer has a $\mathrm{Ru}$ structure, and the $\mathrm{Co}_{64} \mathrm{Cr}_{22} \mathrm{Pt}_{14}$ layer has a Co structure.

The lattice parameter was calculated from the $d$ value. For example, the $d$ value equals $2.132 \AA$ for the Ru(0002) plane. Because lattice parameter $c$ is twice the interplanar spacing of (0002), the lattice parameter $c$ for $\mathrm{Cr}_{43} \mathrm{Ru}_{57}$ equals $4.264 \AA$. The lattice parameter $a$ was determined in a similar way. 


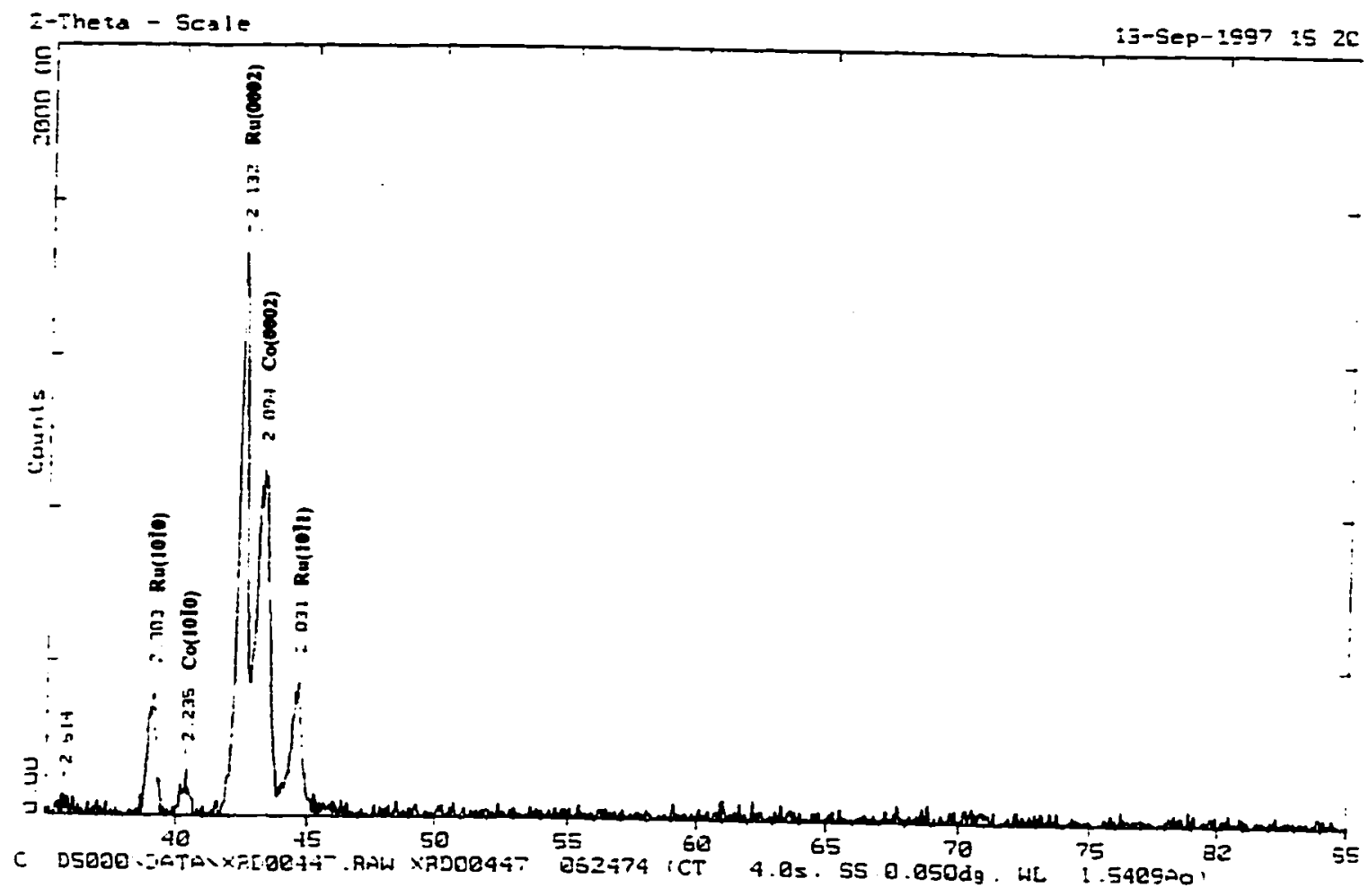

Figure 17. X-ray diffraction output (sample \#23, $\mathrm{Co}_{64} \mathrm{Cr}_{22} \mathrm{Pt}_{14} / \mathrm{Cr}_{43} \mathrm{Ru}_{57}$ )

\subsubsection{Lattice Misfit Determination}

The difference between the interatomic distance on the matching planes along the matching directions is called the lattice misfit. Lattice misfit $(\delta)$ was calculated by the following equation,

$$
\delta=\left|\frac{d_{1}-d_{2}}{d_{1}}\right|
$$

where $d$ represents the interatomic distance. Using Figure 17 as an example, the interatomic distances of $\mathrm{Ru}$ and $\mathrm{Co}$ on the $\{0002\}$ plane along the $<000 \mathrm{l}>$ direction are $2.132 \AA$ and $2.094 \AA$, respectively. Therefore,

$$
\delta=\left|\frac{2.132-2.094}{2.132}\right|=1.78 \%
$$




\subsubsection{Crystallographic Texture Determination}

The relative intensity of individual peaks was used to determine the crystallographic texture of the sample. For a powder sample of Ru, the intensity ratio between (1010) and (0002) is 1.14, which is determined from JCPDS data. In Figure 17, the intensity ratio between (1010) and (0002) is about 0.25 , which implies the sample has more $R u(0002)$ inplane texture than a randomly oriented sample.

\subsection{Film Thickness, Composition and Resistivity Measurement}

Before the films were deposited, the sputtering system needed to be calibrated. A film of roughly $500 \AA$ was deposited. An ink spot was marked on the center of a substrate to shield the substrate before a film was deposited. After the ink was wiped off, a step with the film thickness was created. The film thickness was determined by a profilometer. The difference between the measured thickness from the profilometer and the readout thickness from the sputtering system was eliminated by adjusting a proportional constant called the tooling factor. The thickness needed to be measured by the profilometer only in the calibration stage. After the tooling factor was calculated and input into the sputtering system, the film thickness was read directly from the display of the sputtering system.

The composition of $\mathrm{Cr}_{1 \cdot \mathrm{x}} \mathrm{Ru}_{\mathrm{x}}$ film was calculated by the relative deposition rate of $\mathrm{Cr}$ and $\mathrm{Ru}$. The equations are shown below.

$$
n_{i}(\mathrm{~mol})=\frac{R(\mathrm{~cm} / \mathrm{s}) * t(s) * A\left(\mathrm{~cm}^{2}\right) * \rho\left(\mathrm{g} / \mathrm{cm}^{3}\right)}{A W(\mathrm{~g} / \mathrm{mol})}
$$

$R u$ at $\%=n_{R u} /\left(n_{R u}+n_{C r}\right)$

where $n_{i}$ is the amount of substance $i, R$ is the deposition rate, $t$ is the deposition time, $A$ is the substrate area, $\rho$ is the density, and AW is the atomic weight. 
Some samples which needed more accurate composition measurement was determined by Rutherford Backscattering Spectrometry (RBS). The concentration uncertainty by RBS was \pm 1 at.\%. More information about RBS can be found in other references [46].

The sheet resistance of $\mathrm{Cr}_{\mathrm{l}-\mathrm{x}} \mathrm{Ru}_{\mathrm{x}}$ layer was determined by a 4-point probe right after the samples were taken out of the sputtering chamber to prevent surface contamination. The sheet resistance was converted to resistivity to exclude the influence of the film thickness by the following equation,

$\rho(\Omega \cdot m)=R_{s}(\Omega) *_{t}(m)$

where $\rho$ is resistivity, $R_{s}$ is sheet resistance, and $t$ is film thickness. Changes in resistivity between samples could result from the presence of different phases, different grain sizes, defects, or contamination. Resistivity measurement is a simple way to detect microstructure changes. 


\section{Chapter 4}

\section{Results}

\subsection{X-ray Diffraction Spectra}

The $\mathrm{X}$-ray diffraction spectra of $\mathrm{Cr}_{\mathrm{I}_{-x}} \mathrm{Ru}_{\mathrm{x}}$ thin films with different $\mathrm{Ru}$ concentrations are shown in Figure 18. By comparing the $d$ values with the JCPDS diffraction data cards, the crystal structures and the reflection planes were identified. The identified structures and the reflection planes are also shown.

From the $\mathrm{X}$-ray diffraction spectra, the structure of $\mathrm{Cr}_{1-x} \mathrm{Ru}_{x}$ film with $\mathrm{Ru}$ concentration below $24 \%$ was $\mathrm{Cr}$ structure (BCC). At around $37 \% \mathrm{Ru}$, the structure changed to $\mathrm{Cr}_{2} \mathrm{Ru}$ compound (tetragonal). When Ru concentration increased to $48 \%$, the $\mathrm{Cr}_{1-x} \mathrm{Ru} \mathrm{x}_{\mathrm{x}}$ film appeared amorphous, or very fine-grained. $\mathrm{The} \mathrm{Cr}_{1-\mathrm{x}} \mathrm{Ru} \mathrm{u}_{\mathrm{x}}$ film with a $\mathrm{Ru}$ concentration $53 \%$ or more has Ru structure (HCP).

One interesting thing found in the $\mathrm{X}$-ray diffraction spectra is that the locations of the peaks shift as the Ru concentration changes. Several lines connecting the same peaks of different Ru concentration are shown in the plot. Those lines are not vertical, which indicates the lattice parameter of $\mathrm{Cr}_{1-x} \mathrm{Ru}_{\mathrm{x}}$ increases as the $\mathrm{Ru}$ concentration increases.

The $\mathrm{X}$-ray diffraction spectra of $\mathrm{Co}_{64} \mathrm{Cr}_{22} \mathrm{Pt}_{14} / \mathrm{Cr}_{1-\mathrm{x}} \mathrm{Ru}_{\mathrm{x}}$ thin films are shown in Figure 19. The coercivity of the films are also listed. The difference between Figure 19 and Figure 18 is that the Co diffraction peaks are seen in Figure 19, due to the presence of the $\mathrm{Co}_{64} \mathrm{Cr}_{22} \mathrm{Pt}_{14}$ layer. The Co peaks shift to low $2 \theta$ angle as the Ru concentration increases due to the coherent interface between $\mathrm{Co}_{64} \mathrm{Cr}_{22} \mathrm{Pt}_{14}$ and $\mathrm{Cr}_{1-x} \mathrm{Ru}_{\mathrm{x}}$ layers. The intensity of the Co peaks and the $\mathrm{H}_{C}$ are closely related. For example, $47.5 \%$ Ru sample has low $\mathrm{H}_{\mathrm{C}}$ and very strong $\mathrm{Co}(0002)$ intensity, whereas $57 \%$ Ru sample has high $\mathrm{H}_{\mathrm{c}}$ and a significant $\mathrm{Co}(1 \overline{10} 0)$ peak. More detail will be discussed below. 


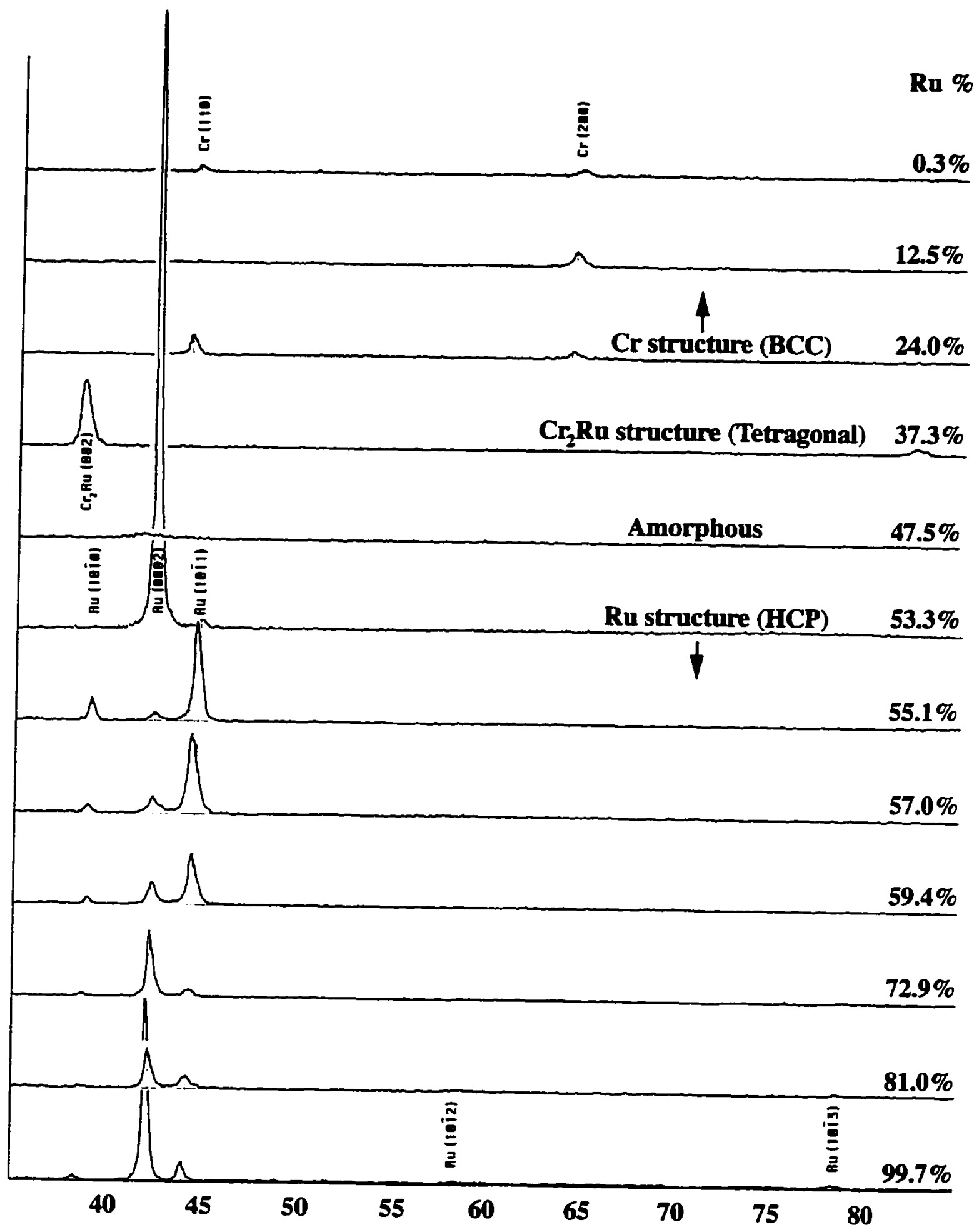

Figure 18. X-ray diffraction spectra of $\mathrm{Cr}_{1-\mathrm{x}} \mathrm{Ru}$ film with different $\mathrm{Ru}$ concentration. 


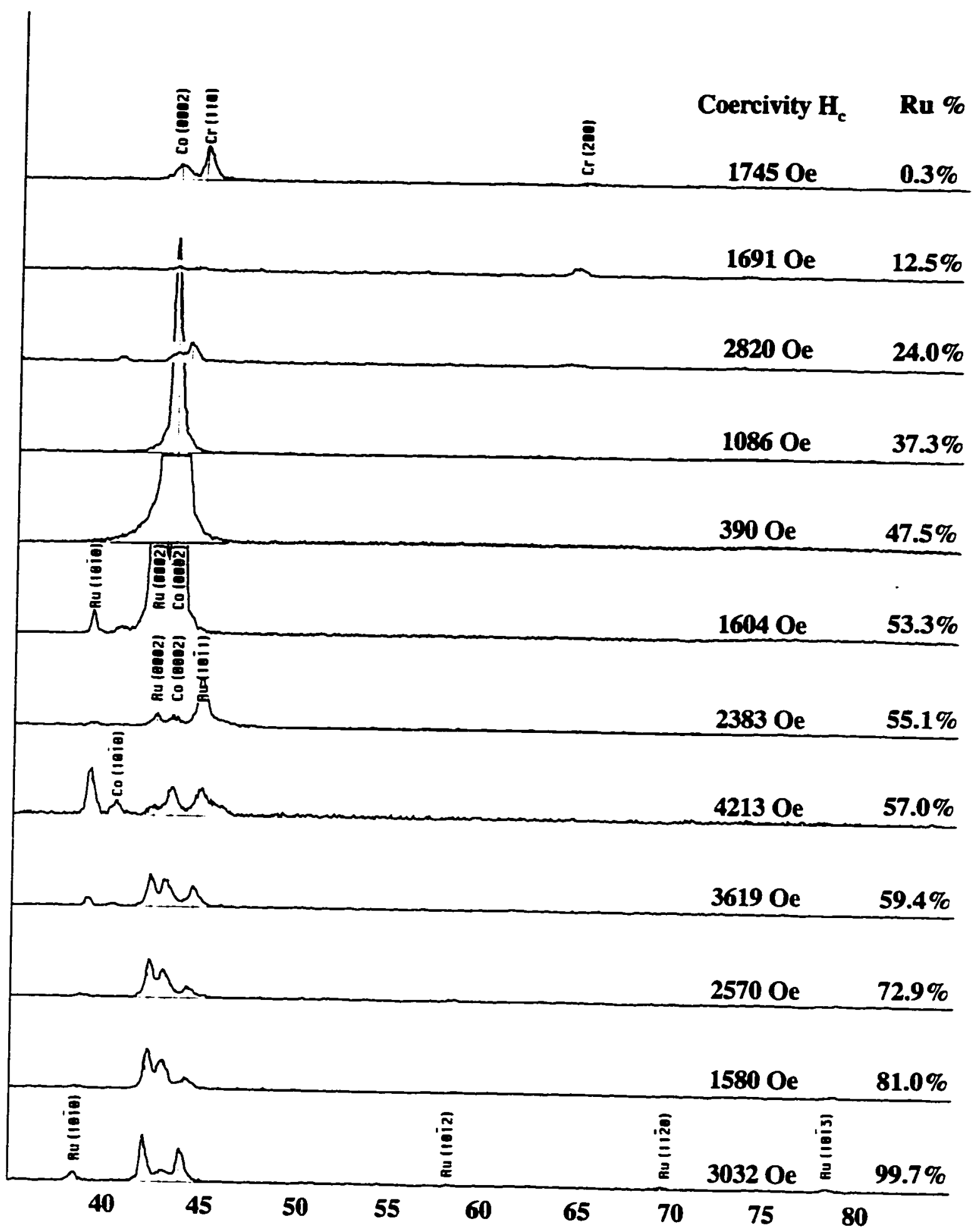

Figure 19. X-ray diffraction spectra of $\mathrm{Co}_{64} \mathrm{Cr}_{22} \mathrm{Pt}_{14} / \mathrm{Cr}_{1-x} \mathrm{Ru}_{\mathrm{x}}$ with different $\mathrm{Ru}$ concentration. 


\subsection{Dependence of $\mathrm{Cr}_{1-x} R u_{x}$ Resistivity on the $R u$ Concentration}

The resistivities of $\mathrm{Cr}_{1-x} \mathrm{Ru}_{\mathrm{x}}$ thin films with different $\mathrm{Ru}$ concentration are listed in Table VII. The resistivities were converted from the sheet resistance which was measured by 4-point probe. Figure 20 shows the plot of the resistivity of $\mathrm{Cr}_{1-x} R u_{x}$ vs. $\mathrm{Ru}$ concentration. The resistivity in the region between $24 \% \mathrm{Ru}$ and $53 \% \mathrm{Ru}$ was higher than the resistivity above or below. The resistivity data might indicate that these $\mathrm{Cr}_{1 \cdot-\mathrm{R}} \mathrm{Ru}_{\mathrm{x}}$ alloys have different crystal structure from the lower resistivity alloys. This prediction was confirmed by the $\mathrm{X}$-ray diffraction spectra. The crystal structures in different $\mathrm{Ru}$ concentration regions are shown in the plot.

The resistivities of pure $\mathrm{Cr}$ and pure $\mathrm{Ru}$ from this experiment are $41.7 \mathrm{E}-8 \Omega \mathrm{m}$ and 16.4E-8 $\Omega \mathrm{m}$, respectively, as shown in Table VII. These resistivities are higher than the published data [47] for bulk element $\mathrm{Cr}$ and $\mathrm{Ru}$, which are 12.6E-8 $\Omega \mathrm{m}$ for $\mathrm{Cr}$, and 7.1E-8 $\Omega \mathrm{m}$ for $\mathrm{Ru}$. Thin films have higher resistivity than bulk samples due to two reasons. First, thin films have more disorder structures and smaller grain size. The electrons are more frequently scattered at the grain boundaries and the other crystal defects. Second, as the thickness decreases, the electrons can also be scattered from the surfaces.

\begin{tabular}{|c|c|c|}
\hline Sample \# & Ru\% & $\begin{array}{c}\text { Resistivity } \\
\text { (E-8 } \Omega \mathrm{m})\end{array}$ \\
\hline 43 & 0.3 & 41.7 \\
\hline 44 & 12.5 & 71.6 \\
\hline 45 & 24.0 & 59.3 \\
\hline 46 & 37.3 & 113.2 \\
\hline 47 & 47.5 & 118 \\
\hline 48 & 53.3 & 60.1 \\
\hline 49 & 55.1 & 54.4 \\
\hline 50 & 57.0 & 55.7 \\
\hline 51 & 57.0 & 58.6 \\
\hline 52 & 58.2 & 56.5 \\
\hline 53 & 72.9 & 53.1 \\
\hline 54 & 81.0 & 47.8 \\
\hline 55 & 99.7 & 16.4 \\
\hline
\end{tabular}

Table VII. Resistivity of $\mathrm{Cr}_{1-x} \mathrm{Ru}_{\mathrm{x}}$ at different $\mathrm{Ru}$ concentrations. 


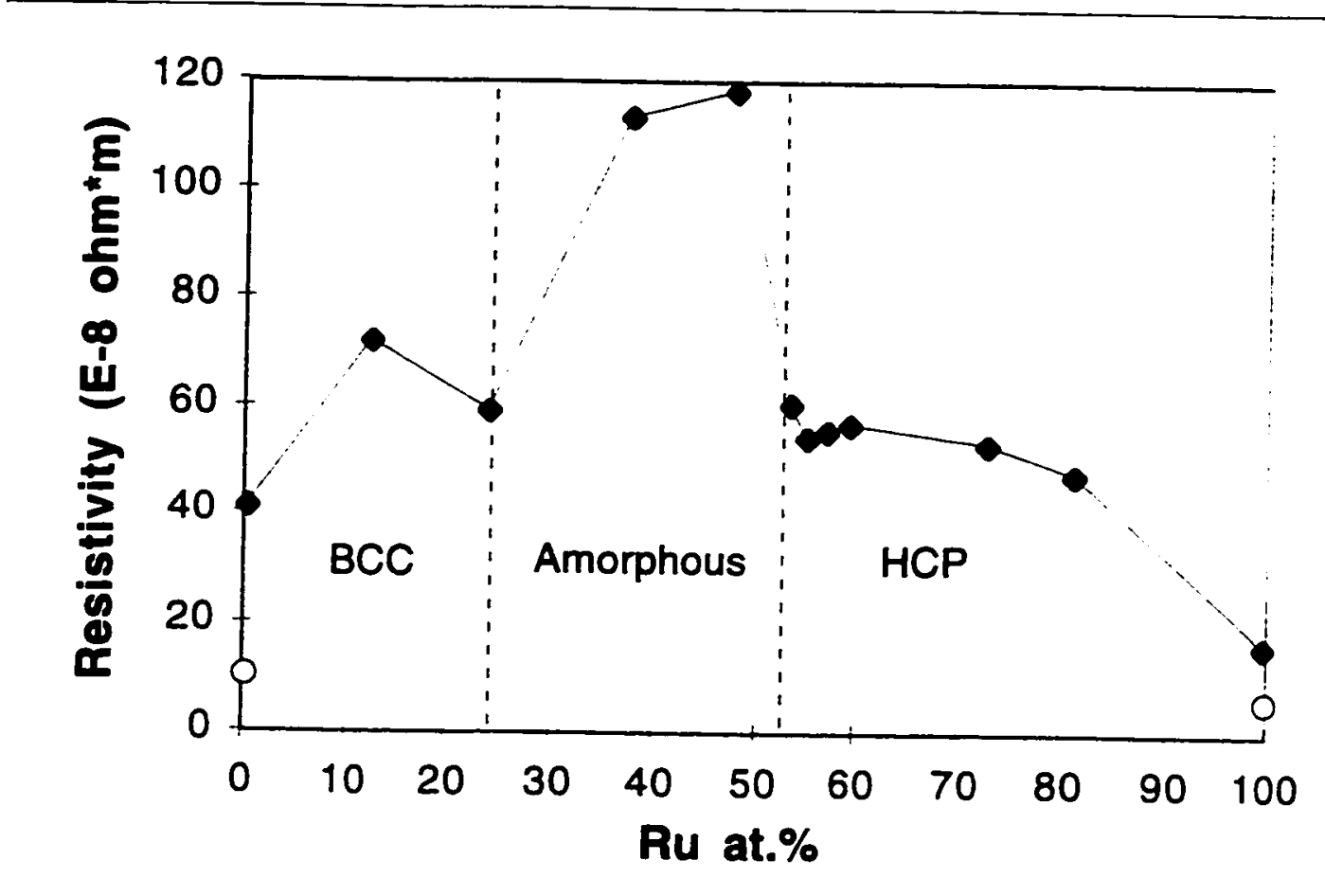

Figure 20. The resistivity of $\mathrm{Cr}_{1-x} \mathrm{Ru}_{\mathrm{x}}$ vs. $\mathrm{Ru}$ concentration. The circles in $0 \%$ and $100 \%$ $\mathrm{Ru}$ indicate the bulk resistivity of $\mathrm{Cr}$ and $\mathrm{Ru}$.

At both $\mathrm{BCC}$ and $\mathrm{HCP}$ regions, the resistivity increases as the alloy concentration increases. The resistivity of the $\mathrm{Cr}_{1-\mathrm{x}} \mathrm{Ru}_{\mathrm{x}}$ solid solution is higher than the resistivity of the pure element because the electrons are more frequently scattered by the impurity atoms. The resistivity of $\mathrm{Cr}_{1-x} \mathrm{Ru}_{\mathrm{x}}$ alloy in the region between $24 \% \mathrm{Ru}$ an $53 \% \mathrm{Ru}$ is higher than the resistivity of $\mathrm{Cr}_{1-x} \mathrm{Ru}_{x}$ with a BCC or HCP structure. In that region, the structure is either amorphous or very fine grained. The disorder structure and the dense grain boundary cause the resistivity to increase.

The $\mathrm{Cr}-\mathrm{Ru}$ resistivity data can be explained by electron scattering. The resistivity data also perfectly match the structures determined from the $\mathrm{X}$-ray diffraction. The $\mathrm{Cr}_{1 \cdot-\mathrm{x}} \mathrm{Ru}_{\mathrm{x}}$ structure as a function of $\mathrm{Ru}$ concentration is further confirmed. 


\subsection{Textures of $\mathrm{Cr}_{1-x} \mathrm{Ru}_{\mathrm{x}}$ and $\mathrm{Co}_{64} \mathrm{Cr}_{22} \mathrm{Pt}_{14}$ thin films}

The crystallographic relationship between the $\mathrm{Cr}$ BCC structure and the Co HCP structure is well known, as discussed in the literature review. Above $53 \% \mathrm{Ru}, \mathrm{Cr}_{1-x} \mathrm{Ru}_{\mathrm{x}}$ film is HCP structure. Only HCP structure is discussed here.

The crystallographic texture of $\mathrm{Cr}_{1 \cdot-x} \mathrm{Ru}_{\mathrm{x}}$ film was strongly dependent on the $\mathrm{Ru}$ concentration, as shown in Figure 18. At 53.3\% $\mathrm{Ru}$, the $\mathrm{Cr}_{1-x} \mathrm{Ru}_{\mathrm{x}}$ film had strong $\mathrm{Ru}(0002)$ texture. This texture changed to the mixed $\mathrm{Ru}(1 \overline{010})$ and $\mathrm{Ru}(1 \overline{0} \overline{1})$ texture when the Ru concentration increased to $55.1 \%$. When the Ru concentration increased further. the $\mathrm{Ru}(0002)$ texture increased gradually again. Figure 21 shows a sketch explaining how the $\mathrm{Cr}_{1-x} \mathrm{Ru}_{\mathrm{x}}$ texture changes as the $\mathrm{Ru}$ concentration changes.

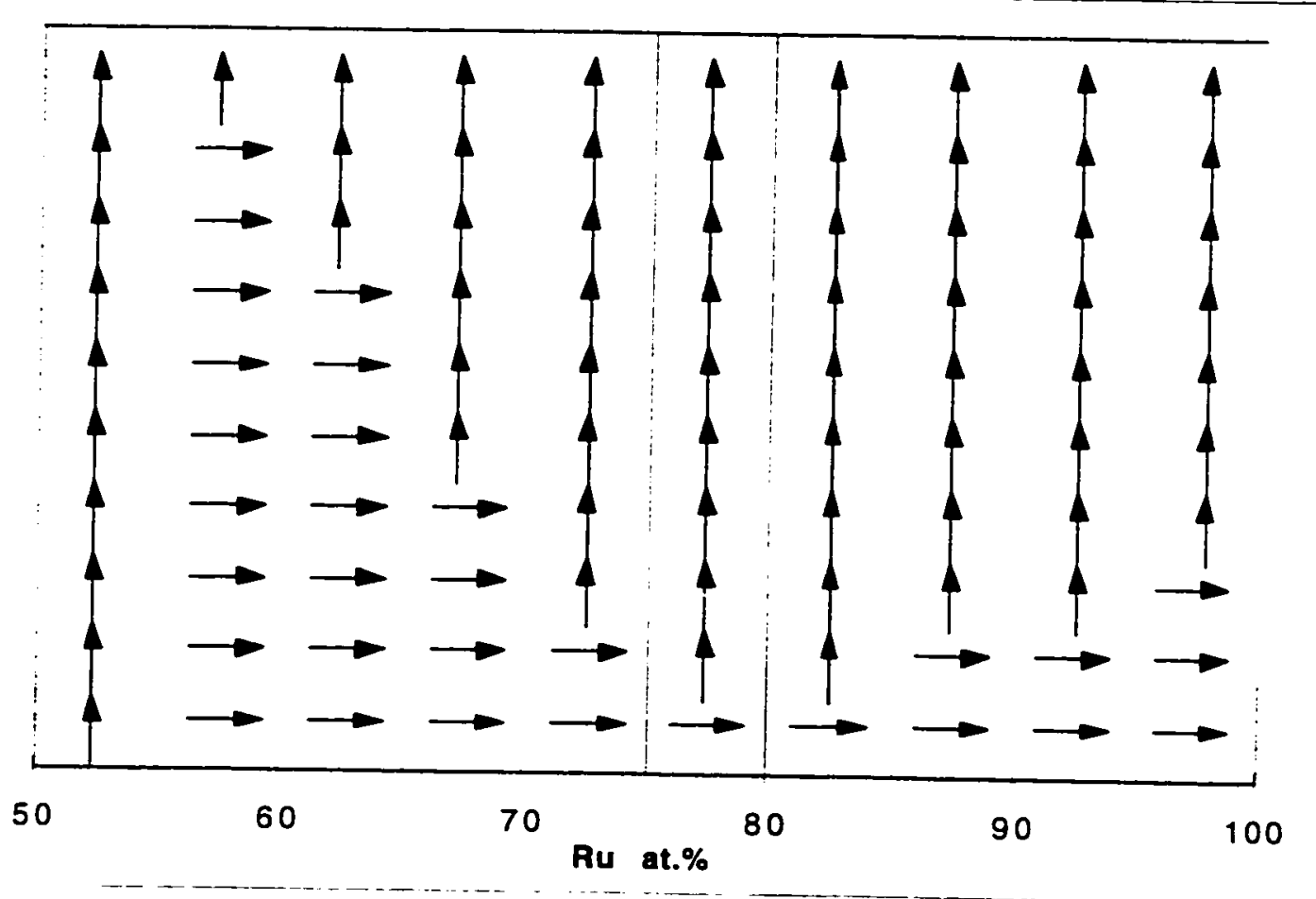

Figure 21. Sketch of $\mathrm{Cr}$-Ru texture as a function of Ru concentration. Only HCP structure is discussed. The horizontal arrows indicate the $c$-axis in-plane component texture. The vertical arrows indicate the $c$-axis out-of-plane component texture. 
There is a direct correlation between $\mathrm{Cr}_{1-x} \mathrm{Ru}_{\mathrm{x}}$ texture and $\mathrm{Co}_{64} \mathrm{Cr}_{22} \mathrm{Pt}_{14}$ texture. By examining the $\mathrm{X}$-ray diffraction spectra in Figure 19, the samples that have higher $\mathrm{Ru}(0002)$ intensity have also higher $\mathrm{Co}(0002)$ intensity. The samples that have higher $\mathrm{Ru}(10 \overline{10})$ intensity have also higher $\mathrm{Co}(10 \overline{1} 0)$ intensity.

Figure 22 shows the $\mathrm{X}$-ray intensity ratio of $\mathrm{Co}(10 \overline{10})$ and $\mathrm{Co}(0002)$ vs. the $\mathrm{X}$-ray intensity ratio of $\mathrm{Ru}(10 \overline{10})$ and $\mathrm{Ru}(0002)$. The ratios indicate the degree of $c$-axis in-plane texture of $\mathrm{Co}_{64} \mathrm{Cr}_{22} \mathrm{Pt}_{14}$ and $\mathrm{Cr}_{1-\mathrm{x}} \mathrm{Ru}_{\mathrm{x}}$ films. These two ratios are positively correlated, indicating that the stronger the $\mathrm{Ru}$ in-plane texture, the stronger the $\mathrm{Co}$ in-plane texture. $\mathrm{Co}_{64} \mathrm{Cr}_{22} \mathrm{Pt}_{14}$ layer tends to duplicate the texture from $\mathrm{Cr}_{1-x} \mathrm{Ru}_{x}$ layer because of the epitaxy relationship between these two layers.

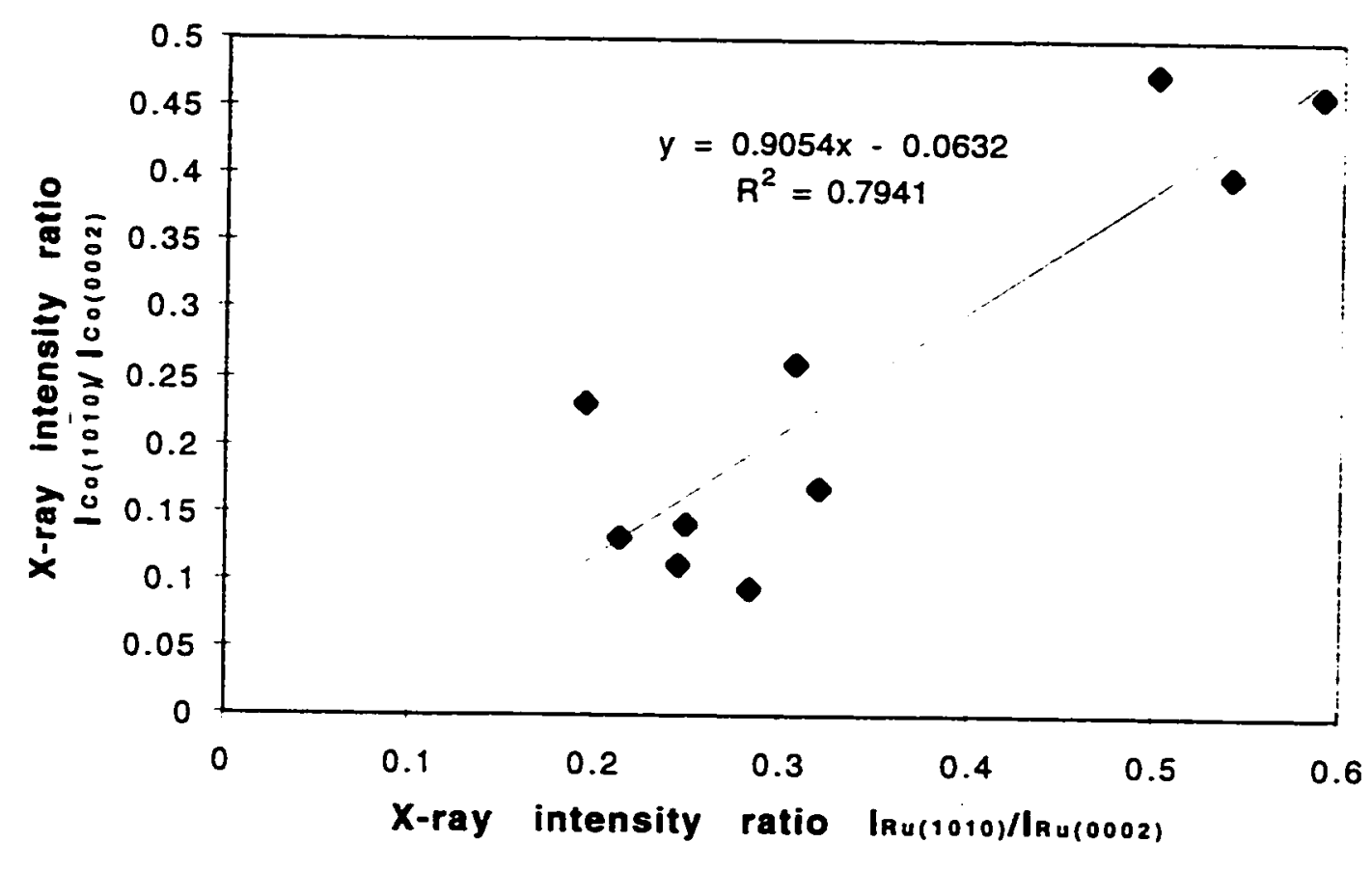

Figure 22. X-ray intensity ratio of $\mathrm{Co}(10 \overline{10})$ and $\mathrm{Co}(0002)$ vs. X-ray intensity ratio of $\operatorname{Ru}(10 \overline{10})$ and $\operatorname{Ru}(0002)$. 


\subsection{Dependence of $\mathrm{H}_{\mathrm{c}}$ and $\mathrm{S}^{*}$ on $\mathrm{Cr}_{1-\mathrm{x}} \mathrm{Ru}$. Composition}

The magnetic properties of the $\mathrm{Co}_{64} \mathrm{Cr}_{22} \mathrm{Pt}_{1 /} / \mathrm{Cr}_{1-x} \mathrm{Ru}_{x}$ films at different $\mathrm{Ru}$ concentrations are summarized in Table VIII. The effects of Ru concentration on the coercivity $\mathrm{H}_{\mathrm{C}}$ and the coercivity squareness $\mathrm{S}^{*}$ of $\mathrm{Co}_{64} \mathrm{Cr}_{22} \mathrm{Pt}_{14} / \mathrm{Cr}_{1-x} \mathrm{Ru}_{\mathrm{x}}$ thin films are shown in Figure 23 and Figure 24.

The $\mathrm{Cr}_{1-x} R u_{x}$ layer with different compositions induced different in-plane $\mathrm{H}_{\mathrm{c}}$ and $\mathrm{S}^{*}$. The most interesting features in Figure 23 is that there is one valley at $43 \% \mathrm{Ru}$ and two peaks at $24 \%$ and $57 \% \mathrm{Ru}$. The $\mathrm{H}_{\mathrm{c}}$ at the valley was about $370 \mathrm{Oe}$. On the other hand, the $\mathrm{H}_{\mathrm{C}}$ at $57 \% \mathrm{Ru}$ reached as high as 4,100 Oe. The $\mathrm{H}_{\mathrm{C}}$ of $\mathrm{Co}_{64} \mathrm{Cr}_{22} \mathrm{Pt}_{14} / \mathrm{Cr}_{1-x} \mathrm{Ru}_{\mathrm{x}}$ thin films was extremely sensitive to the concentration of $\mathrm{Ru}$ at the range between $25 \% \mathrm{Ru}$ and $60 \% \mathrm{Ru}$. The sample with a composition of $57 \% \mathrm{Ru}$ was most interesting. The $\mathrm{H}_{\mathrm{C}}$ peak at $57 \%$ Ru was sharp. Within $2 \%$ Ru variation, the $H_{C}$ varied by as much as 1,000 Oe.

The curve of S* vs. Ru concentration shown in Figure 24 was similar to the curve of $\mathrm{H}_{\mathrm{c}}$ vs. Ru concentration in Figure 23. The $\mathrm{S}^{*}$ at $27.3 \%$ Ru was highest, about 0.8, and the $S^{*}$ at $57 \%$ Ru was about 0.7 . When the Ru concentration was between $27.3 \%$ Ru and $57 \%$ Ru. the $\mathrm{S}^{*}$ dropped sharply and reached a valley of 0.036 at $43.4 \% \mathrm{Ru}$.

The $\mathrm{H}_{\mathrm{C}}$ at $57 \%$ Ru was 4,100 Oe, which is much higher than the typical magnetic media of disk drive nowadays, 2,800 Oe. The $S^{*}$ at $57 \%$ Ru was about 0.7 , which is somewhat lower than the typical value of 0.8-0.9. From the values of $\mathrm{H}_{c}$ and $\mathrm{S}^{*}, 57 \% \mathrm{Ru}$ is a potential underlayer material, but it might not have practical application because of the problem with reproducibility. Seven samples of $57 \%$ Ru were made. The variation of $\mathrm{H}_{\mathrm{C}}$ and $S^{*}$ were quite large because a small variation in Ru concentration caused a large change in $\mathrm{H}_{\mathrm{c}}$ and $\mathrm{S}^{*}$. 


\begin{tabular}{|c|c|c|c|c|c|c|}
\hline \multicolumn{7}{|c|}{$\mathrm{Co}_{64} \mathrm{Cr}_{22} \mathrm{Pt}_{14} / \mathrm{Cr}_{1-x} \mathrm{Ru}_{x} /$ glass } \\
\hline 1 & 0.3 & 1745 & 0.5455 & 0.7335 & 0.00330 & 0.00242 \\
\hline 2 & 6.2 & 1324 & 0.5030 & 0.6403 & 0.00341 & 0.00218 \\
\hline 3 & 12.5 & 1691 & 0.5982 & 0.7006 & 0.00378 & 0.00265 \\
\hline 4 & 18.7 & 2752 & 0.7661 & 0.7791 & 0.00355 & 0.00277 \\
\hline 5 & 21.2 & 2582 & 0.7920 & 0.7708 & 0.00419 & 0.00323 \\
\hline 6 & 24.0 & 2820 & 0.7916 & 0.7572 & 0.00401 & 0.00304 \\
\hline 7 & 25.1 & 2594 & 0.7972 & 0.8040 & 0.00349 & 0.00280 \\
\hline 8 & 27.3 & 2632 & 0.8159 & 0.7980 & 0.00371 & 0.00302 \\
\hline 9 & 29.5 & 2393 & 0.4539 & 0.5438 & 0.00352 & 0.00191 \\
\hline 10 & 30.6 & 1871 & 0.3005 & 0.3744 & 0.00338 & 0.00126 \\
\hline 11 & 37.3 & 1086 & 0.2119 & 0.2682 & 0.00302 & 0.00081 \\
\hline 12 & 43.4 & 368 & 0.0362 & 0.0373 & 0.00285 & 0.00011 \\
\hline 13 & 47.5 & 390 & 0.0451 & 0.0477 & 0.00268 & 0.00013 \\
\hline 14 & 53.3 & 1604 & 0.1775 & 0.2699 & 0.00176 & 0.00048 \\
\hline 15 & 54.2 & 2350 & 0.5987 & 0.4838 & 0.00259 & 0.00126 \\
\hline 16 & 55.1 & 2383 & 0.7865 & 0.7267 & 0.00312 & 0.00227 \\
\hline 17 & 56.1 & 3377 & 0.6290 & 0.5690 & 0.00322 & 0.00183 \\
\hline 18 & 56.1 & 3412 & 0.7550 & 0.7443 & 0.00281 & 0.00209 \\
\hline 19 & 57.0 & 3012 & 0.6609 & 0.6675 & 0.00362 & 0.00241 \\
\hline 20 & 57.0 & 3290 & 0.7062 & 0.6558 & 0.00333 & 0.00218 \\
\hline 21 & 57.0 & 3753 & 0.6632 & 0.6488 & 0.00343 & 0.00223 \\
\hline 22 & 57.0 & 3826 & 0.7075 & 0.6607 & 0.00301 & 0.00199 \\
\hline 23 & 57.0 & 3945 & 0.5590 & 0.5734 & 0.00299 & 0.00171 \\
\hline 24 & 57.0 & 4128 & 0.7390 & 0.8539 & 0.00267 & 0.00228 \\
\hline 25 & 57.0 & 4213 & 0.6941 & 0.7205 & 0.00253 & 0.00182 \\
\hline 26 & 58.2 & 3899 & 0.5190 & 0.5481 & 0.00288 & 0.00158 \\
\hline 27 & 58.2 & 4095 & 0.7037 & 0.6578 & 0.00306 & 0.00201 \\
\hline 28 & 59.4 & 3619 & 0.4816 & 0.5620 & 0.00319 & 0.00180 \\
\hline 29 & 61.2 & 3019 & 0.4187 & 0.5098 & 0.00293 & 0.00150 \\
\hline 30 & 63.9 & 2999 & 0.4011 & 0.4852 & 0.00302 & 0.00147 \\
\hline 31 & 68.4 & 2987 & 0.3886 & 0.4824 & 0.00279 & 0.00135 \\
\hline 32 & 72.9 & 2570 & 0.3200 & 0.3902 & 0.00311 & 0.00121 \\
\hline 33 & 77.4 & 2673 & 0.3538 & 0.4342 & 0.00260 & 0.00113 \\
\hline 34 & 79.2 & 2908 & 0.3789 & 0.4680 & 0.00258 & 0.00121 \\
\hline 35 & 81.0 & 1580 & 0.3110 & 0.3830 & 0.00328 & 0.00129 \\
\hline 36 & 84.1 & 1463 & 0.2067 & 0.3666 & 0.00360 & 0.00132 \\
\hline 37 & 85.6 & 2595 & 0.3479 & 0.4395 & 0.00280 & 0.00123 \\
\hline 38 & 86.4 & 2779 & 0.3595 & 0.4427 & 0.00261 & 0.00116 \\
\hline 39 & 88.7 & 2677 & 0.3606 & 0.4359 & 0.00289 & 0.00126 \\
\hline 40 & 91.7 & 2404 & 0.3726 & 0.4578 & 0.00318 & 0.00145 \\
\hline 41 & 95.6 & 2822 & 0.4240 & 0.5139 & 0.00290 & 0.00149 \\
\hline 42 & 99.7 & 3032 & 0.5657 & 0.6627 & 0.00308 & 0.00204 \\
\hline
\end{tabular}

Table VIII. The experimental data from Phase I. 


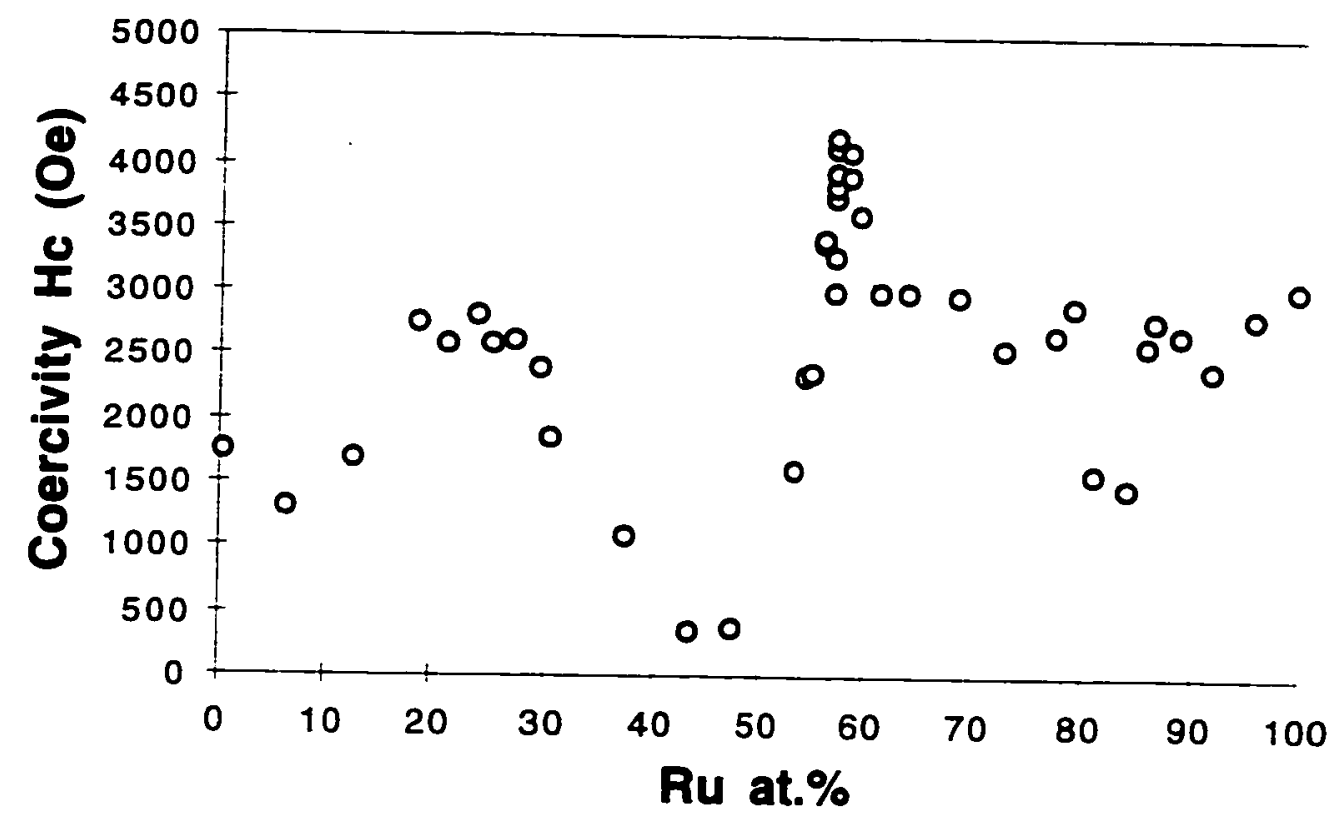

Figure 23. The in-plane coercivity of $\mathrm{Co}_{64} \mathrm{Cr}_{22} \mathrm{Pt}_{14} / \mathrm{Cr}_{1-x} \mathrm{Ru}_{\mathrm{x}}$ vs. Ru concentration.

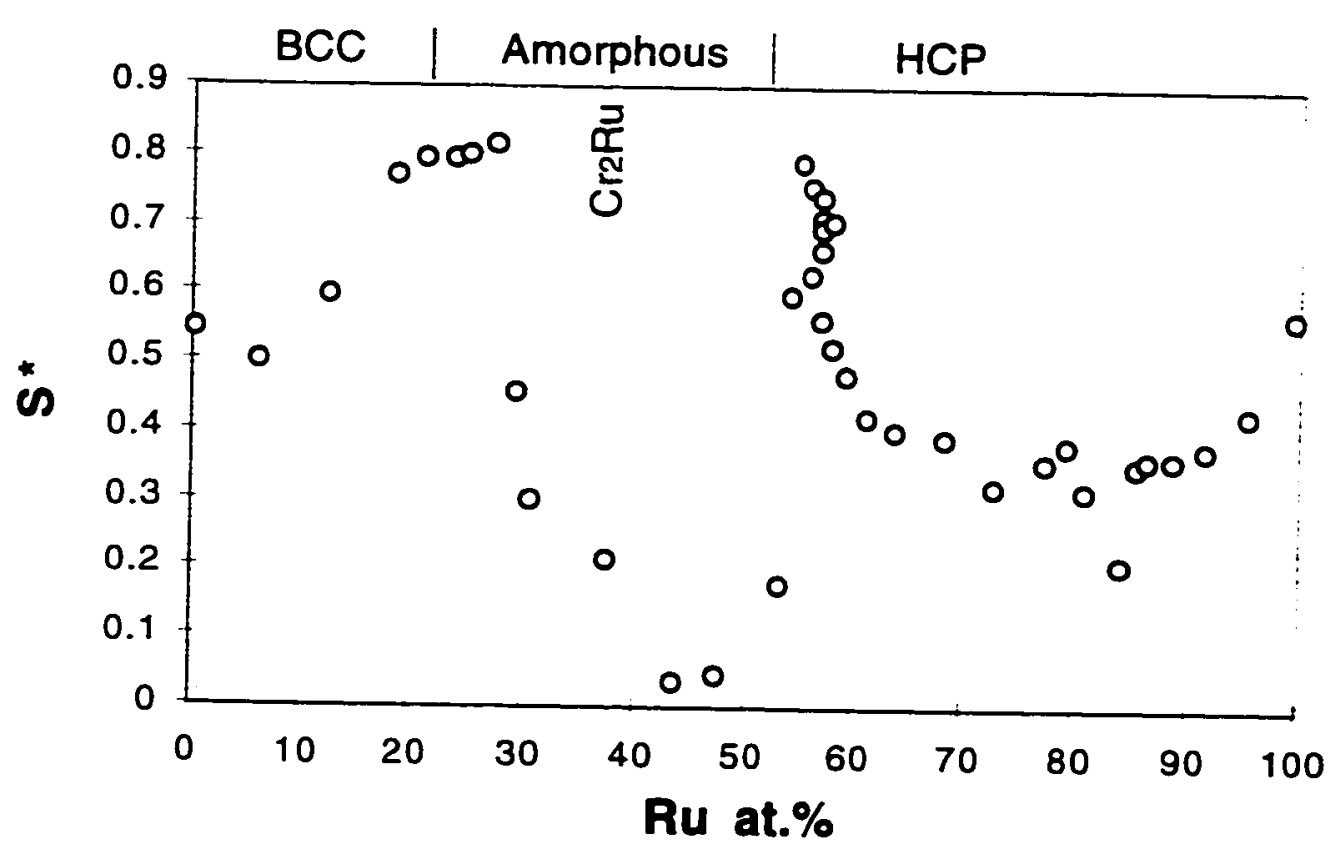

Figure 24. The coercivity squareness of $\mathrm{Co}_{64} \mathrm{Cr}_{22} \mathrm{Pt}_{14} / \mathrm{Cr}_{1-x} \mathrm{Ru}_{\mathrm{x}}$ vs. Ru concentration. 


\subsection{Dependence of $\mathrm{H}_{c}$ and $\mathrm{S}^{*}$ on $\mathrm{Cr}_{1-\mathrm{x}} R u_{\mathrm{x}}$ Thickness and Substrate}

\section{Temperature}

Phase II of the experiment was to study the influence of $C r_{1-x} R u_{x}$ film thickness and substrate temperature on the coercivity at the fixed composition of $\mathrm{Cr}_{43} \mathrm{Ru}_{57}$. The thickness of $\mathrm{Cr}_{1 \cdot x} \mathrm{Ru}_{x}$ layer was varied from $50 \AA$ to $1000 \AA$ and the substrate temperature was varied from $25^{\circ} \mathrm{C}$ to $350^{\circ} \mathrm{C}$. The experimental data from Phase II are shown in Table IX. The data are plotted in Figure 25.

\begin{tabular}{|c|c|c|c|c|}
\hline Sample \# & $\begin{array}{c}\text { Deposition } \\
\text { Temperature }\end{array}$ & $\begin{array}{c}\mathrm{Cr}_{1-x} \mathrm{Ru}_{\mathrm{x}} \\
\text { thickness }\end{array}$ & $\begin{array}{c}\text { Coercivity } \\
\mathrm{H}_{\mathrm{c}} \text { (Oe) }\end{array}$ & $\begin{array}{c}\text { Coercivity } \\
\text { Squareness }\end{array}$ \\
\hline 56 & $25^{\circ} \mathrm{C}$ & $50 \AA$ & 1572 & 0.7598 \\
\hline 57 & $25^{\circ} \mathrm{C}$ & $100 \AA$ & 2133 & 0.4404 \\
\hline 58 & $25^{\circ} \mathrm{C}$ & $250 \AA$ & 2097 & 0.4031 \\
\hline 59 & $25^{\circ} \mathrm{C}$ & $500 \mathrm{~A}$ & 1909 & 0.3187 \\
\hline 60 & $25^{\circ} \mathrm{C}$ & $1000 \AA$ & 849 & 0.1157 \\
\hline 62 & $100^{\circ} \mathrm{C}$ & $50 \mathrm{~A}$ & 2707 & 0.7407 \\
\hline 63 & $100^{\circ} \mathrm{C}$ & $100 \mathrm{~A}$ & 3370 & 0.7953 \\
\hline 64 & $100^{\circ} \mathrm{C}$ & $250 \AA$ & 3628 & 0.7989 \\
\hline 65 & $100^{\circ} \mathrm{C}$ & $500 \AA$ & 4097 & 0.7918 \\
\hline 66 & $100^{\circ} \mathrm{C}$ & $1000 \AA$ & 3710 & 0.7819 \\
\hline 68 & $250^{\circ} \mathrm{C}$ & $50 \AA$ & 3154 & 0.5649 \\
\hline 69 & $250^{\circ} \mathrm{C}$ & $100 \AA$ & 4215 & 0.7197 \\
\hline 70 & $250^{\circ} \mathrm{C}$ & $250 \AA$ & 4182 & 0.7165 \\
\hline 71 & $250^{\circ} \mathrm{C}$ & $500 \AA$ & 4202 & 0.6980 \\
\hline 72 & $250^{\circ} \mathrm{C}$ & $1000 \mathrm{~A}$ & 3804 & 0.6068 \\
\hline 74 & $350^{\circ} \mathrm{C}$ & $250 \AA$ & 1519 & 0.2576 \\
\hline 75 & $350^{\circ} \mathrm{C}$ & $500 \AA$ & 2395 & 0.5109 \\
\hline 76 & $350^{\circ} \mathrm{C}$ & $1000 \AA$ & 2362 & 0.5438 \\
\hline
\end{tabular}

Table IX. The experimental data from Phase II. 


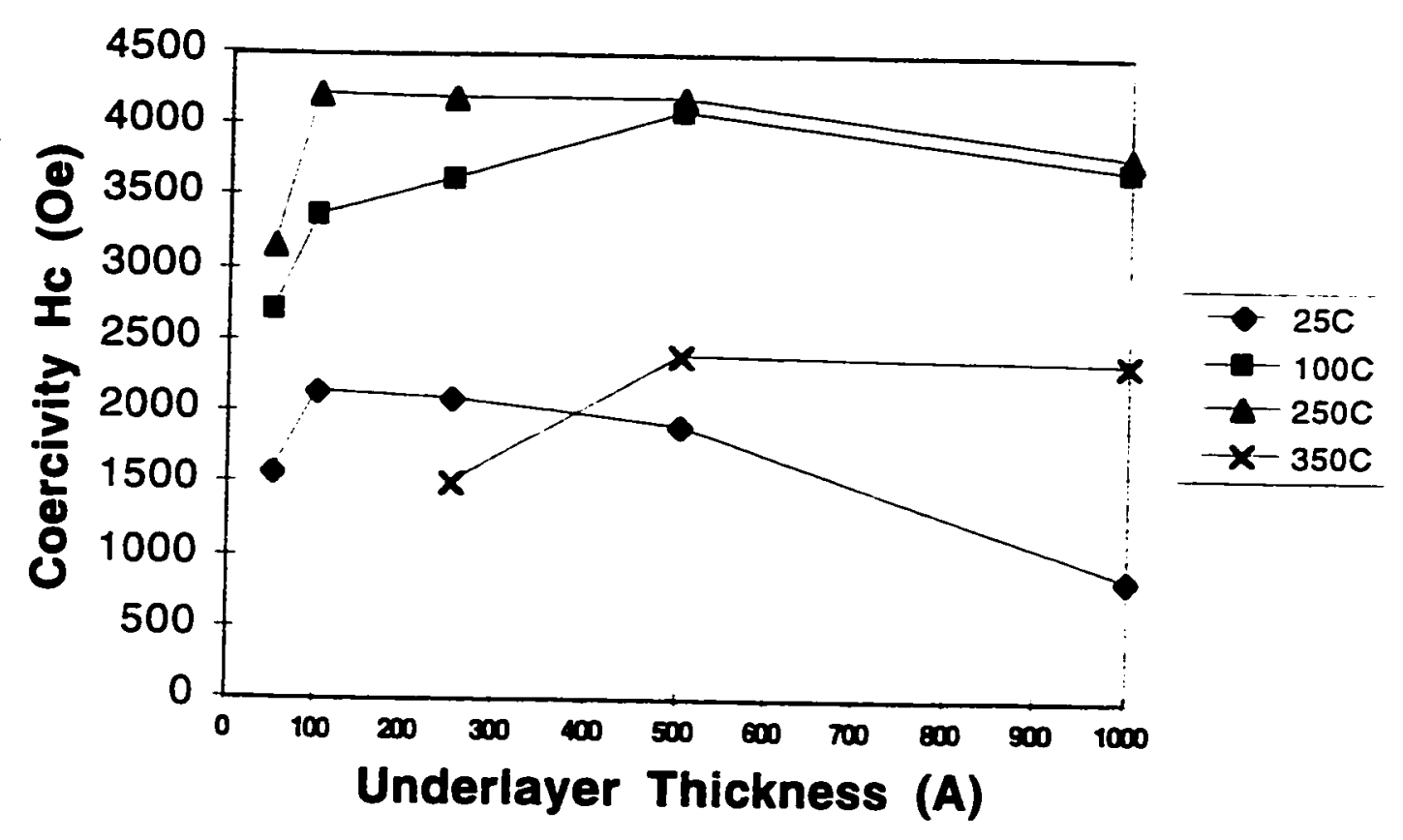

Figure $25 . \mathrm{H}_{\mathrm{c}}$ as a function of the $\mathrm{Cr}_{1-\mathrm{x}} \mathrm{Ru}_{\mathrm{x}}$ layer thickness and substrate temperature.

With the same $\mathrm{Cr}_{1-x} \mathrm{Ru}_{x}$ thickness, the samples deposited at $100^{\circ} \mathrm{C}$ had larger coercivities than the samples deposited at $25^{\circ} \mathrm{C}$. The samples deposited at $250^{\circ} \mathrm{C}$ had larger coercivities than the samples deposited at $100^{\circ} \mathrm{C}$. But when the substrate temperature was increased to $350^{\circ} \mathrm{C}$, the coercivities decreased. This is because the $\mathrm{Cr}_{1-\mathrm{x}} \mathrm{R} \mathrm{u}_{\mathrm{x}}$ film has a preferred deposition texture at different temperatures. From the $\mathrm{X}$-ray diffraction spectra, the $\mathrm{Cr}_{1-x} \mathrm{Ru}_{\mathrm{x}}$ film deposited at $250^{\circ} \mathrm{C}$ has more c-axis in-plane texture which induces more Co c-axis in-plane texture. Figure 26 shows the $\mathrm{X}$-ray diffraction ratio of $\mathrm{Co}(1 \overline{010})$ and $\mathrm{Co}(0002)$ vs. substrate temperature. Only the samples with $500 \AA$ $\mathrm{Cr}_{1-x} \mathrm{Ru}_{x}$ film are shown. The $100^{\circ} \mathrm{C}$ and $250^{\circ} \mathrm{C}$ samples have stronger $\mathrm{Co} \mathrm{c}$-axis in-plane texture, and the higher $\mathrm{H}_{\mathrm{C}}$ than the $25^{\circ} \mathrm{C}$ and $350^{\circ} \mathrm{C}$ samples. 


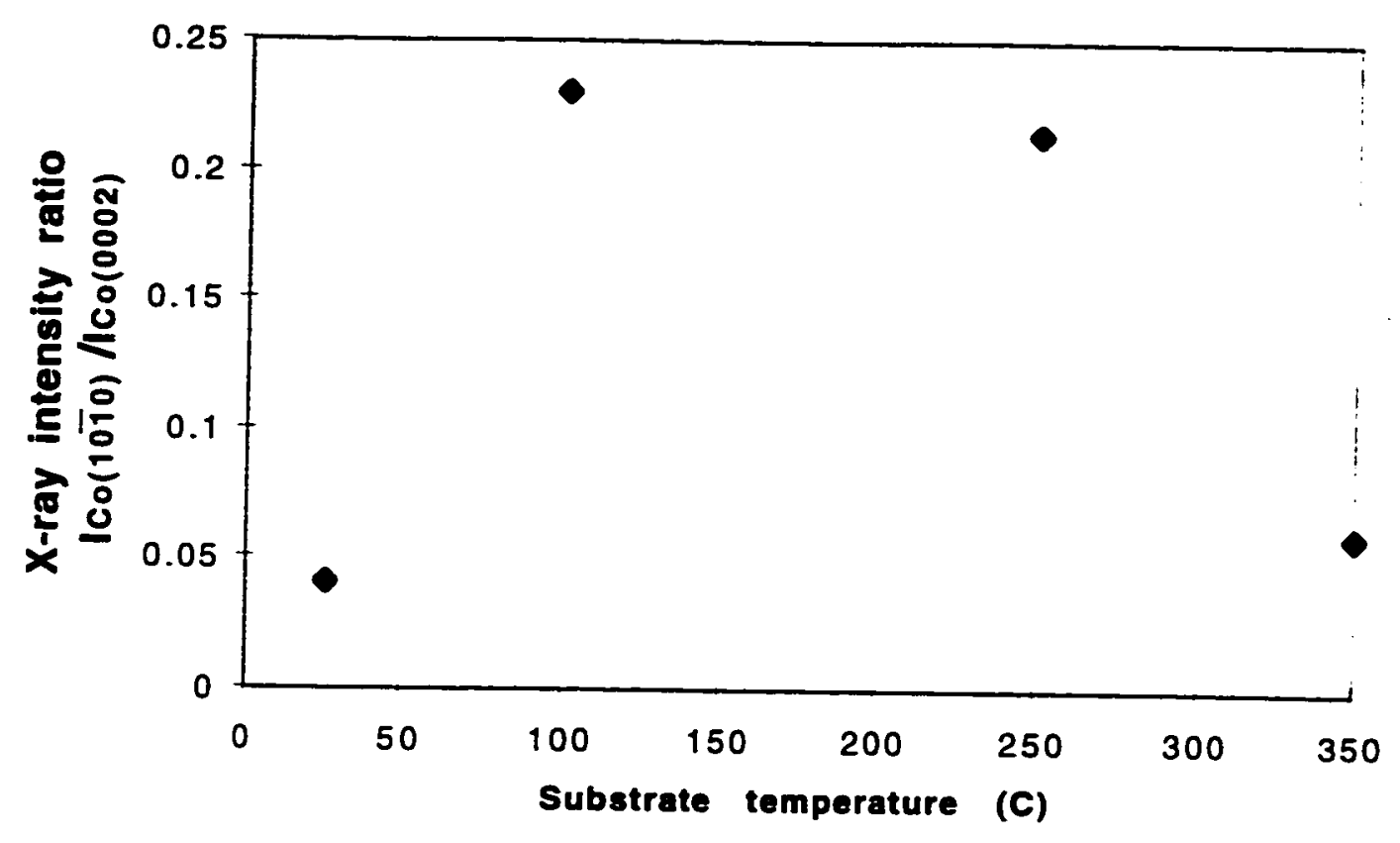

Figure 26. The X-ray diffraction ratio of $\operatorname{Co}(1 \overline{010})$ and $\mathrm{Co}(0002)$ vs. substrate temperature. All the samples have $500 \AA \mathrm{Cr}_{\mathrm{l}-\mathrm{x}} \mathrm{Ru}_{\mathrm{x}}$ layers.

With the same substrate temperature, the coercivity increased between $50 \AA$ and 100 $\AA$. When the $\mathrm{Cr}_{1-\mathrm{x}} \mathrm{Ru}_{\mathrm{x}}$ thickness increased further, the coercivity reached a maximum, and then it starts to decrease slowly. The maximum $\mathrm{H}_{c}$ occurred around somewhere between $100 \AA$ and $500 \AA ̊$ depending on the substrate temperature. At $50 \AA$, the film may be too thin and porous or the grain size too small to establish a good epitaxial relationship with the $\mathrm{Co}_{64} \mathrm{Cr}_{22} \mathrm{Pt}_{14}$ layer. The $\mathrm{H}_{\mathrm{C}}$ also decreased as the thickness of $\mathrm{Cr}_{1-x} \mathrm{Ru}_{\mathrm{x}}$ layer increased to $1,000 \AA$. This may be due to the effect of the grain size. Larger $C_{r_{1-x}} R u_{x}$ thickness will cause larger $\mathrm{Cr}_{1-x} \mathrm{Ru}_{x}$ grain size, and larger $\mathrm{Cr}_{1-x} \mathrm{Ru}_{x}$ grain size will induce larger $\mathrm{Co}_{64} \mathrm{Cr}_{22} \mathrm{Pt}_{14}$ grain size which will decrease $\mathrm{H}_{\mathrm{C}}$. 


\section{Chapter 5}

\section{Discussion}

\subsection{The Structure of $\mathrm{Co}_{64} \mathrm{Cr}_{22} \mathrm{Pt}_{14}$ and $\mathrm{Cr}_{1-x} \mathrm{Ru}_{\mathrm{x}}$ Thin Films}

The structure of $\mathrm{Co}_{64} \mathrm{Cr}_{22} \mathrm{Pt}_{14}$ is $\mathrm{HCP}, \mathrm{Ru}$ is $\mathrm{HCP}$, and $\mathrm{Cr}$ is $\mathrm{BCC}$. Figure 27 illustrates their structures and dimensions. The lattice parameter of $\mathrm{Ru}$ is slightly larger than the lattice parameter of $\mathrm{Co}_{64} \mathrm{Cr}_{22} \mathrm{Pt}_{14}$. The good lattice matching between $\mathrm{Ru}$ lattice and $\mathrm{Co}_{64} \mathrm{Cr}_{22} \mathrm{Pt}_{14}$ lattice make $\mathrm{Ru}$ a potential underlayer for $\mathrm{Co}_{64} \mathrm{Cr}_{22} \mathrm{Pt}_{14}$ thin film.

$\mathrm{Co}_{64} \mathrm{Cr}_{22} \mathrm{Pt}_{14}$ has the same structure as $\mathrm{Co}$, but a larger lattice parameter. The lattice parameters of $\mathrm{Co}_{64} \mathrm{Cr}_{22} \mathrm{Pt}_{14}$ were calculated from the $\mathrm{X}$-ray diffraction spectra. $\mathrm{Co}_{64} \mathrm{Cr}_{22} \mathrm{Pt}_{14}$ has larger lattice than Co because both $\mathrm{Cr}$ atom and $\mathrm{Pt}$ atom are larger than $\mathrm{Co}$ atom.

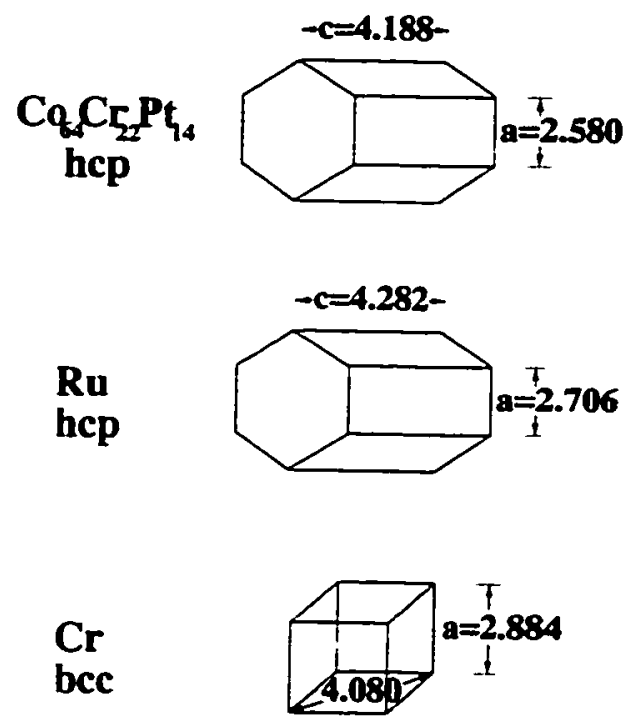

Figure 27. The structures and lattice parameters of $\mathrm{Co}_{64} \mathrm{Cr}_{22} \mathrm{Pt}_{14}, \mathrm{Ru}$ and $\mathrm{Cr}$. 


\begin{tabular}{|c|c|c|c|c|c|c|c|}
\hline Material & Co & $\mathrm{Cr}$ & $\mathrm{Pt}$ & $\mathbf{R u}$ & $\mathrm{Co}_{64} \mathrm{Cr}_{22} \mathrm{Pt}_{14}$ & $\mathrm{Cr}_{76} \mathrm{Ru}_{24}$ & $\mathrm{Cr}_{43} \mathrm{Ru}_{57}$ \\
\hline Structure & HCP & $\mathrm{BCC}$ & FCC & HCP & HCP & $\mathrm{BCC}$ & HCP \\
\hline $\begin{array}{c}\text { Metallic } \\
\text { Radius (A) }\end{array}$ & 1.25 & 1.30 & 1.39 & 1.34 & & & \\
\hline $\begin{array}{c}\text { Lattice } \\
\text { Parameters } \\
(\mathbf{A})\end{array}$ & $\begin{array}{l}a=2.507 \\
c=4.070\end{array}$ & $a=2.885$ & $a=3.924$ & $\begin{array}{l}a=2.706 \\
c=4.282\end{array}$ & $\begin{array}{l}a=2.580 \\
c=4.188\end{array}$ & $a=2.906$ & $\begin{array}{l}a=2.695 \\
c=4.264\end{array}$ \\
\hline Remark & & & & & $\begin{array}{l}\text { Expanded } \\
\text { Co } \\
\text { structure }\end{array}$ & $\begin{array}{c}\text { Expanded } \\
\mathrm{Cr} \\
\text { structure }\end{array}$ & $\begin{array}{c}\text { Compressed } \\
\mathbf{R u}_{\mathbf{u}} \\
\text { structure }\end{array}$ \\
\hline
\end{tabular}

Table X. Structure, radius, and lattice parameters of $\mathrm{Co}, \mathrm{Cr}, \mathrm{Pt}, \mathrm{Ru}$, and their alloys.

Table $\mathrm{X}$ shows the structure type, atomic radius, and lattice parameters of $\mathrm{Co}, \mathrm{Cr}$, $\mathrm{Pt}, \mathrm{Ru}, \mathrm{Co}_{64} \mathrm{Cr}_{22} \mathrm{Pt}_{14}, \mathrm{Cr}_{76} \mathrm{Ru}_{24}$, and $\mathrm{Cr}_{43} \mathrm{Ru}_{57}$. The data of the first four elements are from published data [47]. The data of the last three alloy materials are calculated from the X-ray diffraction data. From Table $\mathrm{X}$, it is clear that large alloying elements will expand the structure, and small alloying elements will compress the structure.

From the experimental results, $\mathrm{Cr}_{1-\mathrm{x}} \mathrm{Ru}_{\mathrm{x}}$ has $\mathrm{Cr}$ structure at $24 \% \mathrm{Ru}$, and becomes $\mathrm{Cr}_{2} \mathrm{Ru}$ tetragonal structure at around $37 \% \mathrm{Ru}$. . Between $37 \% \mathrm{Ru}$ and $53 \% \mathrm{Ru}, \mathrm{Cr}_{1 \cdot-x} \mathrm{Ru}_{x}$ is amorphous-like. When Ru concentration increases to $53 \% \mathrm{Ru}$ or more. $\mathrm{Cr}_{\mathrm{l}_{-x}} \mathrm{Ru}_{\mathrm{x}}$ will transform to $\mathrm{Ru}$ structure

The experimental results are consistent with the $\mathrm{Cr}-\mathrm{Ru}$ binary phase diagram, Figure 28. Comparing the experimental data with the $\mathrm{Cr}$-Ru phase diagram, the phase found in the sputtered $\mathrm{Cr}_{1-x} \mathrm{Ru}_{\mathrm{x}}$ thin films have the structures which would form under equilibrium condition at $1,100^{\circ} \mathrm{C}$, quenched to room temperature. Two compounds, $\mathrm{Cr}_{3} \mathrm{Ru}$ and $\mathrm{Cr}_{4} \mathrm{Ru}$, found in the phase diagram at low temperature, were not found in the experiment. The film structure is equivalent to the structure at high temperature probably due to the energy transferred to the atoms during the sputtering process. The atoms possess some energy other than the thermal energy. 


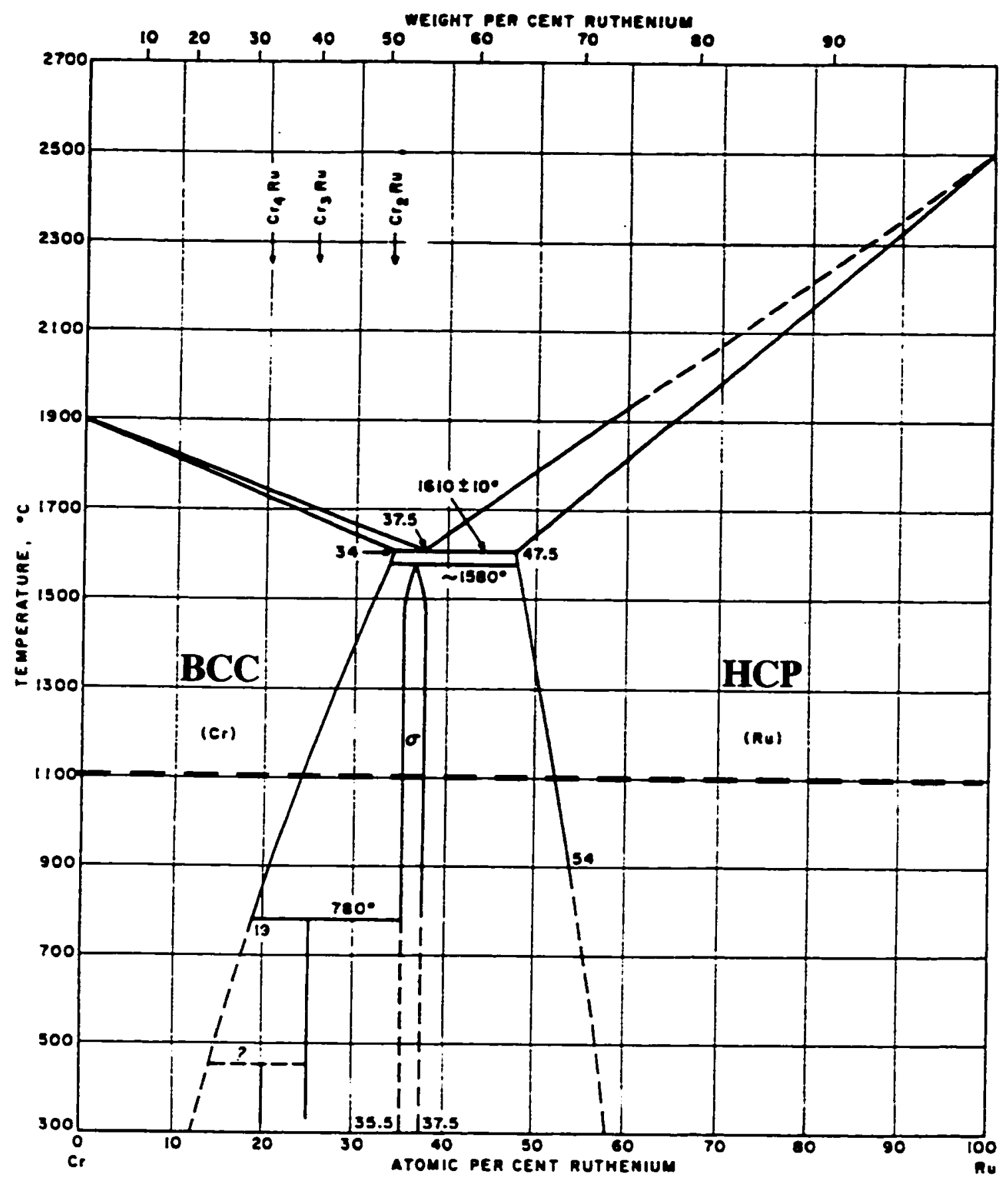

Figure 28. Cr-Ru phase diagram. The phase found in the sputtered $C r_{1 \cdot x} R_{x}$ thin films have the structures which would form under equilibrium condition at $1,100^{\circ} \mathrm{C}$ (shown as horizontal dotted line), quenched to room temperature. 


\subsection{The Magnetic Anisotropy of Co alloy Thin Film}

The magnetic properties of $\mathrm{Co}$ alloy thin film are anisotropic, i.e. the magnitude of magnetic property depends on the crystallographic orientation. The c-axis of $\mathrm{Co}_{64} \mathrm{Cr}_{22} \mathrm{Pt}_{14}$ is the magnetic easy axis. It takes less energy to magnetize and demagnetize along [0002] than along any other directions.

Figure 29 shows the $\mathrm{M}-\mathrm{H}$ loops and the $\mathrm{X}$-ray diffraction spectra of two samples. These two samples have the same thickness of both $\mathrm{Co}_{64} \mathrm{Cr}_{22} \mathrm{Pt}_{14}$ and $\mathrm{Cr}_{1-x} \mathrm{Ru}_{\mathrm{x}}$ layers. The only difference between these two samples is the $\mathrm{Ru}$ concentration of $\mathrm{Cr}_{1-x} \mathrm{Ru}_{x}$ layer. One sample has low $\mathrm{H}_{\mathrm{C}}$ and low $\mathrm{S}^{*}$, and the other has high $\mathrm{H}_{\mathrm{C}}$ and high $\mathrm{S}^{*}$. From the $\mathrm{X}$-ray diffraction spectra, the sample with low $\mathrm{H}_{\mathrm{C}}$ and low $\mathrm{S}^{*}$ has intense $\mathrm{Co}(0002)$ reflection line, indicating that the sample has strong $\mathrm{Co}(0002)$ parallel to the film plane texture. Most of $\mathrm{Co}_{64} \mathrm{Cr}_{22} \mathrm{Pt}_{14}$ grains have their magnetic easy axis , $\mathrm{c}$-axis, normal to the film plane.

The other sample has high coercivity, high $\mathrm{S}^{*}$, and less intense $\mathrm{Co}(0002)$ reflection line. Some of $\mathrm{Co}(0002)$ in-plane texture switches to $\mathrm{Co}(10 \overline{10})$ texture. $\mathrm{Co}(10 \overline{10})$ in-plane texture is c-axis in-plane texture. From the discussion above, to get more Co c-axis inplane texture is one way to get high in-plane coercivity and high in-plane $S^{*}$. Using $\mathrm{Cr}_{\mathrm{r}_{1-x}} \mathrm{Ru}_{\mathrm{x}}$ underlayer is a method to control the orientation of $\mathrm{Co}_{64} \mathrm{Cr}_{22} \mathrm{Pt}_{14}$ layer.

Figure 28 proves that $\mathrm{Co}_{64} \mathrm{Cr}_{22} \mathrm{Pt}_{14}$ has magnetic anisotropy. With more easy axis in-plane texture, the $\mathrm{M}-\mathrm{H}$ loop is broader and more square. On the other hand, with more easy axis out-of-plane texture. the $\mathrm{M}-\mathrm{H}$ loop is almost a straight line. 

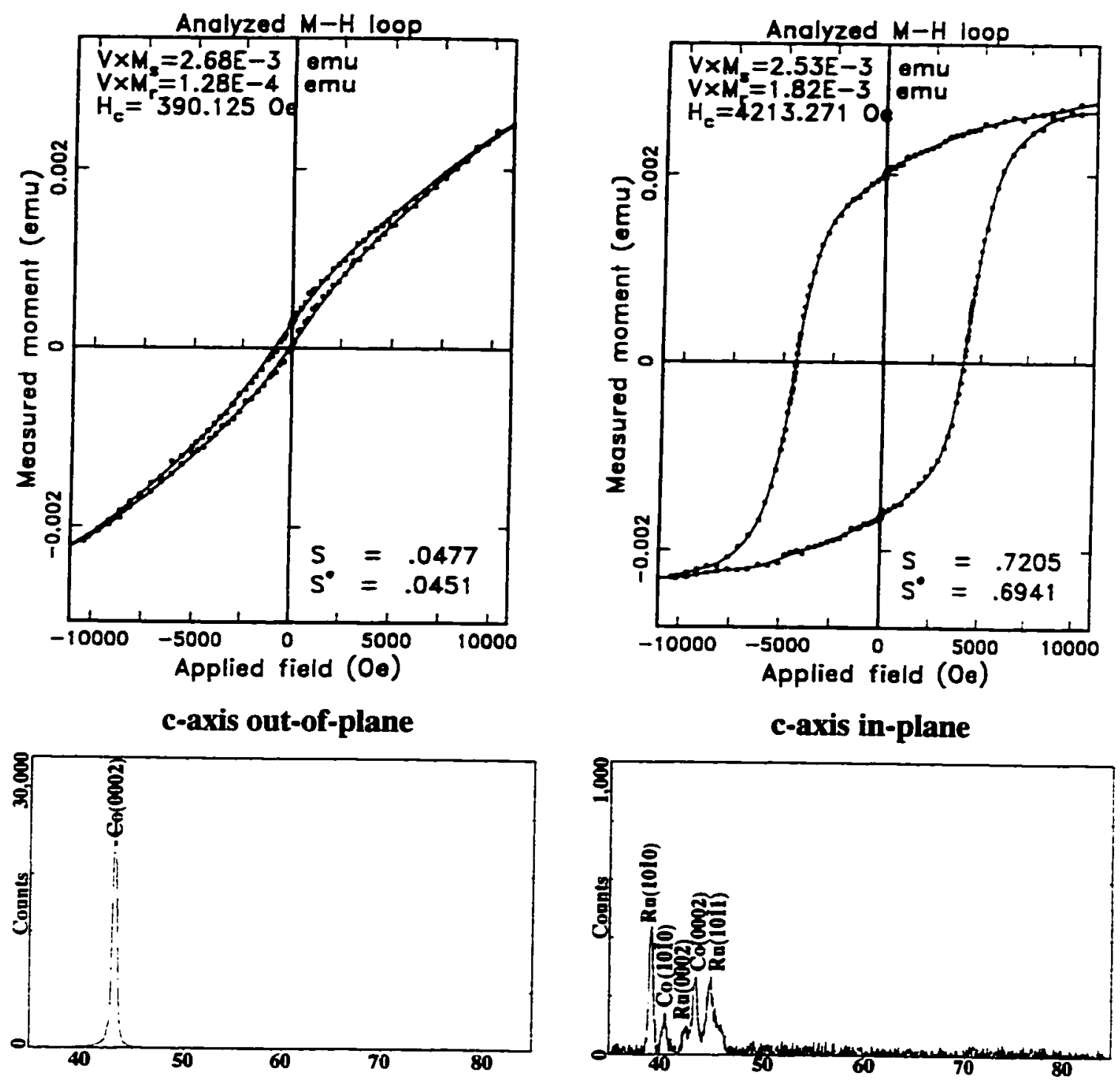

Figure 29. M-H loop comparison of $\mathrm{Co}_{64} \mathrm{Cr}_{22} \mathrm{Pt}_{14}$ with out-of-plane texture and $\mathrm{Co}_{64} \mathrm{Cr}_{22} \mathrm{Pt}_{14}$ with in-plane texture. The left plots are the sample with low coercivity, low $\mathrm{S}^{*}$, and strong $\mathrm{Co}(0002)$ diffraction line. The right plots are the sample with high coercivity, high $S^{*}$, and weak $\mathrm{Co}(0002)$ diffraction line. (Left: sample \#13, right: sample \#25) 


\subsection{The Epitaxy of $\mathrm{Co}_{64} \mathrm{Cr}_{22} \mathrm{Pt}_{14}$ Thin Film on $\mathrm{Cr}_{1-\mathrm{x}} \mathrm{Ru}_{\mathrm{x}}$ Underlayer}

When $\mathrm{Co}_{64} \mathrm{Cr}_{22} \mathrm{Pt}_{14}$ is deposited on $\mathrm{Cr}_{1-x} \mathrm{Ru}_{x}, \mathrm{Co}_{64} \mathrm{Cr}_{22} \mathrm{Pt}_{14}$ grains will be oriented such that the strain energy is lowest. The crystallographic relations of $\mathrm{Co}_{64} \mathrm{Cr}_{22} \mathrm{Pt}_{14}$ grain with a $\mathrm{Cr}$ structure underlayer are well known. Literature Review 2.5.1 has covered this topic. In the amorphous region [24\%-53\% $\mathrm{Ru}$ ], $\mathrm{Cr}_{1-x} \mathrm{Ru}_{x}$ film is like a glass substrate. The $\mathrm{Co}_{64} \mathrm{Cr}_{22} \mathrm{Pt}_{14}$ layer develops a very strong c-axis out-of-plane texture when it deposits on the amorphous $\mathrm{Cr}_{1-x} \mathrm{Ru}_{x}$ layer. At $37.3 \% \mathrm{Ru}, \mathrm{Cr}_{2} \mathrm{Ru}$ compound forms. $\mathrm{Co}_{64} \mathrm{Cr}_{22} \mathrm{Pt}_{14}$ still has strong $c$-axis perpendicular to the plane texture when it is deposited on the $\mathrm{Cr}_{2} \mathrm{Ru}$ compound. $\mathrm{Cr}_{2} \mathrm{Ru}$ compound seems not a good underlayer to develop $\mathrm{Co}_{64} \mathrm{Cr}_{22} \mathrm{Pt}_{14} \mathrm{c}$-axis in-plane texture. In the HCP region [53\%-100\% Ru], $\mathrm{Cr}_{1-x} \mathrm{Ru}_{\mathrm{x}}$ structure and $\mathrm{Co}_{64} \mathrm{Cr}_{22} \mathrm{Pt}_{14}$ structure are similar. They are both $\mathrm{HCP}$ structure and they have similar lattice parameters; therefore, $\mathrm{Cr}_{1-\mathrm{x}} \mathrm{Ru}_{\mathrm{x}}$ layer with a HCP structure is an effective underlayer for $\mathrm{Co}_{64} \mathrm{Cr}_{22} \mathrm{Pt}_{14}$ layer.

Figure 30 shows four common crystallographic planes of HCP structure. If the shaded planes are parallel to the film plane, $(0002)$ is c-axis out-of-plane texture, $(1 \overline{010})$ and $(1 \overline{2} 0)$ are c-axis in-plane textures. and $(10 \overline{1} 1)$ is c-axis $29^{\circ}$ to the plane texture. The $\mathrm{X}$-ray diffraction shows that these four textures are most common in the experiment.
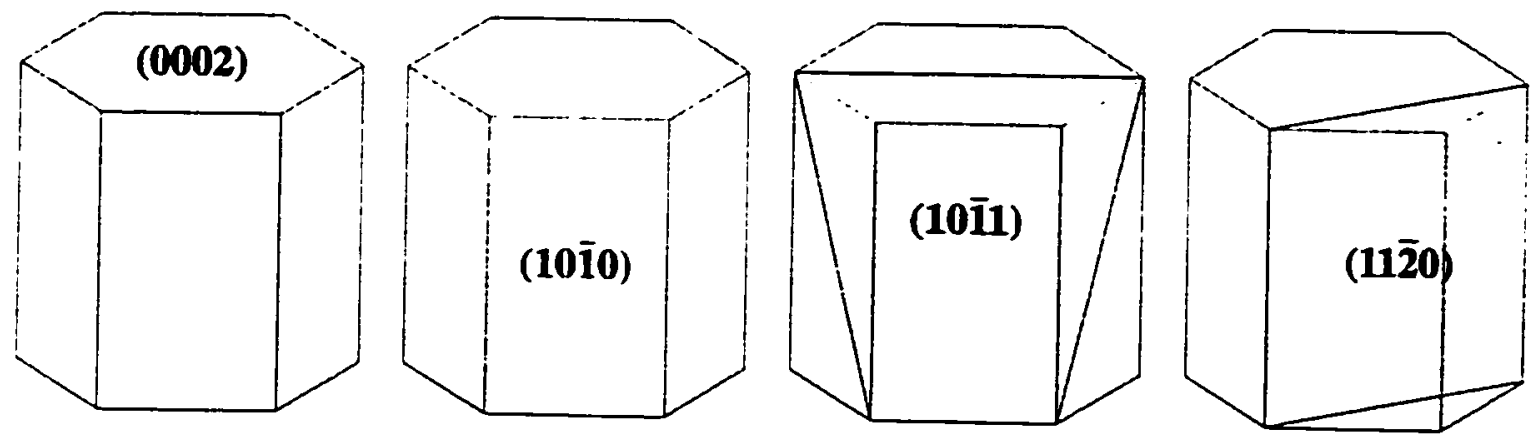

Figure 30. Four common crystallographic planes of HCP structure. 


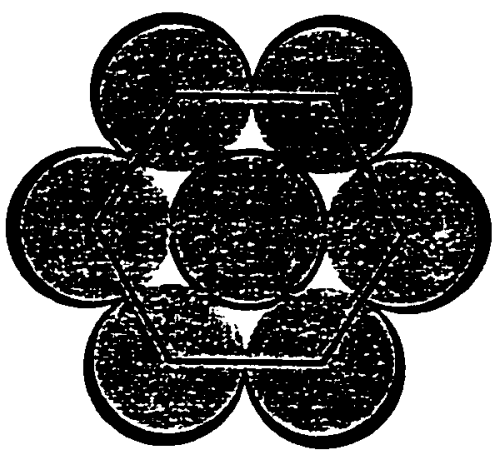

(0002)

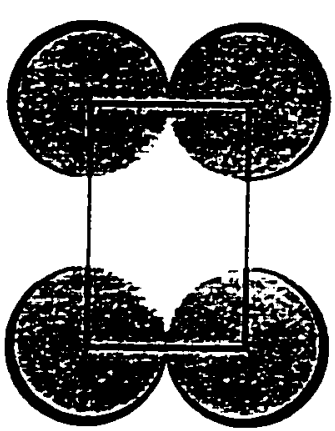

(10̄̄o)

Ril

Figure 31. Plan view of (0002) and (10-10) of Co and Ru lattices.

Figure 31 shows the lattice match of $\mathrm{Co}$ and $\mathrm{Ru}$ lattices. The left diagram is a plan view of (0002) and the right diagram is a plan view of (1010). The Ru atom is slightly larger than the Co atom, and the $\mathrm{Ru}$ lattice is also slightly larger than the Co lattice. The diagrams in Figure $3 \mathrm{I}$ are to scale. The lattice misfit between Co lattice and Ru lattice is small. around $2 \%$ depending on the Ru concentration.

The good lattice match of $\mathrm{Co}$ and $\mathrm{Ru}$ explains the phenomenon that the sample with strong $\mathrm{Ru}(0002)$ in-plane texture also have strong $\mathrm{Co}(0002)$ in-plane texture, and the sample with strong $\mathrm{Ru}(10 \overline{10})$ in-plane texture also has strong $\operatorname{Co}(10 \overline{10})$ in-plane, as shown in Figure 22. When the Ru concentration decreases, the Ru lattice shrinks, and the lattice misfit between $\mathrm{Co}$ and Ru structure decreases. Figure 32 shows the lattice misfit vs. Ru concentration. The lattice misfit is calculated from the X-ray diffraction data, which decreases as the Ru concentration decreases. The HCP Ru structure is destroyed when Ru concentration is lower than $53.3 \%$. At $57 \% \mathrm{Ru}$, the sample has highest $\mathrm{H}_{\mathrm{C}}$ and least lattice misfit. But the high $H_{c}$ is probably due to the texture of $\mathrm{Cr}_{r_{1-x}} R u_{x}$ film, not due to the improvement of the lattice match. 


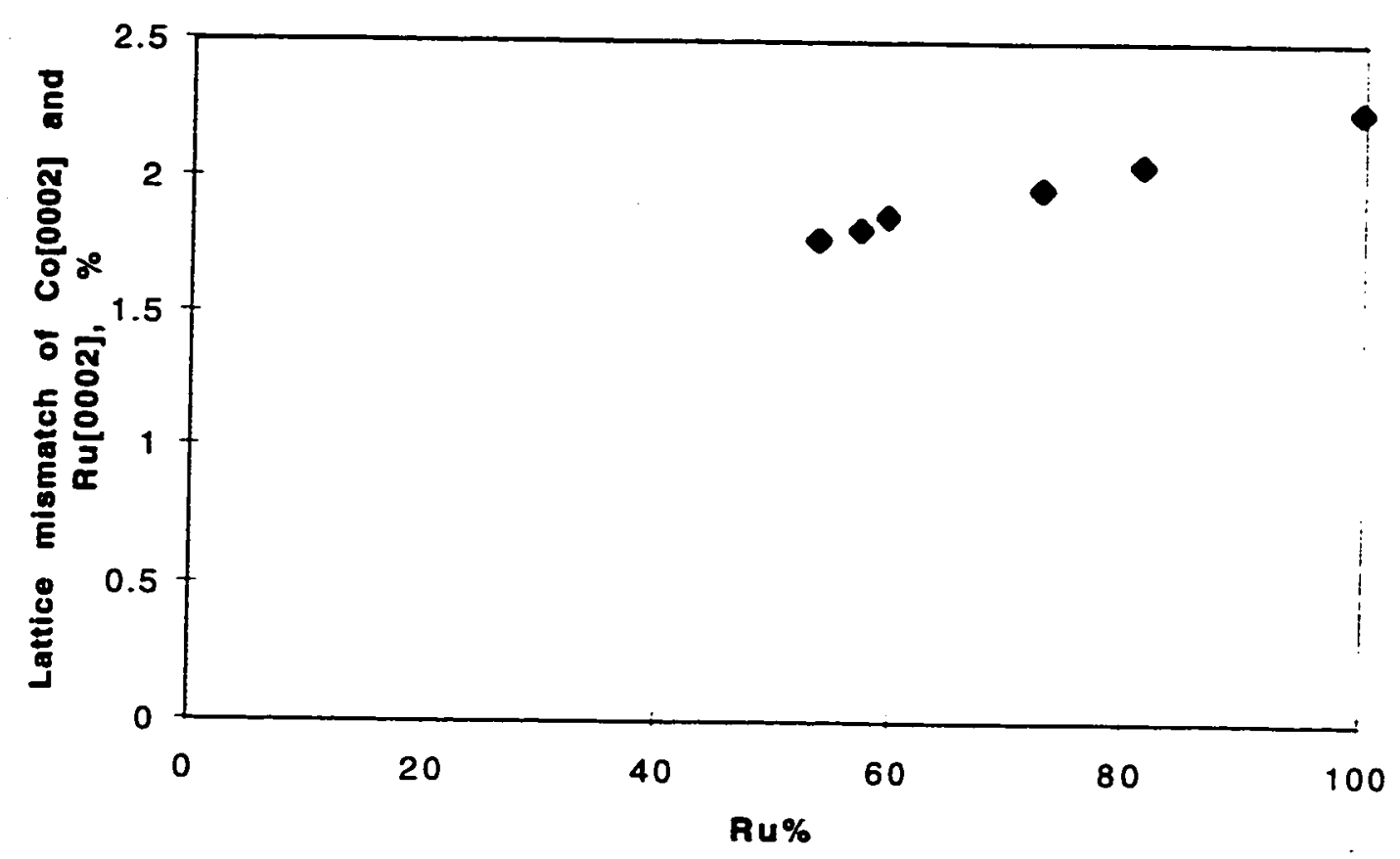

Figure 32. The lattice misfit of $\mathrm{Co}[0002]$ and $\mathrm{Ru}[0002]$ vs. Ru concentration.

\subsection{The Effects of the $\mathrm{Co}_{64} \mathrm{Cr}_{22} \mathrm{Pt}_{14} / \mathrm{Cr}_{1-x} \mathrm{Ru}_{\mathrm{x}}$ Crystallographic Texture on the In-plane Coercivity}

Co c-axis is the magnetic easy axis. To increase the Co c-axis in-plane texture is one way to increase the in-plane $\mathrm{H}_{c}$ and $\mathrm{S}^{*}$. But the crystallographic texture is not the only parameter determining the in-plane $\mathrm{H}_{C}$ and $\mathrm{S}^{*}$. Average grain size, grain size distribution. stacking faults, and degree of crystalline perfection are all possible parameters affecting the magnetic properties.

Different variables have been investigated in the experiment, such as $\mathrm{Ru}$ concentration, underlayer thickness, and deposition temperature. The variables have different effects on the microstructure of $\mathrm{Cr}_{1-x} \mathrm{Ru}_{\mathrm{x}}$ layer. The microstructure of $\mathrm{Cr}_{1-x} \mathrm{Ru}_{\mathrm{x}}$ layer determines the microstructure of Co layer by epitaxy, and the microstructure of $C_{0}$ layer determines the magnetic property of the sample. 
Figure 33 shows evidence that the more c-axis in-plane texture, the higher the coercivity. The samples in the diagram have the same $\mathrm{Co}_{64} \mathrm{Cr}_{22} \mathrm{Pt}_{14}$ thickness. The $\mathrm{X}$-ray intensity ratio of $\mathrm{Co}(10 \overline{10}) / \mathrm{Co}(0002)$ indicates the degree of $\mathrm{Co}$ in-plane texture. The inplane coercivity has strong dependence on the ratio, at least up to 0.2 .

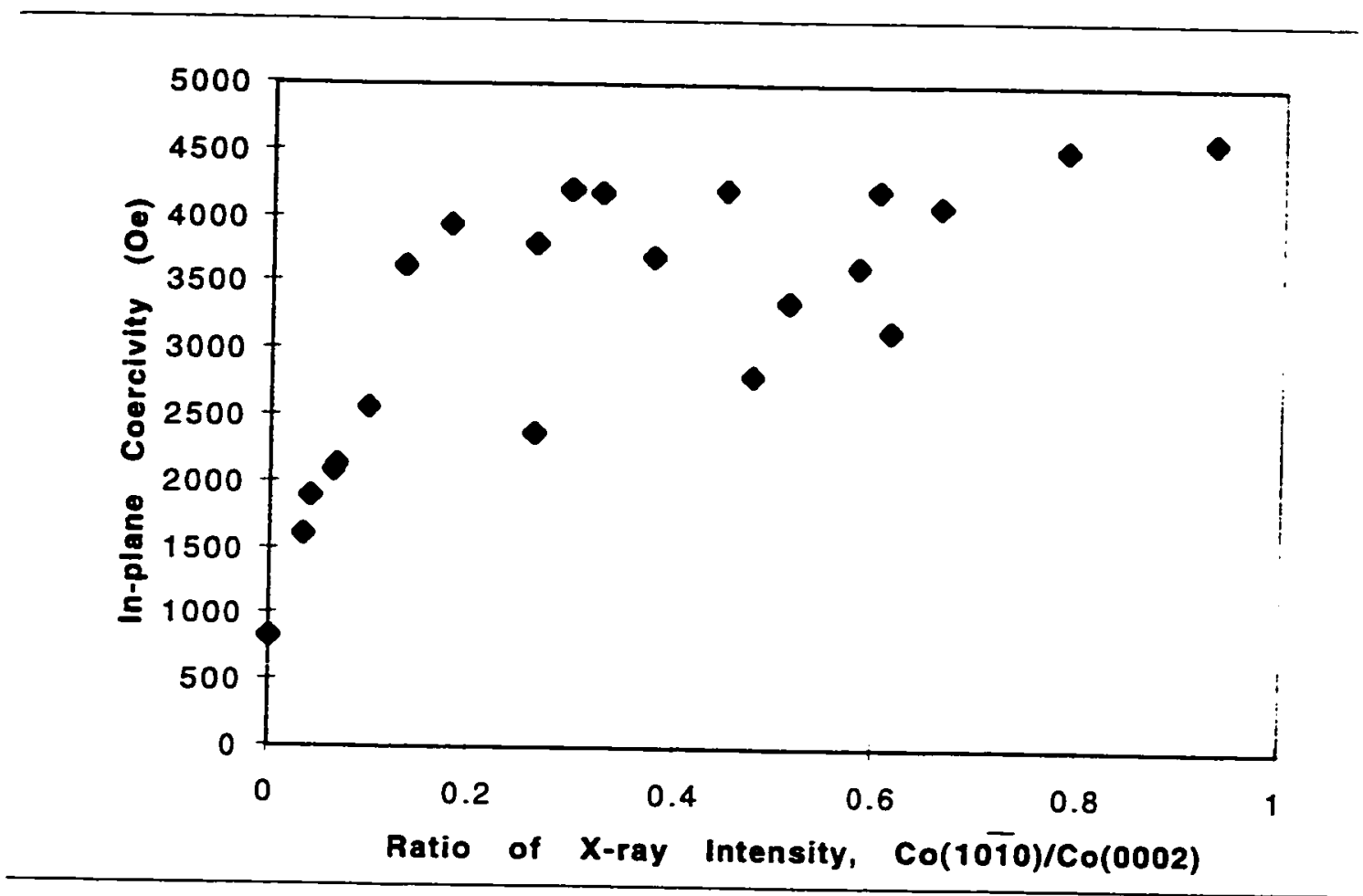

Figure 33 . In-plane coercivity vs. X-ray intensity ratio $\mathrm{Co}(1 \overline{10} 0) / \mathrm{Co}(0002)$. 


\section{Chapter 6}

\section{Conclusions}

\subsection{Summary and Conclusions}

The magnetic properties of $\mathrm{Co}_{64} \mathrm{Cr}_{22} \mathrm{Pt}_{14} / \mathrm{Cr}_{1-x} \mathrm{Ru}_{x}$ thin films were studied in this thesis. $\mathrm{Cr}_{\mathrm{l}-\mathrm{x}} \mathrm{Ru}_{\mathrm{x}}$ underlayers with a composition of $57 \% \mathrm{Ru}$ deposited at $250^{\circ} \mathrm{C}$ induced strong c-axis in-plane $\mathrm{Co}_{64} \mathrm{Cr}_{22} \mathrm{Pt}_{14}$ texture. The $\mathrm{Co}_{64} \mathrm{Cr}_{22} \mathrm{Pt}_{14} / \mathrm{Cr}_{1-x} \mathrm{Ru}_{\mathrm{x}}$ thin films at this sputtering condition had high in-plane $H_{C}$, around 4,100 Oe. Varying the $C_{r_{1-x}} R u_{x}$ thickness and the deposition temperature further optimized the in-plane $H_{c}$ to over 4,500 Oe. Unfortunately, the high $\mathrm{H}_{\mathrm{c}}$ property only appeared within a very narrow $\mathrm{Ru}$ concentration around $57 \% \mathrm{Ru}$. The in-plane $\mathrm{H}_{\mathrm{c}}$ dropped to around 3,000 Oe with $\mathrm{Ru}$ concentration increasing or decreasing only $2 \%$.

The $\mathrm{Cr}_{1-x} \mathrm{Ru}_{\mathrm{x}}$ thickness is an important parameter affecting the $\mathrm{H}_{\mathrm{c}}$ of $\mathrm{Co}_{64} \mathrm{Cr}_{22} \mathrm{Pt}_{14} / \mathrm{Cr}_{1-x} \mathrm{Ru}_{\mathrm{x}}$ thin films. The $\mathrm{H}_{\mathrm{C}}$ increased when $\mathrm{Cr}_{1-x} \mathrm{Ru}_{\mathrm{x}}$ thickness increased from 50 to $100 \AA$. Above $100 \AA, H_{C}$ stopped increasing and then started decreasing gradually. The $\mathrm{H}_{\mathrm{C}}$ dependence on the $\mathrm{Cr}_{1-x} \mathrm{Ru}_{x}$ thickness was due to the grain size. Large grain size caused $\mathrm{H}_{\mathrm{C}}$ to decrease. Deposition temperature was another parameter affecting the $\mathrm{H}_{c}$. The samples had highest $\mathrm{H}_{c}$ when deposited at $250^{\circ} \mathrm{C}$. The samples lost their $\mathrm{H}_{\mathrm{c}}$ and in-plane texture when they were deposited at room temperature or at $350^{\circ} \mathrm{C}$. The $\mathrm{Cr}_{1 \cdot x} \mathrm{Ru}_{\mathrm{x}}$ film had a preference to have $\mathrm{Ru}(10 \overline{10})$ in-plane texture when it was deposited at $250^{\circ} \mathrm{C}$. The preferred texture induced Co c-axis in-plane texture and high in-plane $H_{C}$. $\mathrm{Cr}_{\mathrm{l}-\mathrm{x}} \mathrm{Ru}_{\mathrm{x}}$ may not be a practical underlayer material because of the following three problems. First, the $\mathrm{H}_{\mathrm{C}}$ and $\mathrm{S}^{*}$ of $\mathrm{Co}_{64} \mathrm{Cr}_{22} \mathrm{Pt}_{\mathrm{t}_{4}} / \mathrm{Cr}_{1-x} \mathrm{Ru}_{\mathrm{x}}$ are high at $57 \% \mathrm{Ru}$, but it appears only at a narrow Ru concentration region. That causes a problem to reproduce. 
Second, Ru and most Ru compounds are toxic. The environmental and safety problem prevents Ru to be used for consumer products. Third, the high cost of Ru may limit its application. Even thought, to expand the high $\mathrm{H}_{c}$ region around $57 \%$ Ru maybe worth investigating.

\subsection{Suggestions for Future Study}

There are many elements and alloys that could be a possible material for underlayer. There are also many sputtering parameters affecting the magnetic property of the samples. Some suggestions are given as follows for further underlayer material research.

1. Find a material such that the lattice of the material can match the lattice of Co structure in certain orientation. For example, find a HCP structure material with lattice parameters close to the lattice parameters of Co.

2. Select a element to alloy with the parent material. The minor element will change the lattice parameters of the structure and will improve the lattice matching with Co. The minor element may also change the property of the parent material, e.g., the preferred orientation when deposited. The minor element should not change the structure of the parent material. Check phase diagram that the parent element should have significant solubility of the minor element.

3. Try to optimize and expand the high $\mathrm{H}_{c}$ region by using different sputtering parameters, such as bias voltage, argon pressure, etc.

4. Use TEM to observe the microstructure of the films, such as grain size and stacking fault density. 


\section{References}

[1] K. E. Johnson, and C. M. Mate, "Thin-film media - current and future technology," IBM Journal of Research and Development, 40, 511 (1996).

[2] D. N. Lambeth, E. M. T. Velu, G. H. Bellesis, L. L. Lee, and D. E. Laughlin. "Media for $10 \mathrm{~Gb} /$ in. $^{2}$ hard disk storage: Issues and Status," Joumal of Applied Physics, 79 (8), 4496 (1996).

[3] E. Murdock, "Roadmap for $10 \mathrm{~Gb} / \mathrm{in}^{2}{ }^{2}$ media: challenges," IEEE Transactions on Magnetics, 28, 3078 (1992).

[4] Kanu G. Ashar, Magnetic Disk Drive Technology, IEEE, 163, (1997).

[5] S. Doss and T. Michaelson, "Electroless plating of some Ni-P-Cu alloys and their microhardness," proceeding Third Electroless Nickel Conference, Chicago, March 29$31,1983$.

[6] J. K. Lee, A. Chao, J. Enguero, M.Smallen, H. J. Lee, and P. Dion, "Effect of disk cross hatch texture on tribological performance," IEEE Transactions on Magnetics, 28, 2880 (1992).

[7] B. Bhushan, "Magnetic slider/rigid disk substrate materials and disk texture techniques-status and future outlook," ASME Adv. Info. Stor. Syst., 5, 175, (1993).

[8] David E. Laughlin, , Li-Lien Lee, Li Tang and David N. Lambeth, "The control and characterization of the crystallographic texture of longitudinal thin film recording media," IEEE Transactions on Magnetics, 32, 3632 (1996).

[9] R. A. Baugh, E. S. Murdock, and B. R. Natarajan, "Measurement of noise in magnetic media," IEEE Transactions on Magnetics, 19, 1722 (1983).

[10] J. A. Thornton, "The microstructure of sputter-deposited coatings," J. Vac. Sci. Technol., 4, 3059 (1986).

[11] T.Yogi, T. A. Nguyen, S. E. Lambert, G. L. Gorman, and G. Castillo, "Role of atomic mobility in the transition noise of longitudinal media," IEEE Transactions on Magnetics, 26, 1578 (1990).

[12] J. N. Chapman, I. R. Mc Fadyen, and J. P. C. Bernards, "Investigation of Cr segregation within RF-sputtered CoCr films," J. Magn. \& Magnet. Mater., 62, 359 (1986).

[13] D. J. Rogers, J. N. Chapman, J. P. C. Bernards, and S. B. Luitjens, "Determination of local composition in CoCr films deposited at different substrate temperatures," IEEE Transactions on Magnetics, 25, 4180 (1989).

[14] E. E. Murdock, B. R. Natarajan, and R. G. Walmaley, "Noise properties of multilayered Co-Alloy magnetic recording media," IEEE Transactions on Magnetics, 
[15] H. Suzuki, N. Tsumita, M. Hayashi, Y. Shiroishi, and Y. Matsuda, "Magnetic and crystallographic properties of sputtered Co-Ni- $\mathrm{Zr}$ films on $\mathrm{Cr}$, Mo and $\mathrm{W}$ underlayer," IEEE Transactions on Magnetic, 26 (5), 2280 (1990).

[16] R. Ranjan, J. Chang, T. Yamashita, and T. Chen, "Delta-M, vertical component, and media noise of $\mathrm{NiP}$ - and $\mathrm{Cr}$-underlayer media for longitudinal recording," Journal of Applied Physics, 73 (10), 5542 (1993).

[17] Rajiv Ranjan, "Beta tungsten underlayer for low-noise thin-film longitudinal media," Journal of Applied Physics, 67 (9), 4698 (1990).

[18] T. Kogure and S. Katayama, "High-coercivity magnetic hard disks using glass substrates," Journal of Applied Physics, 67 (9), 4701 (1990).

[19] Li-Lien Lee, David E. Laughlin, and David N. Lambeth, "NiAl underlayers for CoCrTa magnetic thin films," IEEE Transactions on Magnetics, 30 (6), 3951 (1994).

[20] Li-Lien Lee, David E. Laughlin, Leo Fang, and David N. Lambeth, "Effects of Cr intermediate layers on CoCrPt thin film mdeia on NiAl Underlayers," IEEE Transactions on Magnetics, 31 (6), 2728 (1995).

[21] Li-Lien Lee, David E. Laughlin, and David N. Lambeth, "Seed layer induced (002) crystallographic texture in NiAl underlayers," Journal of Applied Physics, 79 (8), 4902 (1996).

[22] A. Nakamura and M. Futamoto, "Epitaxial growth of $\mathrm{Co} / \mathrm{Cr}$ bilayer films on $\mathrm{MgO}$ single crystal structures," Japenese Journal of Applied Physics, 32, L1410 (1993).

[23] M. A. Parker, J. K. Howard, R. Ahlert, and K. R. Coffey, "Crystallographic structure of $\mathrm{CoPtCr} / \mathrm{CrV}$ thin films as revealed by cross-section TEM and X-ray polefigure analysis and its relevance to magnetic properties," Journal of Applied Physics. 73 (10), 5560 (1993).

[24] Y. Matsuda, Y. Yahisa, J. Inagaki, E. Fujita, and A. Ishikawa, "Reduction of Co-CrPt media noise by addition of Ti to Cr underlayer," Journal of Applied Physics, 79 (8), 5351 (1996).

[25] N. Tani, M. Hashimoto, Y. Murata, M. Ishikawa, Y. Ota, and K. Nakamura, "Effects of substituted elements into the $\mathrm{Cr}$ layer on a $\mathrm{CoNiCr} / \mathrm{Cr}$ sputtered hard disk," Journal of Applied Physics, 67 (12), 7507 (1990).

[26] N. Inaba, A. Nakamura, T. Yamamoto, Y. Hosoe, and M. Futamoto, "Magnetic and crystallographic properties of $\mathrm{CoCrPt}$ thin films formed on $\mathrm{Cr}$-Ti single crystalline underlayers," Journal of Applied Physics, 79 (8), 5354 (1996).

[27] D.E. Lanughlin and B. Y. Wong, "The crystallography and texture of Co-based thin film deposited on $\mathrm{Cr}$ underlayers," IEEE Transactions on Magnetics, 27, 4713 (1991).

[28] T. Yogi, C. Tsang, T. A. Nguyen, K. Ju, G. L. Gorman, and G. Castillo, "Longitudinal media for $1 \mathrm{~Gb} / \mathrm{in}^{2}$ areal density," IEEE Transactions on Magnetics, 26, 2271 (1990). 
[29] Y. Shen, D. N. Lambeth, and D. E. Laughlin, "Effects of substrate temperature on magnetic properties of $\mathrm{CoCrTa} / \mathrm{Cr}$ films," IEEE Transactions on Magnetics, 28, 3261 (1992).

[30] Y. Shen, B. Y. Wong, and D. E. Laughlin, "Materials and processing aspects of $\mathrm{CoCrTa} \mathrm{Cr}$ longitudinal recording media. II. Microstructure," Journal of Applied Physics, 76 (12), 8174 (1994).

[31] J. G. Zhu and H. N. Bertram, "Micromagnetic studies of thin metallic films," Journal of Applied Physics, 63, 3248 (1988).

[32] T. Chen and T. Yamsahita, "Physical origin of limits in the performance of thin-film longitudinal recording media," IEEE Transactions on Magnetics, 24, 2700 (1988).

[33] T. Yamashita and T. Chen, "Sputtered NiP underlayer for CoPt-based thin film magnetic media," IEEE Transactions on Magnetics, 27, 4727 (1991).

[34] J. A. Christner, R. Ranjan, R. L. Peterson, and J. I. Lee, "Low-noise metal medium for high-density longitudinal recording," Journal of Applied Physics, 63, 3260 (1988).

[35] Y. Maeda and K. Takei, "Compositional inhomogeneities in $\mathrm{Co}-\mathrm{Cr}-\mathrm{Ta} / \mathrm{Cr}$ films for longitudinal recording," IEEE Transactions on Magnetics, 27, 4721 (1991).

[36] B. Cheong, Y. C. Feng, and D. E. Laughlin, Scripta Metallurgica et Materialia, 30, 1419 (1994).

[37] K. Hono, B. G. Demczyk, and D. E. Laughlin, Appl. Phys. Lett. 55, 229 (1989).

[38] L. H. Chan, G. Thomas, and J. S. Gau, "Magnetic properties and microstructure of Co-Cr bulk alloys," J. Magn. \& Magnet. Mater., 79, 95 (1989).

[39] H. Suzuki, Journal of Applied Physics, 17, 322 (1962).

[40] David E. Laughlin, B. Cheong, Y. C. Feng, D. N. Lambeth, Li-Lien Lee, and Bunsen Wong, "The control of microstructural features of thin films for magnetic recording," Scripta Metallurgica et Materialia, 33, 1525 (1995).

[41] Y. C. Feng, D. E. Laughlin , and D. N. Lambeth, "Formation of crystallographic texture in rf sputter-deposited $\mathrm{Cr}$ thin films," Journal of Applied Physics, 76 (11), 7311 (1994).

[42] Y. Deng, D. N. Lambeth, L. L. Lee, and D. E. Laughlin, "Magnetic properties and crystal texture of Co alloy thin films prepared on double bias Cr," Journal of Applied Physics, 73 (10), 6677 (1993).

[43] H. S. Chang, K. H. Shin, T. D. Lee, and J. K. Park, "Effect of $\mathrm{Cr} / \mathrm{Al}$ underlayer on magnetic properties and crystallography in CoCrPtTa/Cr/Al thin films," IEEE Transactions on Magnetics, 32 (5), 3617 (1996).

[44] Wen-Yuang Lee, unpublished data. 

[45] Richard J. Lewis, Sr., Sax's Dangerous Properties of Industrial Materials, eighth
edition, (1992).

[46] Leonard C. Feldman, and James W. Mayer, Fundamentals of Surface and Thin Film Analysis, (1986).

[47] T. K. Varga, and C. Bello, Periodic Table of the Element, (1994). 


\section{IMAGE EVALUATION \\ TEST TARGET (QA-3)}
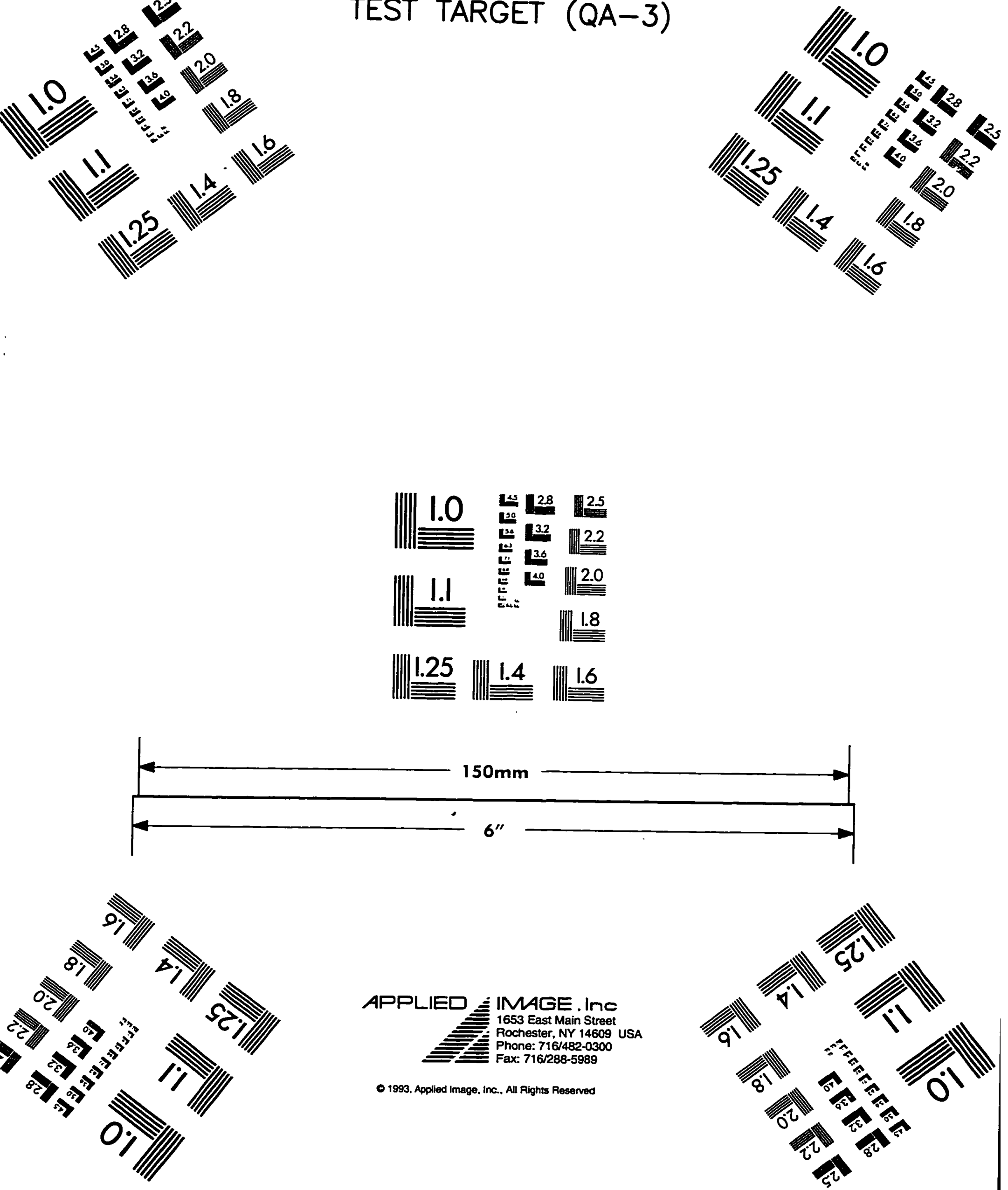